\title{
Gallium Nitride Phase Shifters
}

\author{
by
}

\section{Tyler Neil Ross}

\begin{abstract}
A thesis submitted to the Faculty of Graduate and Postdoctoral Affairs in partial fulfillment of the requirements for the degree of
\end{abstract}

\author{
Doctor of Philosophy \\ in \\ Electrical Engineering \\ Department of Electronics \\ Carleton University \\ Ottawa, Ontario, Canada
}

(C) 2015

Tyler Neil Ross 


\section{Abstract}

This thesis presents two different types of high-power gallium nitride (GaN) phase shifters designed for X-band (8-12 GHz) but offering good performance over a much wider band. The first type of phase shifter is a novel design having $22.5^{\circ}$ phase shift, which promises wide bandwidth (in this case limited by the SPDT switch also designed), but achieves decent insertion loss (5 dB), good return loss (better than $11 \mathrm{~dB}$ ) and very low phase variation $\left(1^{\circ}\right)$ across $\mathrm{X}$-band. The components for a $45^{\circ}$ differential phase shift using the same structure were also fabricated and verified with measurements. The second type of phase shifter is a $22.5^{\circ}$ switched-filter phase shifter which has much wider bandwidth than is typically found with this configuration, while maintaining low insertion loss $(<2 \mathrm{~dB})$, good return loss (>11.15 dB) and an amplitude imbalance of less than $1.03 \mathrm{~dB}$ across X-band. The $1 \mathrm{~dB}$ compression point was higher than the laboratory equipment was able to measure $(>38 \mathrm{dBm})$ and the phase shifter monolithic microwave integrated circuit (MMIC) exhibited an input-referred third- 
order intercept point $\left(\mathrm{IIP}_{3}\right)$ higher than $46 \mathrm{dBm}$. A K-band phase shifter was also designed to test the limits of the technology. The high-power phase shifters have been fabricated in a $0.5 \mu \mathrm{m}$ GaN HEMT process and were designed using an accurate, customized switch HEMT model. Suspended inductors offering improved quality factor and increased self-resonance frequency were also used in the design of some of the phase shifters. 


\section{Acknowledgements}

I wish to acknowledge the guidance and support of my thesis advisors here at Carleton, Professors Jim Wight and Gabriel Cormier (also at l'Université de Moncton). I am glad that they gave me the freedom and resources to explore a variety of topics over the past few years. Some of those topics have even found their way into this thesis!

I must also thank Dr. Khelifa Hettak from Communications Research Centre Canada, who also co-advised this work with Jim and Gabriel. Our discussions were instrumental in shaping the direction of my doctoral research. Mr. Adrian Momciu, also at CRC, was invaluable as well. His assistance with measurements is greatly appreciated and our discussions on measurement techniques were both interesting and enlightening. His willingness and ability to always find time, equipment and patience in the measurement laboratory - particularly amid the turmoil and difficulties at CRC over the past couple of years—are immensely appreciated. 
Naturally, I am also grateful to my family back in Dieppe, New Brunswick, as well as to my friends here in Ottawa and abroad, who encouraged (and pushed) me when needed. The name of one fellow Ph.D. student in particular should be highlighted. Kimia Taghizadeh Ansari has been exceedingly kind, funny, helpful, generous, encouraging and a very good friend to me. The rest of my friends at Carleton and in the Blue Room have also been very warm and encouraging and I thank them for that.

Finally, I must also note the financial support of my advisors, the Natural Sciences and Engineering Research Council of Canada, the Government of Ontario and Carleton University. Without this support, I would have been unable to complete this thesis. Or eat. 


\section{Table of Contents}

Abstract ......................... ii

Acknowledgements ..................... iv

Table of Contents $\ldots \ldots \ldots \ldots \ldots$. .............. vi

List of Figures $\ldots \ldots \ldots \ldots \ldots \ldots \ldots \ldots$

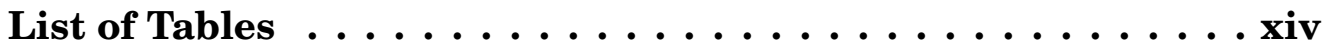

List of Acronyms . . . . . . . . . . . . . . . . xv

1 Introduction $\ldots \ldots \ldots \ldots \ldots \ldots \ldots \ldots$

1.1 Summary of thesis contributions . . . . . . . . . . 3

1.2 Thesis overview $\ldots \ldots \ldots \ldots \ldots$

2 A Review of the Literature ................... 6

2.1 Review of gallium nitride at microwave frequencies . . . . . 7

2.2 Use of GaN in phase-shifting systems . . . . . . . . . . . 15 
2.3 Previous work on phase shifter design . . . . . . . . . 18

2.4 Summary ........................ 30

3 GaN Switch Device Modeling . . . . . . . . . . . . . . . 32

3.1 Review of GaN modeling . . . . . . . . . . . . . 33

3.2 GaN switch model . . . . . . . . . . . . . . 37

3.3 Summary ......................... 45

4 Suspended Inductors . . . . . . . . . . . . . . 46

4.1 Inductor modeling . . . . . . . . . . . . . . 49

4.2 Suspended inductor . . . . . . . . . . . . . . 51

4.3 Summary ....................... 56

5 LC Resonator GaN Phase Shifter . . . . . . . . . . . . . . . 59

5.1 Phase shifter design . . . . . . . . . . . . . 61

5.2 GaN SPDT switch design . . . . . . . . . . . . . . 69

5.3 Phase shifter results . . . . . . . . . . . 74

5.4 Summary ........................ 77

6 Switched-filter GaN Phase Shifters . . . . . . . . . . . 80

6.1 X-band switched-filter phase shifter . . . . . . . . 81

6.2 K-band phase shifter using suspended inductors . . . . . . . 92

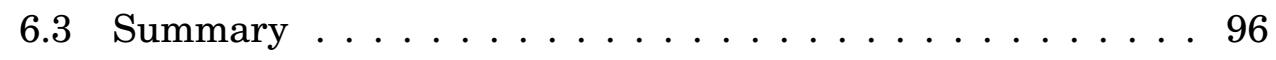

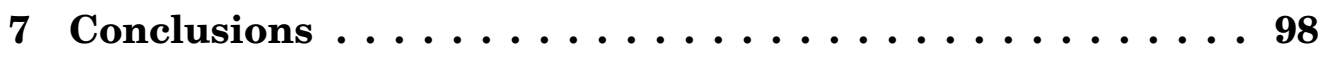


7.1 Scientific contributions . . . . . . . . . . . . . 101

7.2 Future work . . . . . . . . . . . . . . . . 102

List of References . . . . . . . . . . . . . . . . . . . 104 


\section{List of Figures}

2.1 Simplified RF front-end for a typical beamforming system in a non-GaN technology. . . . . . . . . . . . . . 15

2.2 Example RF front-end possible with GaN with key components

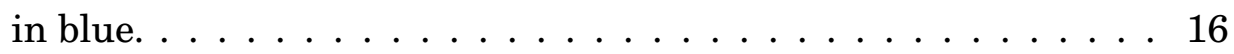

2.3 A 4-bit cascaded digital phase shifter. . . . . . . . . . . . . 20

2.4 Switched-line phase shifter. . . . . . . . . . . . 21

2.5 Reflection phase shifter. The circuits function with either openor short-circuit terminations. . . . . . . . . . . . 22

2.6 Loaded line phase shifter. . . . . . . . . . . . . . . 24

2.7 High-pass-low-pass phase shifter. . . . . . . . . . . . . 25

2.8 Schiffman phase shifter. . . . . . . . . . . 27

3.1 Linear model used to model the switching GaN HEMT transistors. Parameters correspond to a transistor with total gate width of $160 \mu \mathrm{m}$ and scale with gate width. $C_{g}, R_{i}, R_{s w}$ and $C_{s w}$ vary with gate bias as indicated. . . . . . . . . . . 38 
3.2 Photographs of two standalone AlGaN/GaN HEMT devices from the NRC foundry. . . . . . . . . . . . . . . . . 39

3.3 Equivalent circuits used in determining the extrinsic transistor parameters. Elements in blue vary between the two bias points, while the extrinsic elements in black are bias-independent. . . . 40

3.4 Measured (lines) and modeled (circles) S-parameters (026.5 GHz) for a $4 \times 40 \mu$ m common-gate GaN HEMT's on- and off-states. The foundry model predictions are included for comparison (dashed). . . . . . . . . . . . . . . . 43

4.1 Illustration and microphotograph of a $1 \mathrm{nH}$ suspended inductor. 48

4.2 Schematic of the linear inductor model used in this work. The frequency-dependent series resistance accurately captures skin effect......................... 50

4.3 Comparison of the model in Figure 4.2 with electromagnetic simulation for a $1 \mathrm{nH}$ inductor directly on the substrate. The definition of quality factor used is $Q=\operatorname{Im}\{Z\} / \operatorname{Re}\{Z\} \ldots$. . . . . . 52

4.4 Microphotographs of $1 \mathrm{nH}$ inductors (a) laying directly on the substrate, and (b) using an airbridge to lift most of the inductor off of the substrate. . . . . . . . . . . . . . . 52

4.5 Substrate capacitance as a function of the distance between substrate and inductor metal. The parameters shown in the inset table have negligible variation with airbridge height. . . . 53 
4.6 Inductor quality factor and self-resonance frequency for different airbridge heights. . . . . . . . . . . . . . . 54

4.7 Measured S-parameters of the on-substrate (x) and suspended (o) inductors. . . . . . . . . . . . . . . . . 55

4.8 Measured inductance. The model in Figure 4.2 is also fitted to low-frequency measurements to enable accurate interpolation and extrapolation. .................... 56

4.9 Measured quality factor (Q) and equivalent series resistance for the standard and suspended inductors. . . . . . . . . . 57

5.1 Schematic of a new type of lumped-element phase shifter. . . . . 60

5.2 Microphotograph of the second $0^{\circ} / 22.5^{\circ}$ broadband GaN phase shifter. Circuit dimensions are $1169 \mu \mathrm{m} \times 900 \mu \mathrm{m}$ (Area:

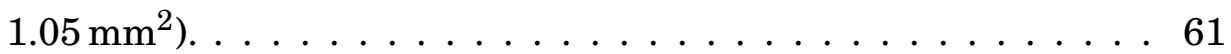

5.3 Stub-based phase shifter. . . . . . . . . . . . 62

5.4 Single-stub equivalent of the circuit in Figure 5.3 . . . . . . . . 63

5.5 Comparison of theoretical phase shift versus frequency for the distributed and lumped circuits. . . . . . . . . . . . . 67

5.6 Photograph of the resonator and $22.5^{\circ}$ phase reference. Dimensions: $436 \mu \mathrm{m} \times 693 \mu \mathrm{m} \ldots \ldots \ldots$. . . . . . . . . . . 6 . . .

5.7 Measured and simulated S-parameters for the resonator and $22.5^{\circ}$ phase reference. . . . . . . . . . . . . 68 
5.8 Photograph of resonator and $45^{\circ}$ phase reference. Dimensions: $434 \mu \mathrm{m} \times 691 \mu \mathrm{m} . \ldots \ldots \ldots$. . . . . . . . . . . . 69

5.9 Measured and simulated S-parameters for the resonator and $45^{\circ}$ phase reference. . . . . . . . . . . . . 70

5.10 Schematic of the SPDT switch showing its operation. . . . . . . 71

5.11 Photograph of the SPDT switch. Some test structures, unrelated to the SPDT switch, are in the centre. Dimensions (including pads and access lines): $1038 \mu \mathrm{m} \times 787 \mu \mathrm{m} . \ldots \ldots \ldots . \ldots 72$

5.12 Measured and simulated isolation, insertion loss and return loss for the proposed SPDT switch. . . . . . . . . . . 75

5.13 Insertion loss, return loss and phase shift for the complete $0 \% 22.5^{\circ}$ phase shifter shown in Figure 5.2. . . . . . . . . . . 76

5.14 Phase shift and phase error for the separate $22.5^{\circ}$ and $45^{\circ}$ phase shifters, as well as for the complete $22.5^{\circ}$ phase shifter with SPDT. 77

5.15 Simulated voltages on the terminals of the worst-case transistor, $T_{1}$, with $C T R L=0$. The source of this transistor is grounded, so $V_{s}$ is not shown. . . . . . . . . . . . 78

5.16 Measured power handling ( $\operatorname{IIP}_{3}$ and compression) of the complete $0 \% 22.5^{\circ}$ phase shifter. The power handling is the same for both states. . . . . . . . . . . . . . . 79 
6.1 Schematic of the switched-filter phase shifter, and the conceptual equivalent for $C T R L=1\left(V_{C T R L}=0 \mathrm{~V}\right)$ and $C T R L=0$ $\left(V_{\overline{C T R L}}=-10 \mathrm{~V}\right)$. The dotted components have a negligible effect for the given phase state. . . . . . . . . . . . . . 82

6.2 Microphotograph of the $0^{\circ} / 22.5^{\circ} \mathrm{GaN}$ switched-filter phase shifter. Circuit dimensions are $448 \mu \mathrm{m} \times 678 \mu \mathrm{m}$ (Area: $\left.0.304 \mathrm{~mm}^{2}\right) \ldots \ldots \ldots \ldots \ldots \ldots \ldots$

6.3 Measured and simulated insertion loss of the $0^{\circ} / 22.5^{\circ}$ phase

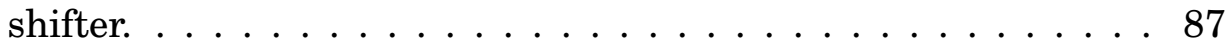

6.4 Measured and simulated return loss for the phase shifter circuit. 88

6.5 Measured and simulated phase shift for the $0^{\circ} / 22.5^{\circ}$ phase shifter. 89

6.6 Simulated voltages on the terminals of the worst-case transistor, $T_{2}$, in the phase-shift state. The source of this transistor is grounded, so $V_{s}$ is not shown. . . . . . . . . . . 90

6.7 Linearity measurement (gain compression and third-order intermodulation) results for the phase shifting circuit. . . . . . . 91

6.8 Microphotograph of the $0^{\circ} / 45^{\circ} \mathrm{GaN}$ phase shift circuit. Chip dimensions: $532 \mu \mathrm{m} \times 311 \mu \mathrm{m}\left(\right.$ area: $\left.0.165 \mathrm{~mm}^{2}\right) \ldots \ldots . \ldots 93$

6.9 Simulated S-parameters of the K-band $0 \% 45^{\circ}$ phase shifter. . . . 94

6.10 Measured behaviour of the $0^{\circ} / 45^{\circ}$ phase shifter. . . . . . . . . 95

6.11 Third order intermodulation for the $0^{\circ} / 45^{\circ}$ phase shifter. . . . . 96 


\section{List of Tables}

2.1 Comparison between properties of the three most commonlyused MMIC technologies. The first two rows highlight the high voltage ability of GaN, the middle two rows demonstrate its current handling ability and the final four rows demonstrate its ability to operate at high frequencies. Excerpted from [30]. . . . 9

2.2 Thermal conductivities at $300 \mathrm{~K}\left(\kappa_{300}\right)$ and thermal coefficients $(\alpha)$ for several common materials. . . . . . . . . . . . . 10

2.3 Parameters used in the selection of a substrate for GaN devices: lattice constant $(a)$, thermal conductivity at $300 \mathrm{~K}\left(\kappa_{300}\right)$, thermal expansion coefficient $\left(\alpha_{L}\right)$, wafer diameter and approximate cost. . . . . . . . . . . . . . . . . 14

3.1 Switching figure of merit for different technologies . . . . . . . 43

5.1 Characteristic impedances required for flat phase shift, from (5.8). 64

7.1 Comparison with some other phase shifters . . . . . . . . . 99 


\section{List of Acronyms}

CMOS Complementary metal-oxide-semiconductor

FET Field-effect transistor

HBT Heterojunction bipolar transistor

HEMT High electron mobility transistor

HVPE Hydride vapour phase epitaxy

IIP $_{3}$ Input-referred third-order intercept point

LNA Low-noise amplifier

LTE Long term evolution

MBE Molecular beam epitaxy

MEMS Micro-electromechanical systems

MHMIC Miniature hybrid microwave integrated circuit 
MIM Metal-insulator-metal

MMIC Monolithic microwave integrated circuit

MOCVD Metal-organic chemical vapour deposition

NRC National Research Council Canada

$\mathbf{P}_{\mathbf{1 d B}} 1 \mathrm{~dB}$ compression point

PCB Printed circuit board

RF Radiofrequency

SOI Silicon-on-insulator

SPDT Single-pole-double-throw

SPST Single-pole-single-throw 


\section{Chapter 1}

\section{Introduction}

The requirement for phase shifting in microwave systems has grown enormously in the past few years. Historically, the demand was largely driven by phased array radar systems, mostly for defence purposes, and operated over relatively narrow bandwidths. In recent years however, this has been changing. Interest in wideband phased array radars [1], [2] is still strong, as it has been for many years, but increasingly, phased arrays are being investigated for inclusion in cellular telephony base stations, such as those for 4G/LTE [3], [4] and 5G [5]-[7] networks. The idea is that by using phased arrays for beamforming, less transmit power is needed, and that power is focused in the direction of a specific mobile user, increasing efficiency and decreasing loss as well as interference between users.

As a result of this move towards broadband phased array systems, phase 
shifters must be able to satisfy the requirements of such systems. Radar and next-generation cellular systems are and will be operating at relatively high frequencies. X-band is quite common for satellite and radar systems. Broadband radar systems commonly employ true time delay phase shifters, which do not offer a flat broadband phase response [8]. Automotive systems are operating at $21-27 \mathrm{GHz}$ and $77-81 \mathrm{GHz}$ [9] and $5 \mathrm{G}$ cellular is expected to use $28 \mathrm{GHz}$ and $38 \mathrm{GHz}$ spectrum, and other bands up to $100 \mathrm{GHz}$ are being explored [7], [10]. While operating at these higher frequencies, radar systems and cellular base-stations (along with the phase shifters integrated in their arrays) will also continue to need to handle high power levels.

In the field of microwave and millimetre-wave circuit design, gallium nitride $(\mathrm{GaN})$ has attracted considerable attention in the past few years. It has been studied with great interest by engineers and researchers primarily due to its high breakdown voltage and high power handling capability. In addition, it exhibits good stability in harsh environments, including those with high levels of ionizing radiation and heat. In short, it offers excellent performance at high power and at high frequencies-an attractive combination.

Gallium nitride and other III-V technologies generally offer better performance than silicon (CMOS or BiCMOS) solutions. However, the lower costs associated with silicon integrated circuts are compelling. Innovations in the system architecture can also sometimes compensate for the perfor- 
mance difference. The presence of both N-type and P-type FETs in CMOS (and also NPN and PNP devices in BiCMOS) could also be used to narrow the performance gap.

The majority of research into GaN microwave circuits to date has focused on high-efficiency power amplifiers. While the many studies into power amplifier design have certainly been useful and interesting, the benefits offered by gallium nitride transistors can certainly be exploited in other types of circuits, such as switches, duplexers, active circulators and phase shifters. However, these types of circuits have been the subject of relatively few research studies.

This work fills in some of the gaps. It focuses on GaN phase shifters operating at relatively high power levels. Phase shifters operating at $\mathrm{X}$-band and K-band are designed and discussed.

\subsection{Summary of thesis contributions}

This thesis presents two types GaN phase shifters. The first is a novel lumped-element phase shifter inspired by a distributed-element circuit topology which offers wide bandwidth using a resonator-loaded topology. This design also requires two switches. A novel single-pole-double-throw (SPDT) switch is also designed for this purpose. The resulting circuit covers the intended band quite well and is competitive with previously 
reported designs, but the bandwidth of the complete phase shifter is ultimately limited by the SPDT switch. The second GaN phase shifter is based on a switched-filter topology, and offers good bandwidth and high power handling.

The thesis makes two further contributions required for the accurate design of GaN phase shifters. Both involve building blocks with which a phase shifter may be designed.

First, an accurate linear HEMT (high electron mobility transistor) model useful for the design of switches is discussed. Switching models differ from the more general models used for other types of circuits, such as amplifiers or oscillators. These more general models are usually not suitable for the design of switching circuits, especially where an accurate phase response is required, such as phase shifters.

Second, a suspended inductor offering a higher self-resonance frequency and higher quality factor, while occupying exactly the same amount of substrate area is presented and analyzed. This type of inductor is useful when designing very high frequency circuits. It is also compatible with many III-V MMIC processes.

\subsection{Thesis overview}

The remainder of the thesis is organized as follows: 
- Chapter 2 reviews the existing scientific literature on phase shifter design and discusses how GaN phase shifters can fit in and impact the design of microwave systems.

- Chapter 3 discusses the required characterization of the GaN transistors in order to accurately design switching circuits.

- Chapter 4 presents a suspended inductor, which offers increased quality factors and self-resonance frequencies.

- Chapter 5 presents a novel SPDT switch which is then used in the design of a new wideband lumped-element phase shifter.

- Chapter 6 discusses a switched-filter phase shifter offering wider bandwidth than is normally obtained from this topology.

- Finally, some concluding remarks and considerations for future phase shifter designs are given in Chapter 7. 


\section{Chapter 2}

\section{A Review of the}

\section{Literature}

Phase shifters find use in many systems and components. For example, they can be used in vector modulators [11], [12], radiolocation systems [13] and frequency translators [14]-[16]. However, they are most often found in phased array systems, such as radar systems [8], [17] and increasingly in communications systems using beamforming, such as fifth-generation mobile networks [5]-[7] and 802.11ac wireless networks [18].

While this thesis does not deal specifically with the design or analysis of any of these systems, it is beneficial to see how phase shifters fit into the microwave front-end of these systems. Indeed, the RF front-ends for 
many systems are quite similar. Therefore, the role of the phase shifter in a front-end is studied in this chapter, and how the structure of a conventional front-end can be simplified when implemented in gallium nitride will be discussed. Along the way, a review of gallium nitride and how it is useful in microwave circuits is presented.

This chapter is divided into the following sections. Section 2.1 reviews the properties of gallium nitride at microwave frequencies. Section 2.2 discusses how phase shifters fit in the front-end of microwave systems. It also discusses how the unique properties of $\mathrm{GaN}$ can affect the design and architecture of the front-end. Section 2.3 examines phase shifters found in the scientific literature. This literature review will include analog and digitally-controlled phase shifters and implementations in a variety of technologies, including vanilla PCB/MHMIC/MMIC designs, but also other exotic solutions, and MEMS (micro-electromechanical systems) phase shifters. The final section then summarizes the chapter and discusses how the new work in this thesis fits into the existing landscape.

\subsection{Review of gallium nitride at microwave frequencies}

Since gallium nitride is receiving more and more attention from microwave system and circuit designers, it is helpful to review the characteristics of 
GaN which have led to this interest. However, the material still poses some difficulties with respect to fabrication.

The material is well known for being useful in high power applications. It offers high breakdown field, excellent thermal conductivity and ability to operate at high temperatures. While this thesis is focused on microwave applications, it has also found wide use at low (kilohertz) frequencies where high efficiency is required [19]-[24] and optics [25], [26].

This section will review these properties and how this technology is used in various circuits and systems. Its disadvantages and difficulties are also studied.

\section{MMIC design considerations}

Table 2.1 shows a comparison between the three most commonly-used technologies for microwave integrated circuits. The first two rows show clearly that gallium nitride posseses a much larger bandgap and breakdown field than both silicon and gallium arsenide. As a result, GaN devices offer a much higher breakdown voltage than the other technologies. For comparison purposes, IHP's $0.25 \mu \mathrm{m}$ CMOS process has a typical breakdown voltage of $4.8 \mathrm{~V}$ [27] and TriQuint's $0.25 \mu \mathrm{m}$ gallium arsenide (GaAs) process has a typical breakdown voltage of $15 \mathrm{~V}$ [28]. TriQuint's $0.25 \mu \mathrm{m} \mathrm{GaN}$ process, on the other hand, has a typical breakdown voltage of $100 \mathrm{~V}$ [29]. 
Table 2.1: Comparison between properties of the three most commonly-used MMIC technologies. The first two rows highlight the high voltage ability of $\mathrm{GaN}$, the middle two rows demonstrate its current handling ability and the final four rows demonstrate its ability to operate at high frequencies. Excerpted from [30].

\begin{tabular}{lccc}
\hline & Silicon & GaAs & GaN \\
\hline Bandgap $(\mathrm{eV})$ & 1.12 & 1.42 & 3.39 \\
Breakdown field $(\mathrm{MV} / \mathrm{cm})$ & 0.3 & 0.4 & 5 \\
\hline Channel charge density $\left(1 / \mathrm{cm}^{2}\right)$ & $0.3 \times 10^{13}$ & $0.2 \times 10^{13}$ & $1 \times 10^{13}$ \\
Thermal conductivity $(\mathrm{W} / \mathrm{cm} \cdot \mathrm{K})$ & 1.45 & 0.46 & $1.3(\mathrm{SiC}: 4)$ \\
\hline Electron mobility $\left(\mathrm{cm}^{2} / \mathrm{V} \cdot \mathrm{s}\right)$ & 1450 & 8500 & 1500 \\
Saturation velocity $(\mathrm{cm} / \mathrm{s})$ & $0.9 \times 10^{7}$ & $1.3 \times 10^{7}$ & $2.7 \times 10^{7}$ \\
Resistivity $(\Omega \cdot \mathrm{cm})$ & $\approx 1.5$ & $>1 \times 10^{7}$ & $\mathrm{SiC}:>1 \times 10^{5}$ \\
Loss tangent $(\mathrm{at} 10 \mathrm{GHz})$ & $\approx 0.015$ & 0.0004 & $\mathrm{SiC}: 0.003$ \\
\hline
\end{tabular}

The next two rows of Table 2.1 illustrate the high current-carrying ability of GaN devices, with a channel charge density which is significantly higher than silicon and GaAs. The thermal conductivity of the gallium nitride layer as well as its silicon carbide substrate also allow for heat generated in the device to be dissipated efficiently. As a result, current densities in excess of $2 \mathrm{~A} / \mathrm{mm}$ have been reported [31]-[33]. High power densities of $40 \mathrm{~W} / \mathrm{mm}$ have also been reported (at $4 \mathrm{GHz}$ with $1.2 \mathrm{~A} / \mathrm{mm}$ ) by Cree using field-plated devices [34].

The last four rows demonstrate that gallium nitride circuits function adequately at high frequencies. The combination of good electron mobility and extremely high saturation velocity enable high speed operation of active devices. Indeed, transistors with $f_{\max }$ of $300 \mathrm{GHz}$ have been re- 
ported [35], and more recently even transistors with $f_{t}$ of $300 \mathrm{GHz}$ have been disclosed [36], demonstrating the ability to operate at high frequencies. Of note, the $30 \mathrm{~nm}$ GaN HEMTs (with this high $f_{t}$ ) from TriQuint still have a relatively high reported breakdown voltage over $10.7 \mathrm{~V}$ [36]. Meanwhile, the high-resistivity substrate and its low loss tangent ensure that at microwave frequencies, power will not be lost due to the substrate.

\section{Heating and power handling}

The ability of gallium nitride to transfer heat has been studied and compared to other materials commonly used to fabricate integrated circuits. One of the most important parameters is thermal conductivity. The thermal conductivities and thermal coefficients are shown in Table 2.2.

Table 2.2: Thermal conductivities at $300 \mathrm{~K}\left(\kappa_{300}\right)$ and thermal coefficients $(\alpha)$ for several common materials.

\begin{tabular}{cccc}
\hline Material & $\kappa_{300}(\mathrm{~W} / \mathrm{K} \cdot \mathrm{m})$ & $\alpha$ & Ref. \\
\hline $\mathrm{Si}$ & 148 & -1.65 & {$[37]$} \\
$\mathrm{Ge}$ & 60 & -1.25 & {$[37]$} \\
$\mathrm{GaAs}$ & 46 & -1.25 & {$[37]$} \\
$\mathrm{InP}$ & 68 & -1.4 & {$[37]$} \\
$\mathrm{GaN}$ & 130 & -0.43 & {$[38]$} \\
$\mathrm{AlN}$ & 285 & -1.57 & {$[38]$} \\
$\mathrm{InN}$ & 38.5 & - & {$[39]$} \\
$6 \mathrm{H}-\mathrm{SiC}$ & $390 / 490$ & -1.5 & {$[38],[40]$} \\
$4 \mathrm{H}-\mathrm{SiC}$ & 330 & - & {$[41]$} \\
Sapphire & 41 & -1 & {$[42]$} \\
Diamond & 2000 & -1.85 & {$[43]$} \\
\hline
\end{tabular}


According to Table 2.2, the thermal conductivity of gallium nitride is much higher than that of gallium arsenide and indium phosphide, and slightly lower than silicon. However, $4 \mathrm{H}$ silicon carbide-the substrate most commonly used in GaN MMICs-has a thermal conductivity much higher than silicon, which allows for waste heat to be removed much more easily.

Gallium nitride also has a lower thermal coefficient $(\alpha)$ than silicon. This results in GaN and silicon having the same thermal conductivity at $333.6 \mathrm{~K}\left(60.5^{\circ} \mathrm{C}\right)$, and $\mathrm{GaN}$ being a better thermal conductor at even higher temperatures, as the temperature dependence of the thermal conductivity is commonly modeled as [38]

$$
\kappa(T)=\kappa_{300}\left(\frac{T}{300 \mathrm{~K}}\right)^{\alpha} .
$$

This is important, as junction temperatures can reach up to $200^{\circ} \mathrm{C}$ or more in high power applications [44], [45]. GaN transistors are also commonly rated for operation up to $225^{\circ} \mathrm{C}$ or higher [29], [46].

The substrate used also plays a major role in power handling, as heat generated in the active device must be removed. Sapphire $\left(\mathrm{Al}_{2} \mathrm{O}_{3}\right)$ is used in optical applications due to its low cost, but it is generally inappropriate for high power microwave applications due to its quite low thermal conductivity as shown in Table 2.2. This results in increased transistor temperature which is associated with reduced high-frequency performance. 
Some research has gone into using silicon substrates [47]. Silicon substrates are inexpensive and there is interest in the possibility for integrating it with digital circuitry, but there is a high degree of lattice constant mismatch. This leads to mechanical stress (bowing) and cracking, exacerbated by GaN's piezoelectric effect [48]. Furthermore, due to the substrate being a semiconductor, substrate loss limits gain and efficiency at higher frequences [47].

Other substrates have also been researched, such as diamond and gallium nitride itself. Diamond offers a relatively close lattice constant, excellent electrical resistivity (at least seven orders of magnitude higher than silicon carbide) and extremely high thermal conductivity (over five times better than silicon carbide) [49]. Concerns linger regarding cost and substrate size, however. Gallium nitride as a substrate has also been proposed, which would lead to low defect density (due to lattice matching) [50]. Growing GaN crystals to a sufficient size in a practical time period has been problematic, although the situation is improving [50].

\section{Fabrication}

The manufacturing of gallium nitride transistors poses several unique challenges. The first is choosing an appropriate substrate.

For silicon or gallium arsenide circuits for example, a silicon or gallium arsenide substrate is normally used. For gallium nitride however, it is 
difficult to manufacture a gallium nitride substrate. In fact, only in the past few years has there been any meaningful progress in building GaN substrates.

The difficulty in building a GaN substrate is a chemistry problem, because single-crystal GaN is needed for integrated circuits. But when GaN is melted to reform a single GaN crystal, it simply forms elementary gallium and nitrogen gas [51]. Since gallium nitride is not found in nature, it must be grown on another substrate, typically silicon carbide or sapphire. Most commonly, this is done using metal organic chemical vapour deposition (MOCVD), after which the substrate is removed [26]. However, GaN substrates are typically limited to two or three inches in diameter and thicknesses of about $100 \mu \mathrm{m}$, due in large part to mechanical stresses and mechanical deformations.

A second way to grow GaN, which is currently the most commonly used technique, is by HVPE (hydride vapour phase epitaxy) [50]. This is faster and has lower defect density than MOCVD $\left(5 \times 10^{4} / \mathrm{cm}^{2}\right.$ for HVPE, compared to $8 \times 10^{7} / \mathrm{cm}^{2}$ for MOCVD).

A third method for growing GaN is by ammonothermal growth [52]. This technique offers even better defect densities $\left(1 \times 10^{3} / \mathrm{cm}^{2}\right)$. However, growth of the crystal is much slower: $0.4-16 \mu \mathrm{m} / \mathrm{h}$ [53], compared to 100 $500 \mu \mathrm{m} / \mathrm{h}$ for HVPE [54]. 
The use of gallium nitride substrates is desired largely for improving the lifetimes of devices and to improve power handling for HEMTs [55]. Gate leakage current is reduced, which improves reliability and improves breakdown [56]. This must be balanced with the reduced thermal conductivity of the substrate, compared to silicon carbide substrates, however.

Gallium nitride substrates are still uncommon, with silicon carbide being the usual choice. The decision must consider several factors: lattice constant, thermal conductivity, thermal expansion coefficient, wafer size and, of course, cost. Table 2.3 presents some important parameters to consider when selecting a substrate. It is desirable to have $a, \kappa_{300}$ and $\alpha_{L}$ similar to GaN, to reduce defects and stress due to heating.

In the process used throughout this thesis, a silicon carbide substrate is used. Silicon carbide provides a good compromise between cost, mechanical and thermal properties, and RF performance.

Table 2.3: Parameters used in the selection of a substrate for GaN devices: lattice constant $(a)$, thermal conductivity at $300 \mathrm{~K}\left(\kappa_{300}\right)$, thermal expansion coefficient $\left(\alpha_{L}\right)$, wafer diameter and approximate cost.

\begin{tabular}{cccccc}
\hline Material & $\begin{array}{c}a \\
(\AA)\end{array}$ & $\begin{array}{c}\kappa_{300} \\
(\mathrm{~W} / \mathrm{K} \cdot \mathrm{m})\end{array}$ & $\begin{array}{c}\alpha_{L} \\
\mathrm{ppm} / \mathrm{K}\end{array}$ & $\begin{array}{c}\text { Diameter } \\
(\text { inches })\end{array}$ & Cost \\
\hline GaN [38] & 3.189 & 130 & 5.59 & $\leq 4$ & High \\
$\mathrm{SiC}[41]$ & 3.08 & 490 & 4.2 & $\leq 4$ & Medium \\
Sapphire [42] & 2.747 & 41 & 7.5 & $\leq 6$ & Low \\
Si [37] & 5.4301 & 148 & 3.59 & $\leq 12$ & Low \\
AlN [38] & 3.112 & 285 & 4.2 & $\leq 2$ & High \\
Diamond [43] & 3.57 & 2000 & 1.18 & $\leq 4$ & High \\
\hline
\end{tabular}




\subsection{Use of GaN in phase-shifting systems}

Figure 2.1 shows a simplified RF front-end for a beamforming system. If using a phase shifter implemented in a low-power technology, such as silicon or gallium arsenide, it may have to be placed in the transmit and receive chains, where it will not be damaged by large signals. Power limiting circuitry is also required in the receive path to protect the low-noise amplifier.

This duplication of the phase shifters in both the receive and transmit paths is clearly not optimal. Extra circuit area will be consumed. Furthermore, having a limiter before the low-noise amplifier on the receive side introduces loss, increases noise figure and reduces the sensitivity of the system. Moving the limiter to after the low-noise amplifier reduces its

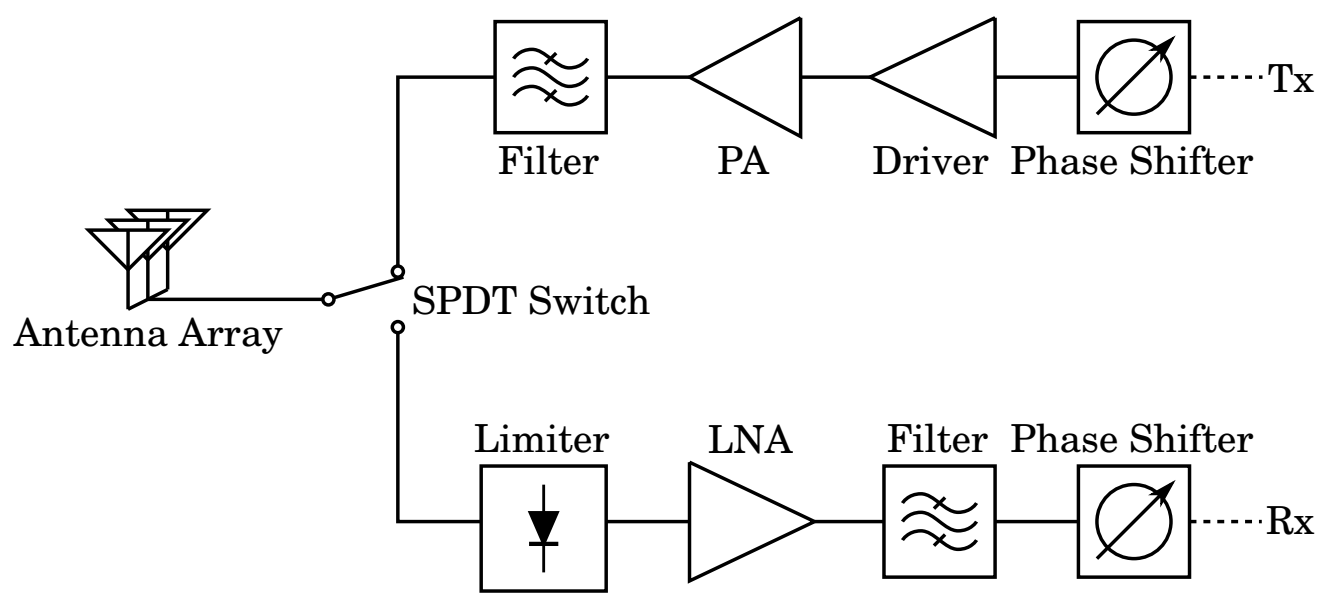

Figure 2.1: Simplified RF front-end for a typical beamforming system in a non-GaN technology. 
impact on noise figure.

However, if these important parts of the transceiver are implemented in a high power technology such as gallium nitride, the front-end can be designed more efficiently. An example of this is shown in Figure 2.2.

First, the phase shifter may be placed closer to the antenna, in the common path. Since the active devices in the phase shifter can handle both weak and strong signals, the circuit will operate properly and will not be damaged. As it is in the common path, only one phase shifter per antenna element is required as well, simplifying the transceiver and reducing its size and cost.

A second advantage is that the limiting circuitry in front of the lownoise amplifier can be eliminated. A low-noise amplifier implemented

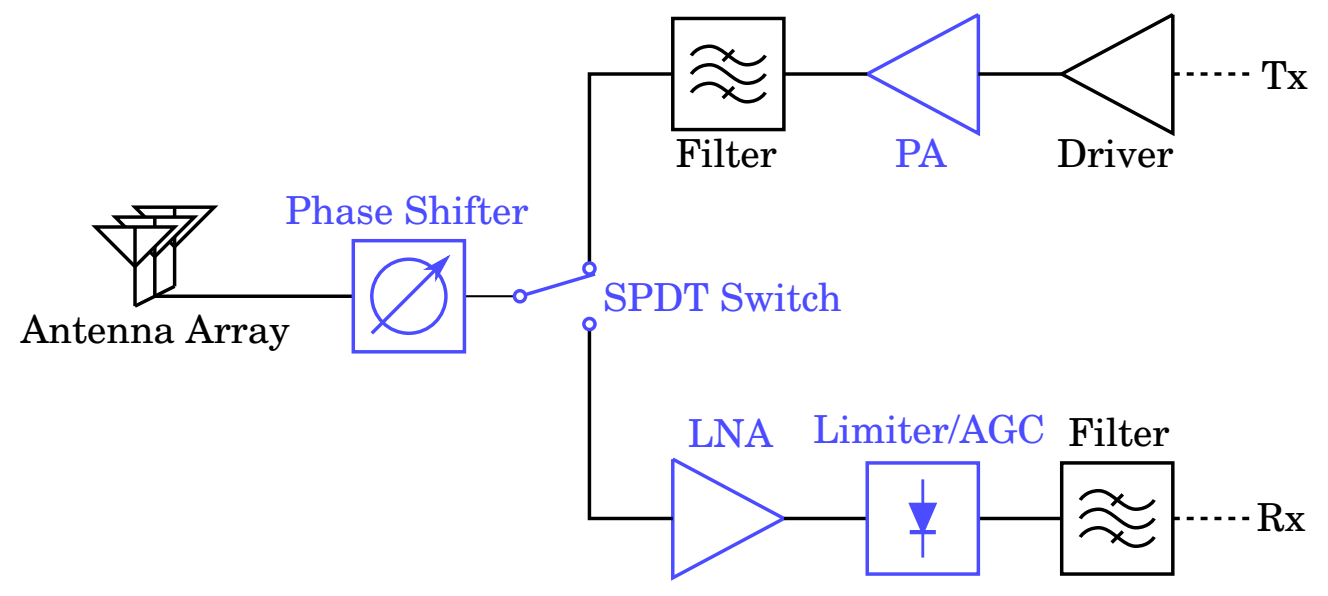

Figure 2.2: Example RF front-end possible with GaN with key components in blue. 
in GaN can withstand extremely high input power levels. For example, $0.15 \mu \mathrm{m}$ and $0.25 \mu \mathrm{m}$ GaN low-noise amplifiers (LNAs) have withstood $37 \mathrm{dBm}$ and $39 \mathrm{dBm}$ input power without any degradation in performance at X-band [57]. A limiter (which might be instead called an automatic gain control circuit in this situation) might still be placed further along in the receive chain, simply to protect the silicon baseband circuitry. While it may still affect the noise figure of the receiver, its effect would be greatly reduced if placed after the low-noise amplifier.

In addition, the high power circuitry, including the phase shifter, power amplifier and switch are simpler to design. For the power amplifier, for example, fewer stages are required, and power combining requirements are reduced [58]. Thermal constraints are also relaxed due to the ability to operate devices at higher temperatures and evacuate waste heat through the thermally conductive substrate.

If placing the phase shifter close to the antenna, it is critical that the loss of the phase shifter be as low as possible. A lossy circuit between the power amplifier and the antenna will reduce the efficiency of the transmitter. The power amplifier would also have to be larger and produce more output power than would otherwise be required, only to have that extra power dissipated in the lossy network that follows. For the receiver, a high-loss circuit between the antenna and the low-noise amplifier will increase the noise figure of the receiver and reduce the sensitivity of the system. 
The previous discussion illustrates why a GaN front-end is beneficial, and why an integrated GaN front-end offers attractive properties compared to front-ends implemented in other technologies. The system may be structured in a manner which reduces the number of required components while increasing the performance of the system, particularly the noise figure and sensitivity.

\subsection{Previous work on phase shifter design}

This section reviews the theory and implementation of microwave phase shifters. It will cover digitally-controlled and analog phase shifters. While it focuses on IC-friendly designs, there will be some discussion of other, more exotic technologies.

The essence of a phase shifter can be seen in its simplest S-parameter representation,

$$
\mathbf{S}=\left(\begin{array}{cc}
0 & \exp (-j \phi) \\
\exp (-j \phi) & 0
\end{array}\right)
$$

This equation shows that a phase shifter should be perfectly matched, have unity gain, and present an insertion phase which is constant for all frequencies. This phase may be controlled, but should be flat over frequency. There is another class of circuit, the true-time delay, which is sometimes also called a phase shifter but presents a constant group delay (which is 
$-d \phi / d \omega)$. The true-time delay therefore presents a non-constant phase shift $\phi(\omega)$ which depends linearly on frequency.

The true-time delay is common in ultra-wideband pulsed radar systems as it avoids signal distortion and beam squinting [8], [59], [60]. However, in communications systems for example, where there may be multiple narrow channels, it is important that each channel be transmitted in the same direction. In order to ensure this is so, a constant phase shift over frequency is important. Also, in large phased array systems, it can be beneficial to use both types of phase shifters for wideband operation as it can reduce the number of phase shift/time delay elements required and simplifies amplitude equalization [61], [62].

Analog and digital phase shifters also exist. Analog phase shifters provide continuous phase shift control, for example from $0^{\circ}$ to $360^{\circ}$. Continuous control is most often accomplished using varactors, as will be discussed later on. Digital phase shifters provide discrete phase shifts, with the phase resolution determined by the number of control bits. For example, Figure 2.3 shows an example of a 4-bit phase shifter offering $360^{\circ}$ phase shift. An $N$-bit phase shifter will provide a phase resolution of $360^{\circ} / 2^{N}$. For $N=4$, a phase resolution of $22.5^{\circ}$ is available. In other words, phases of $0^{\circ}, 22.5^{\circ}, 45^{\circ}, 67.5^{\circ}, 90^{\circ}$, and so on, up to $337.5^{\circ}$ are possible. The insertion losses (in $\mathrm{dB}$ ) of the four individual phase shifters will also add.

While Figure 2.3 shows the individual phase shift elements as a series 


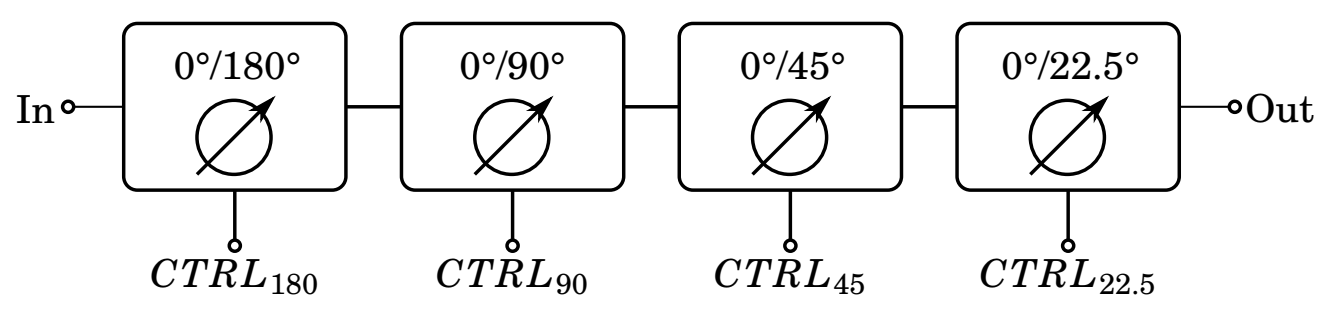

Figure 2.3: A 4-bit cascaded digital phase shifter.

or cascaded system, they could in principle be connected in parallel. This would be problematic however, for two reasons. First, to be equivalent to the 4-bit network shown, 16 different phase shift networks would be needed, instead of four. Second, two SP16T (single-pole-sixteen-throw) switches would be required to select the appropriate phase shift circuit. Such a switch will probably be difficult to design and implement at microwave frequencies. While the insertion losses would not add as they do in the series cascaded phase shifter, it is not clear that the overall performance would be improved, because of the higher loss of the SP16T switches.

The rest of this section will review the work done on phase shifters in the past. Their behaviour with respect to the criteria described above is also discussed.

\section{Switched-line phase shifter}

The first type of phase shifter is the switched-line phase shifter. With this type of phase shifter, it is possible to switch between two (or more) delay lines as shown in Figure 2.4. This type of phase shifter offers constant 
phase shift across a relatively narrow bandwidth, and is in fact better used as a time delay. The phase shift provided by this circuit is the difference in electrical lengths of the two transmission lines.

If a true-time delay is required, this circuit performs well. However, it does suffer some problems. First, the line lengths are unequal, resulting in a variable insertion loss, depending on whether the long delay line or short delay line is active. Second, if a long delay is required, the transmission lines used in its design will also be quite long. In an integrated circuit, this may be impractical and costly to implement, particularly at lower frequencies.

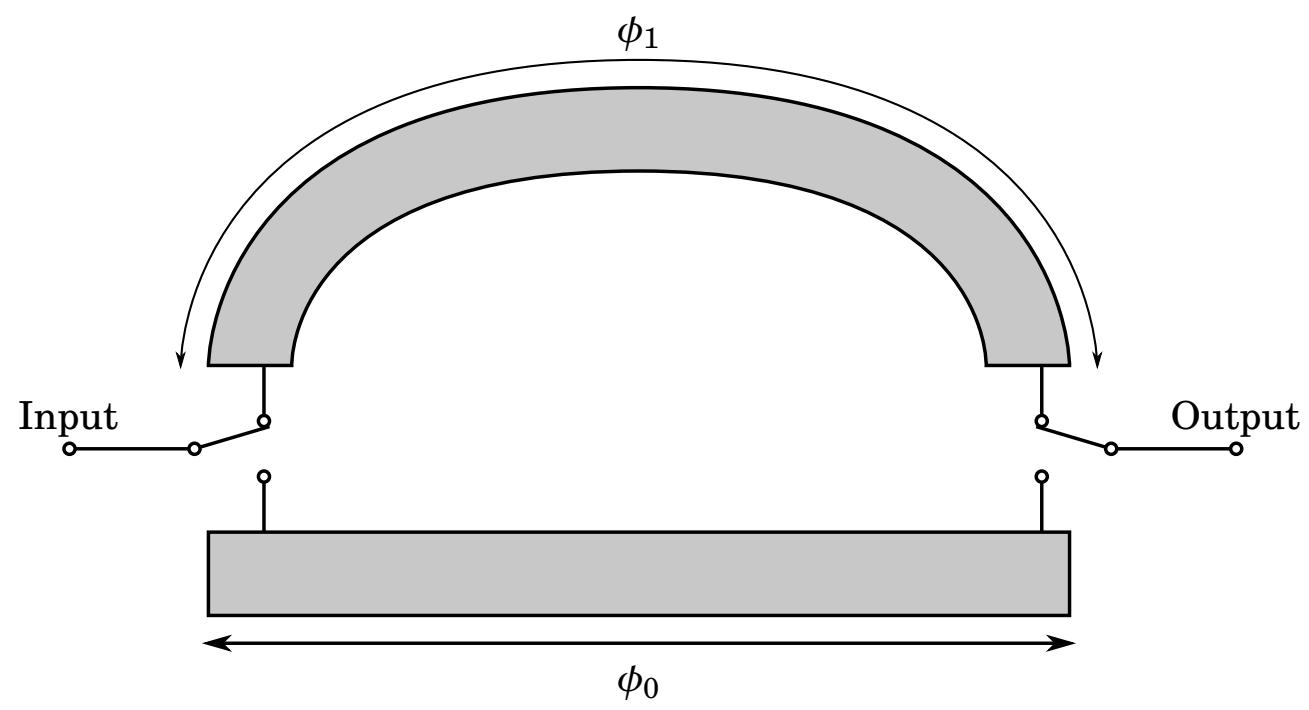

Figure 2.4: Switched-line phase shifter. 


\section{Reflection phase shifter}

Reflection phase shifters, pictured in Figure 2.5, work on a similar principle. In a coupler-based circuit, the input signal is split, and is either reflected by a short-circuit or a stub with a length equal to half the desired phase shift. As a wave will travel through the stub in both directions, the desired phase shift is achieved.

This circuit also performs best as a true-time delay. Since isolation between the input and output ports is improved, there can be better matching at each port. However, the circuit will occupy more chip area and loss is worse because of the coupler. A circulator may also be used in much the same way. In both cases, the phase shift network can use open-circuit or short-circuit terminations to obtain the phase shift.

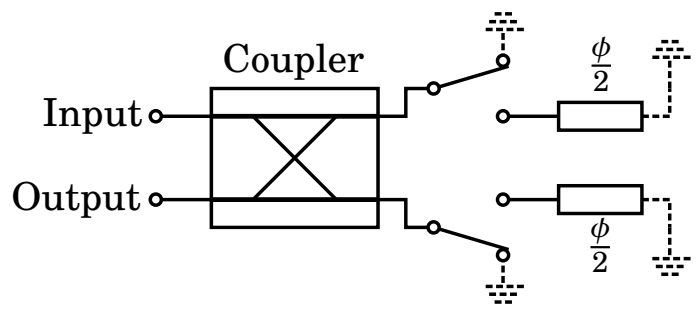

(a) Using a directional coupler.

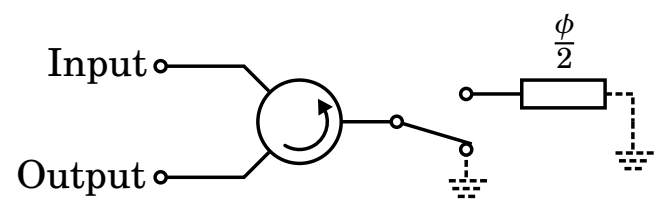

(b) Using a circulator.

Figure 2.5: Reflection phase shifter. The circuits function with either openor short-circuit terminations. 
It is also possible to insert varactors in the terminations (in series with or replacing entirely the transmission line). Matching is negatively affected, but it is possible to achieve continuous control of the phase shift in this manner.

\section{Loaded-line phase shifters}

Loaded-line phase shifters are another topology [63], shown in Figure 2.6. The circuit may be analyzed using ABCD parameters. Using a line with $Z=Z_{0}$, the network's combined ABCD matrix is

$$
\begin{aligned}
\mathbf{A B C D} & =\left(\begin{array}{cc}
1 & 0 \\
j B & 1
\end{array}\right) \cdot\left(\begin{array}{cc}
0 & j \\
j & 0
\end{array}\right) \cdot\left(\begin{array}{cc}
1 & 0 \\
j B & 1
\end{array}\right) \\
& =\left(\begin{array}{cc}
-B & j \\
j\left(1-B^{2}\right) & -B
\end{array}\right) .
\end{aligned}
$$

The insertion gain of the circuit (with switches closed) is found as

$$
\begin{aligned}
S_{21} & =\frac{2}{A+B+C+D} \\
& =\frac{2}{-B+j+j\left(1-B^{2}\right)-B} \\
& =\frac{2}{-2 B+j\left(2-B^{2}\right)} \\
\left|S_{21}\right| & =\sqrt{\frac{4}{4+B^{4}}} .
\end{aligned}
$$


The insertion phase will be

$$
\begin{aligned}
\Delta \phi & =\tan ^{-1} \frac{\operatorname{Im}\left\{S_{21}\right\}}{\operatorname{Re}\left\{S_{21}\right\}} \\
& =\tan ^{-1}\left(\frac{1}{B}-\frac{B}{2}\right)
\end{aligned}
$$

and the return loss will be (assuming lossless elements)

$$
\begin{aligned}
\left|S_{11}\right| & =\sqrt{1-\left|S_{21}\right|^{2}} \\
& =\sqrt{1-\frac{4}{4+B^{4}}} .
\end{aligned}
$$

One big problem with this topology is that it is impossible to have a matched circuit in both states. There is only a perfect match when $B=0$ (switches are open), from (2.12). The matching also deteriorates when a larger phase shift (larger value of $B$ ) is needed. The circuit will also have different attenuations depending on whether the switches are open or closed, as seen in (2.8). In Figure 2.6, there is a single-pole-singlethrow (SPST) switch, either enabling phase shift, or disabling it; an SPDT

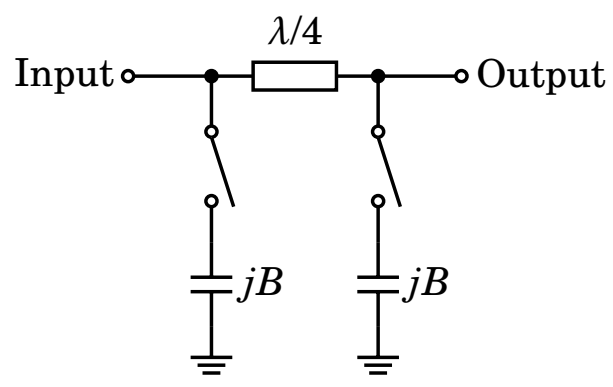

Figure 2.6: Loaded line phase shifter. 
switching between two shunt impedances (such as between a capacitor and inductor) is another option.

As with the previous phase shifter configuration, varactors may be used instead of switched impedances. Again, perfect matching is still not possible with this type of circuit even without the varactors.

\section{High-pass-low-pass phase shifter}

Another type of phase shifter is the high-pass-low-pass phase shifter, illustrated in Figure 2.7. The form shown in this figure is the preferred form, but four combinations of the circuit are possible, using either $\Pi$ or $\mathrm{T}$ networks in each of the low-pass and high-pass filter networks. The circuit shown is preferred simply because it has the fewest inductors, which are often lossy and much larger than capacitors.

This network is analyzed in a similar manner to the previous phase

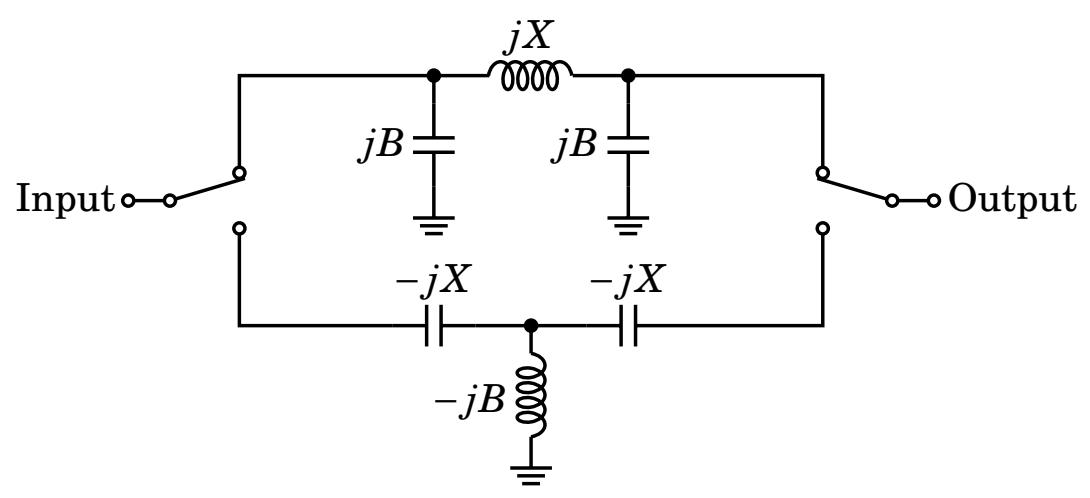

Figure 2.7: High-pass-low-pass phase shifter. 
shifter. Its ABCD matrix is found to be

$$
\begin{aligned}
\mathbf{A B C D} & =\left(\begin{array}{cc}
1 & j X \\
0 & 1
\end{array}\right) \cdot\left(\begin{array}{cc}
1 & 0 \\
j B & 1
\end{array}\right) \cdot\left(\begin{array}{cc}
1 & j X \\
0 & 1
\end{array}\right) \\
& =\left(\begin{array}{cc}
1-B X & j\left(2 X-B X^{2}\right) \\
j B & 1-B X
\end{array}\right) .
\end{aligned}
$$

The transmission coefficient $S_{21}$ is then found as

$$
S_{21}=\frac{2}{2(1-B X)+j\left(B+2 X-B X^{2}\right)}
$$

The phase shift is twice the insertion phase of a single branch (as $B$ and $X$ both change sign when switching):

$$
\Delta \phi=2 \angle S_{21}=2 \tan ^{-1}\left(\frac{B X^{2}-2 X-B}{2(1-B X)}\right) .
$$

Using the matched condition $\left(\left|S_{11}\right|=\sqrt{1-\left|S_{21}\right|^{2}}=0\right)$, the component reactances and susceptances are found as a function of phase shift:

$$
\begin{aligned}
& X=\tan \left(\frac{\Delta \phi}{4}\right), \\
& B=\sin \left(\frac{\Delta \phi}{2}\right) .
\end{aligned}
$$

A variety of high-pass-low-pass phase shifters have been reported in different technologies [64]-[66]. They are typically designed as integrated circuits. They are generally limited to no more than $40 \%$ fractional bandwidth (above this, distributed configurations are used). A modified version 
of this type phase shifter was also presented in [67]. Sometimes, switching transistors are also integrated into the phase shifter, reducing size and the number of required components [68]-[70].

\section{Schiffman phase shifters}

Schiffman phase shifters represent another broad class of phase shifters. They employ coupled lines to provide phase shift [71], [72]. A schematic of a single-section circuit is shown in Figure 2.8. This type of phase shifter is known for their extremely wide bandwidths, and like many distributed circuits, its bandwidth can be increased by employing multiple sections.

The coupled-line section (with two ends tied together) has an image impedance $Z=\sqrt{Z_{0 o} Z_{0 e}}$ and insertion phase [73]:

$$
\phi=\cos ^{-1} \frac{\frac{Z_{0 e}}{Z_{0 o}}-\tan ^{2} \theta}{\frac{Z_{0 e}}{Z_{0 o}}+\tan ^{2} \theta},
$$

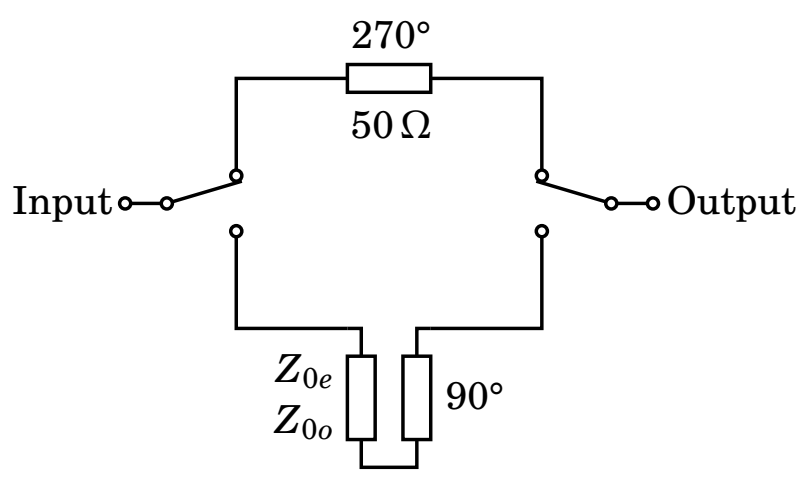

Figure 2.8: Schiffman phase shifter. 
and the total phase shift is the difference between this and the length of the reference line. The proper even and odd impedances of the coupled lines can be found analytically for a desired maximum phase error, as in [74].

Many people have studied this phase shifter and have proposed variations [71], [74], [75]. The circuits generally consume a large amount of circuit space. Another major limitation is that it is limited to phase shifts of $90^{\circ}$ while maintaining a matched circuit. If some mismatch is tolerable, other phase shifts can be obtained by varying the length of the $270^{\circ}$ reference line by the desired phase difference and adjusting the even and odd impedances of the coupled line section.

\section{Other distributed phase shifters}

Other broadband distributed phase shifters have been proposed over the years. Various stub-based phase shifters have been proposed [76]-[79]. Broadside-coupled elements have also been used to realize broadband phase shift [80].

While these circuits offer wideband performance, they also tend to be quite large. They often incorporate multiple quarter-wavelength transmission lines. Another key consideration is that they typically require SPDT switches to switch between the states. Most studies do not include the required switch, while broadband switches are difficult to design and are often the limiting factor in a phase shifter design. 


\section{MEMS-based phase shifters}

Microelectromechanical systems (MEMS) have also attracted considerable attention in recent years. This has been due in large part to their potential to offer extremely low loss switching.

Several MEMS phase shifters have been reported [59], [81]-[83]. Most of these phase shifters are time delay circuits using delay lines and therefore offer constant phase shift over a limited bandwidth. More recently however, broadband MEMS-based circuits have been presented [84]-[86].

The high bandwidth and high power handling of MEMS-based switches is also very promising [84], [87]. Since their early reliability problems (notably stiction [88]) are now being resolved and lifetimes are now in the billions of switching cycles [87], they are likely to be strong candidates for phase shifting and switching applications when integrated with other processes.

\section{Exotic phase shifters}

Other ways to achieve phase shift between two signals have been proposed. One example is using dual-gate devices [89], [90], although it seems a cascode arrangement should work as well. Here, it is possible to achieve gain and phase shift simultaneously. However, the gain tends to vary with the phase shift which is a rather undesirable characteristic. 
Some researchers have also proposed using ferroelectric materials, notably $\mathrm{BaSrTiO}_{3}$ (BST), to achieve a tunable phase shift [91]-[93]. Unfortunately, these solutions combine narrow bandwidth, non-flat insertion loss and tuning voltages on the order of hundreds of volts while requiring the integration of an uncommon material into a circuit. Metamaterials have also been proposed to realize microwave phase shifters [94].

\subsection{Summary}

This chapter has presented a review of gallium nitride technology for microwave applications. It was shown that gallium nitride enables high frequency designs at high power levels.

The manner by which gallium nitride can affect the design of a phaseshifting system is also presented. Since the active devices can support very high power signals, the phase shifter could be placed immediately before an antenna element. As well, protection circuitry, needed in a GaAs or silicon receiver, is not required in $\mathrm{GaN}$ because an LNA can withstand much stronger input signals than in other technologies.

A review of phase shifters found in the literature has also been presented. The bandwidth of lumped-element phase shifters is usually limited, while distributed topologies can offer an octave or more bandwidth. However, distributed circuits typically occupy a large amount of chip area at low 
frequencies. In addition, many wideband phase shifters presented in the literature do not include any switching mechanism, which can significantly limit the bandwidth as well. Circuits which can bridge the gap between small size and wide bandwidth would therefore be quite helpful. This is the goal of the next few chapters. 


\section{Chapter 3}

\section{GaN Switch Device}

\section{Modeling}

The circuits presented in this thesis were manufactured by the National Research Council Canada (NRC). NRC operates a foundry where they are developing a $0.5 \mu \mathrm{m}$ aluminum gallium nitride/gallium nitride (AlGaN/GaN) HEMT-based MMIC process. The foundry's fabrication process currently offers transistors with an $f_{t}$ of $27 \mathrm{GHz}$, which are fabricated on semi-insulating $4 \mathrm{H}$ silicon carbide $(4 \mathrm{H}-\mathrm{SiC})$ substrates. The devices are formed using ammonia molecular beam epitaxy (MBE) and are comprised of a $3 \mathrm{~nm}$ aluminum nitride (AlN) nucleation layer, a $1.1 \mu \mathrm{m}$ carbon-doped GaN insulating buffer, a $0.2 \mu \mathrm{m}$ undoped GaN layer, a $1.5 \mathrm{~nm}$ AlN spacer and $20 \mathrm{~nm}$ AlGaN barrier [95]. Two layers of $1 \mu \mathrm{m}$ gold interconnects are 
present, and the second layer may be used to form either $100 \mathrm{~nm}$ metalinsulator-metal (MIM) capacitors or $1 \mu \mathrm{m}$ airbridges. Thin-film nichrome resistors with sheet resistance of $50 \Omega / \square$ are also available. Spiral inductors in this process typically have a measured quality factor of about 12 to 18 , while capacitors with measured quality factors of at least 50 at X-band are attainable.

However, for any microwave circuit to function as designed, the fabrication process must be properly and accurately characterized. Often, this is done by the foundry as part of their process development, and a set of models and a design manual are provided to users of the process. In the GaN fabrication process used, there is considerable doubt as to whether the models provided are accurate for switching applications (such as is needed in a digital phase shifter), as will be illustrated later.

This chapter is divided as follows. In Section 3.1, a brief review of GaN modeling is presented. In Section 3.2, a small-signal transistor model useful for analyzing and designing $\mathrm{GaN}$ switching circuits is presented.

\subsection{Review of GaN modeling}

There has been considerable interest in modeling gallium nitride transistors. To date, most of these efforts have focused on empirical and semiphysical formulations. Usually, GaN models are based on GaAs models, 
and are then extended or modified to better suit the properties of the GaN device.

There are multiple approaches to modeling a transistor and a good overview is presented in [96]. They can be broken down into the following groups:

- physical models;

- behavioural or black box models; and

- analytical compact models.

Physical models are those developed by considering the fundamental physics of a transistor's operation and considering quantities such as the potential and charge distributions, doping profiles and heat flow within the device. One example is BLAZE [97]. These models are generally not suitable for use in circuit design because of the long solution time.

Black box models include models based on neural networks [98], [99] or X-parameters [100]. They usually don't consider the inherent properties of the device they are modeling and behave only how they were trained to behave. Whether the underlying device being modeled is a resistor or a transistor is inconsequential. While they are sometimes appreciated for their simplicity and ability to model effects which are not widely understood, 
they are generally not scalable or adjustable. For example, a model fitted to a 4 finger transistor cannot predict the behaviour of a 10 finger device.

Analytical compact models are generally preferred for circuit design, because they combine speed and accuracy. They can be scaled over geometry and temperature, and can be used to predict behaviour beyond what is measurable and behaves like the underlying device, because they are based on physical behaviour, but at a higher level than the pure physical models. For example, a physical model for a heterojunction bipolar transistor (HBT) might consider the dopant concentration, lattice constants and chemical composition and proceed to work through the Schrödinger-Poisson equation. A compact model takes advantage of the knowledge that the collector current will be an exponential function, and might use a couple of physical parameters to calculate the current, and at a much greater speed.

For gallium nitride HEMTs, most models are semi-empirical. They use functions which seem to work well for HEMT devices, usually employing functions involving the hyperbolic tangent function to approximate drain current for example. Of particular note for GaN HEMTs, the following effects are significant and should be included in a nonlinear model:

- self-heating; including temperature dependence of

- drain current;

- capacitances; and 
- intrinsic resistances; as well as

- surface traps; including

- gate-lag effects;

- drain-lag effects; and finally

- dependence of $Q_{g s}, Q_{d s}$ and $Q_{g d}$ on all three terminal voltages.

It is important to accurately measure all of these effects when extracting a model. If it is not possible to isolate them, problems normally arise because it is generally possible to extract a model which fits all measurements but which later fails to predict the performance of a circuit [101], [102]. Therefore, if it is not possible to measure the applicable effects, it should be better to use a more simplistic model than to guess and hope.

The most common model for GaN devices is the Chalmers model [103][107], as many properties of the transistor can be included. Other choices are Agilent's EEHEMT model and Curtice's C_HEMT model [108], [109].

Some work has been done on physics-based compact modeling of GaN devices, although it is still an ongoing process [110]-[112]. Some of the difficulties to be addressed by these models include $g_{m}$ collapse at high gate-source voltages and negative differential electron mobility [110], an analytical, physical expression representing the 2-D electron gas (2DEG) 
density [111], and unified physical expressions representing all operating regions of the device [112].

Studies on nonlinear GaN switch modeling have also started to appear recently [113], [114]. There are some differences between transistor modeling for switches and for other circuits. For example, switches normally have a symmetrical operation and construction, while amplifiers tends to have their gates offset towards the source.

\subsection{GaN switch model}

Since the foundry does not provide a transistor model suitable for designing switching circuits and the available laboratory facilities are not equipped to extract accurate nonlinear models of high power GaN devices (such as capturing thermal and trapping effects typically present in GaN devices [115], [116]), a linear model for a switch HEMT was extracted. The equivalent circuit of the model is shown in Figure 3.1. Photographs of two standalone transistors (one common-source, the other common-gate) are also shown in Figure 3.2.

Initial estimates of model parameters can be obtained analytically. There are a variety of ways this may be done [117]-[119]. An approach similar to that in [119] is adopted here in the common-source configuration, using broadband S-parameters with the transistor in pinch-off and with all 


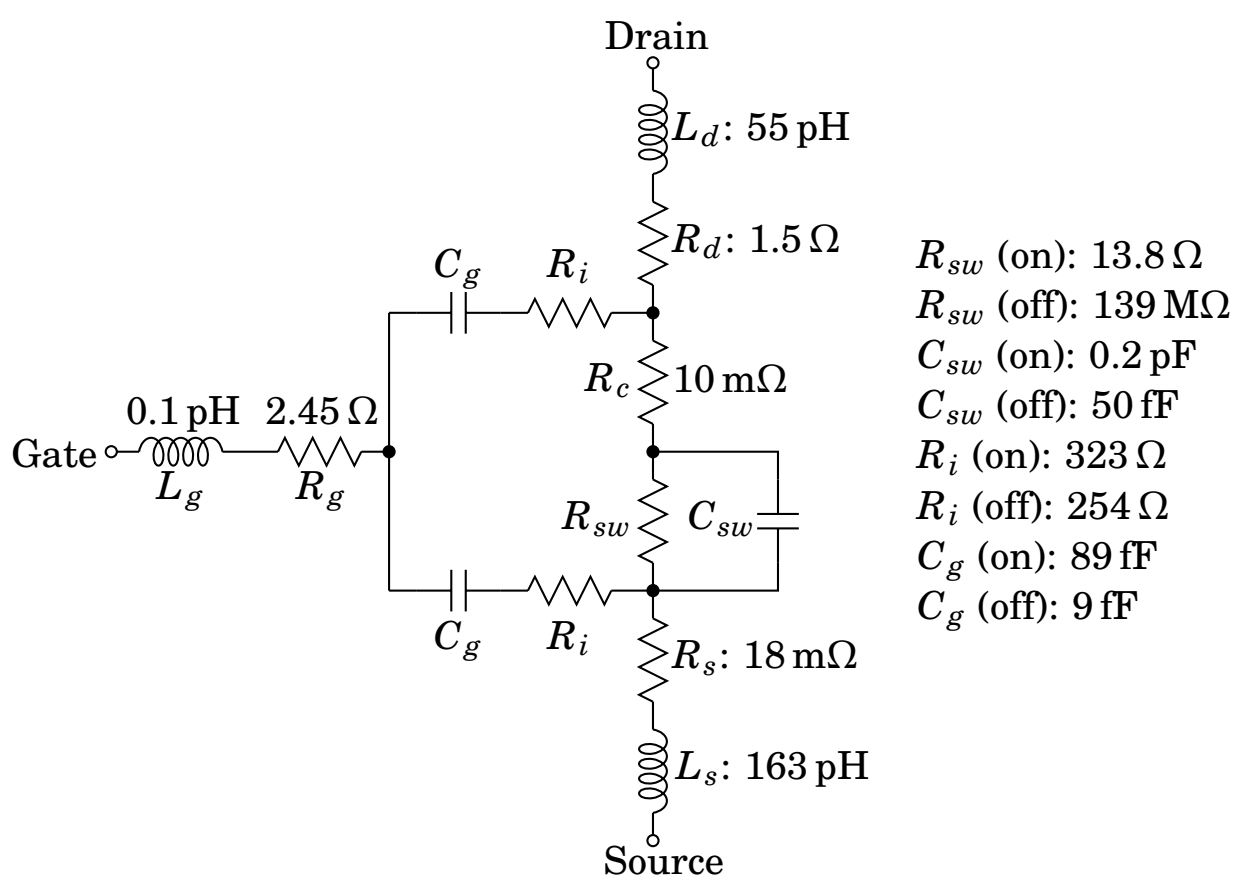

Figure 3.1: Linear model used to model the switching GaN HEMT transistors. Parameters correspond to a transistor with total gate width of $160 \mu \mathrm{m}$ and scale with gate width. $C_{g}, R_{i}, R_{s w}$ and $C_{s w}$ vary with gate bias as indicated.

terminals at zero bias.

As shown in Figure 3.3, two relatively simple circuits represent the transistor in both states. When in pinch-off, the channel is represented by only a capacitor, whereas at zero-bias, it is modeled by the channel resistance. Extrinsic parameters $\left(L_{g}, L_{s}, L_{d}, R_{g}, R_{s}\right.$ and $\left.R_{d}\right)$ are present and equal in both circuits, since they are bias-independent.

First, values for $R_{g}, R_{d}, L_{g}, L_{d}$ and $L_{s}$ are found using the unbiased 


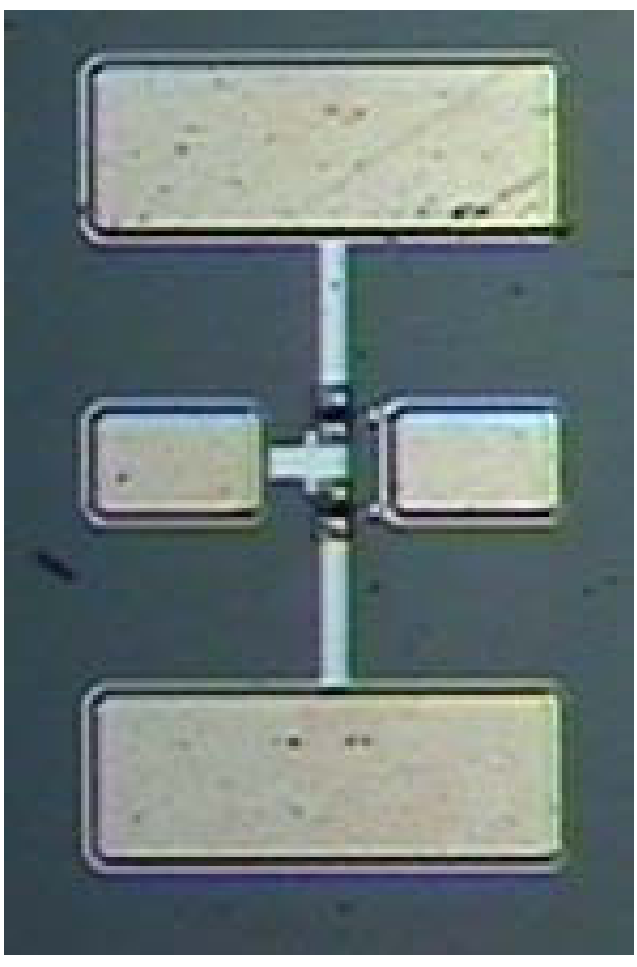

(a) A common-source HEMT.

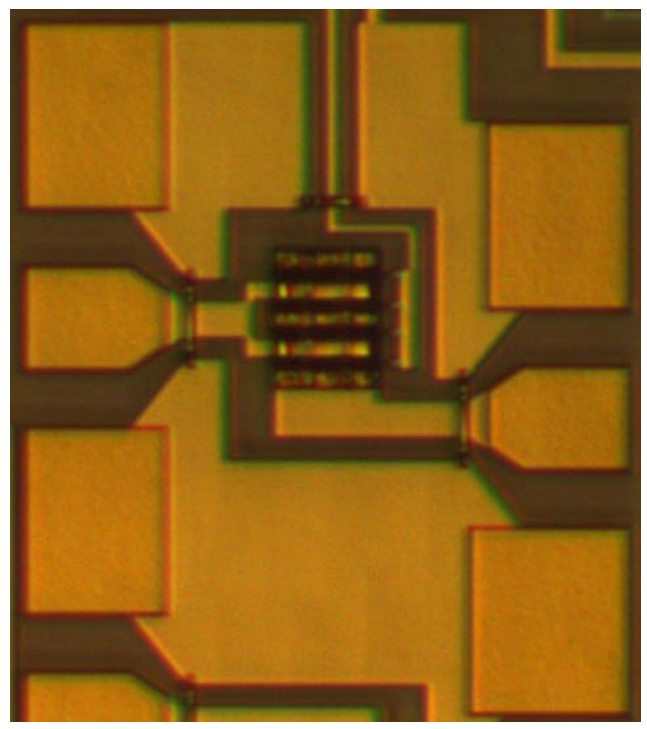

(b) A common-gate HEMT.

Figure 3.2: Photographs of two standalone AlGaN/GaN HEMT devices from the NRC foundry.

transistor's Z-parameters. Its Z-parameters are given by

$$
\begin{aligned}
& Z_{11}=R_{s}+\frac{R_{c}}{2}+R_{g}+j\left[\omega\left(L_{g}+L_{s}\right)-\frac{1}{\omega C_{g}}\right] \\
& Z_{12}=R_{g}+\frac{R_{c}}{2}+j \omega L_{s} \\
& Z_{22}=R_{s}+R_{c}+R_{d}+j \omega\left(L_{d}+L_{s}\right) .
\end{aligned}
$$

The source inductance can be found easily using (3.2), and then $L_{d}$ from (3.3). $L_{g}$ is a little more complicated, requiring two frequencies and a 


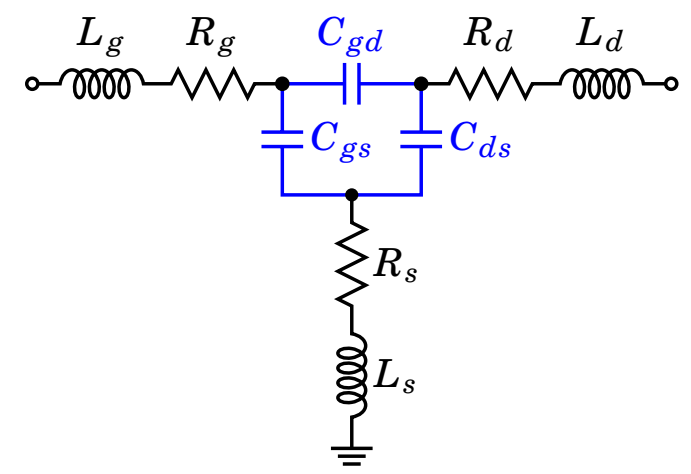

(a) Pinch-off

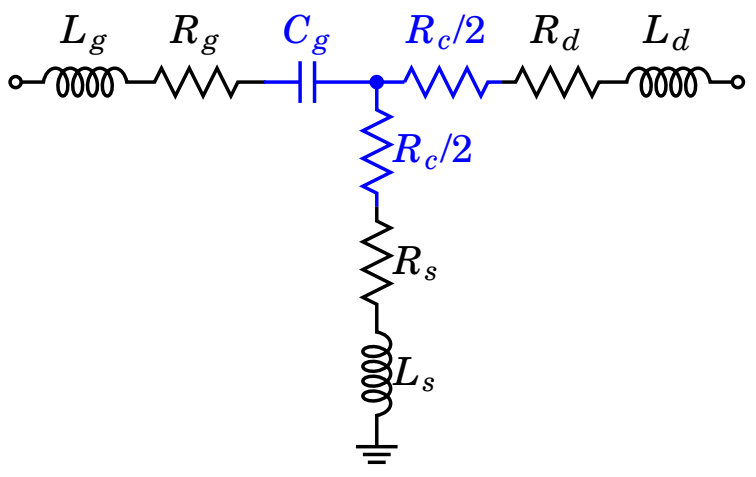

(b) Zero-bias

Figure 3.3: Equivalent circuits used in determining the extrinsic transistor parameters. Elements in blue vary between the two bias points, while the extrinsic elements in black are bias-independent.

system of equations, as it must be found at the same time as $C_{g}$, using $Z_{11}$.

To find the resistances involves both the pinched-off and unbiased measurements. The real part of $Z_{11}$ is $R_{s}+R_{g}$. There are enough equations therefore to find $R_{s}, R_{g}, R_{d}$ and $R_{c}$.

Once determined, these parameters can be subtracted from pinched-off Z-parameter matrix, and Y-parameters can then be used to determine the 
intrinsic parameters. Specifically,

$$
\begin{aligned}
C_{g s} & =-\frac{\operatorname{Im}\left\{Y_{12}\right\}}{\omega}, \\
C_{d s} & =\frac{\operatorname{Im}\left\{Y_{22}\right\}}{\omega}-C_{g s} .
\end{aligned}
$$

These calculations are merely estimates, and the precise value is not required. In addition, not all of the parameters are extracted in this way. For example, $R_{c}$ includes a constant part and a bias-dependent part. Likewise, $C_{d s}$ represents $C_{s w}$ in the on and off states. These are difficult to separate analytically. As a result, once estimates for the model parameters are found, the Levenberg-Marquardt algorithm is used to refine the component values, using measured small-signal common-gate measurements. Whether the model is extracted using common-source or common-gate measurements should make no difference, but the results should at least be checked against common-gate measurements in case of extraction sensitivity.

As with most transistor models, several parameters vary with bias: $C_{g}$, $R_{i}, R_{s w}$ and $C_{s w}$. As might be expected, most of the model parameters scale with gate width [120]. While not entirely accurate, the series inductances are modeled as varying with gate width. For large gate widths, moderate coupling between gate and drain is also included, with a coupling factor of 0.3. A comparison of the S-parameters of both the on- and off-states is shown in Figure 3.4. As shown, the fit between model and measurements 
is very good. The figure also includes the foundry model's S-parameter predictions in green dashed lines. The foundry model does not agree very well with actual transistor behaviour. Using the foundry model in the design of a switching circuit would probably result in poor measured performance.

The most common figure of merit when evaluating semiconductor processes for switching purposes is the $R_{o n} \cdot C_{\text {off }}$ product. The on-resistance directly affects the insertion loss, while the off-capacitance affects the isolation. Their product is constant and independent of total transistor gate width. A comparison of the switching figures of merit for various technologies, including the GaN process used in this work is shown in Table 3.1. As shown in the table, this $0.5 \mu \mathrm{m}$ GaN process has a relatively poor switching figure of merit, but the situation improves for a $0.25 \mu \mathrm{m}$ GaN process. Small-signal performance of switches in this $0.5 \mu \mathrm{m}$ will likely be worse than for a more modern GaAs or silicon process, but power handling should be significantly better due to increased breakdown voltage and current density. With evolutions in the foundry's process (currently in progress) to reduce contact resistances and gate length, the on-resistance will decrease and the figure of merit will improve.

The power handling ability of gallium nitride was discussed in Chapter 2 , where very high breakdown voltages and current densities are common. In the design of such circuits, it is important to be able to estimate 


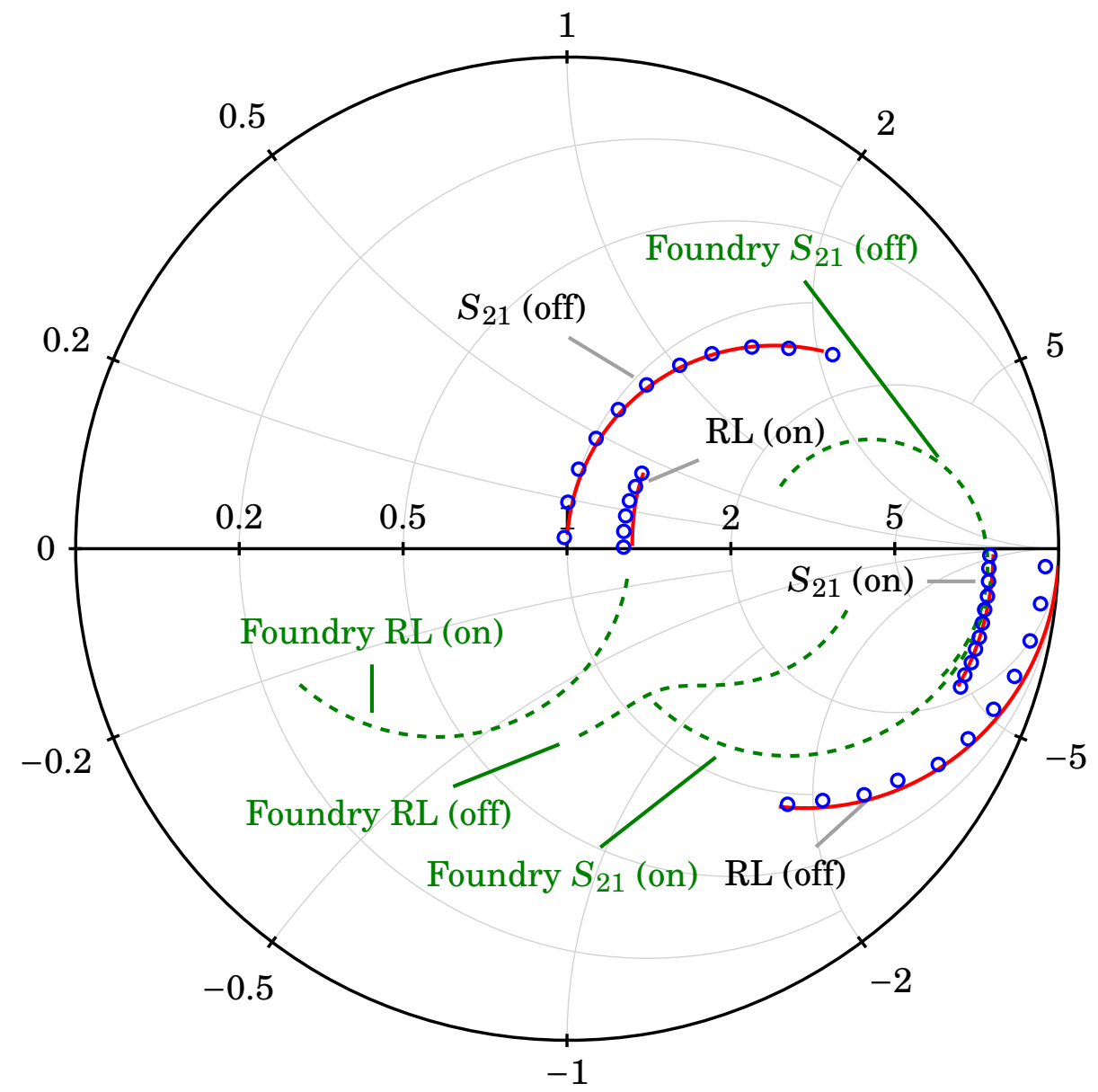

Figure 3.4: Measured (lines) and modeled (circles) S-parameters (0$26.5 \mathrm{GHz}$ ) for a $4 \times 40 \mu \mathrm{m}$ common-gate GaN HEMT's on- and off-states. The foundry model predictions are included for comparison (dashed).

Table 3.1: Switching figure of merit for different technologies

\begin{tabular}{cc}
\hline Technology & $R_{\text {on }} \cdot C_{\text {off }}(\mathrm{fs})$ \\
\hline $0.25 \mu \mathrm{m}$ GaAs pHEMT [121] & 145 \\
65 nm CMOS [122] & 300 \\
$0.18 \mu \mathrm{m}$ CMOS SOI [123] & 250 \\
$0.25 \mu \mathrm{m}$ GaN [124] & 300 \\
$0.5 \mu \mathrm{m} \mathrm{GaN}$ (this process) & 690 \\
\hline
\end{tabular}


the power handling ability of a circuit.

A complete non-linear model is preferred for this purpose, but a simple linear model such as the one presented here can be useful in estimating the power-handling capability of a circuit. The model presented can be easily integrated into the full circuit simulation, and the voltages across the transistor's terminals and the current through the device can be determined using a linear ac analysis available in virtually all simulators. As long as the input RF power does not induce a voltage swing across transistor's terminals that reaches the transistor's pinch-off voltage or breakdown voltage, the switch-based circuit should function largely as predicted from a linear S-parameter analysis. This type of analysis is performed and illustrated in the following chapters.

This simulation does not lend itself well to a quantitative prediction of the $1 \mathrm{~dB}$ compression point $\left(P_{1 \mathrm{~dB}}\right)$ or input-referred third-order intercept point $\left(\mathrm{IIP}_{3}\right)$. However, it does provide a designer with some useful information on the power-handling capability of the circuit, which can be refined once a large-signal model can be extracted, or when measurements are performed. 


\subsection{Summary}

This chapter presented an overview of gallium nitride modeling at microwave and millimetre-wave frequencies, and switch modeling in particular. Examples of the phenomena that affect GaN transistors have been discussed. These include breakdown, temperature dependence, self-heating, trapping and related memory effects.

To accurately represent the device, a nonlinear model should incorporate these effects. It should also offer a symmetrical (around $V_{d s}=0$ ) response for switching circuits. The foundry-provided model does not satisfy these criteria. However, specialized laboratory equipment is generally required to extract this information for the development of a custom model, such as a thermal chuck (for wafer probing) and a precision pulsed measurement system (for performing isothermal measurements) which can trigger other measurement equipment. Because this equipment was not available, a linear device model was extracted and used instead.

The model proposed and implemented in this work is scalable and is quite accurate over frequency. While it is a linear model, power handling can be estimated by studying the currents and voltages in the transistor, and ensuring that for a given input power level, the transistor's maximum current rating and breakdown voltage are not exceeded, and that the voltage swing does not cause the transistor to self-switch. This model is used for the remainder of the work presented in this thesis. 


\section{Chapter 4}

\section{Suspended Inductors}

The inductor is one of the most difficult to realize $\mathrm{RF}$ and microwave circuit elements. It often suffers from high loss, and hence has a low quality factor. It also usually has a low self-resonance frequency. Yet it occupies an inordinate amount of chip area. At higher microwave frequencies where transmission line lengths shrink, distributed replacements hold some appeal, however, this circuit component can be found in many integrated circuit designs, up to millimetre-wave frequencies. There are two reasons for this. First, the transmission-line equivalent usually has the same response at a single frequency; its broadband response is different, for better or for worse. Second, the transmission-line equivalents are still quite large, in general. Meandering, slow-wave and loading techniques help somewhat, but they come with their own trade-offs and restrictions. The required in- 
ductance (along with its parasitics and size) generally also scale downwards with frequency, reducing the advantage distributed components.

Some researchers have gone to great lengths to avoid using the inductor altogether, whether by using gyrators and active inductors [125]-[128], or by completely avoiding circuit topologies which employ them. Others have attempted to compensate for its shortcomings, for example using active Q-enhancement techniques [129]-[131]. These active approaches are not without their own disadvantages, including added noise from the active devices, poor linearity as well as DC power consumption [132]. The techniques using feedback must also consider circuit stability and the risk of oscillation, and active Q-enhancement circuits increase chip area further. Other approaches include micromachining or using MEMS or MEMS-like techniques [133]-[135], both of which require additional postprocessing techniques after MMIC fabrication.

In this thesis, a technique is proposed to improve the quality factor and self-resonance frequencies by using the airbridge commonly found in MMIC processes. An early study examined the effects of airbridges in microstrip processes [136]. While that study concluded that substrate capacitance has a large effect on self-resonance, in this works, full-wave electromagnetic simulation and a simple but very accurate model of the inductor are used to determine that the decrease in substrate capacitance is the only meaningful cause of the improvement. From measurements, 


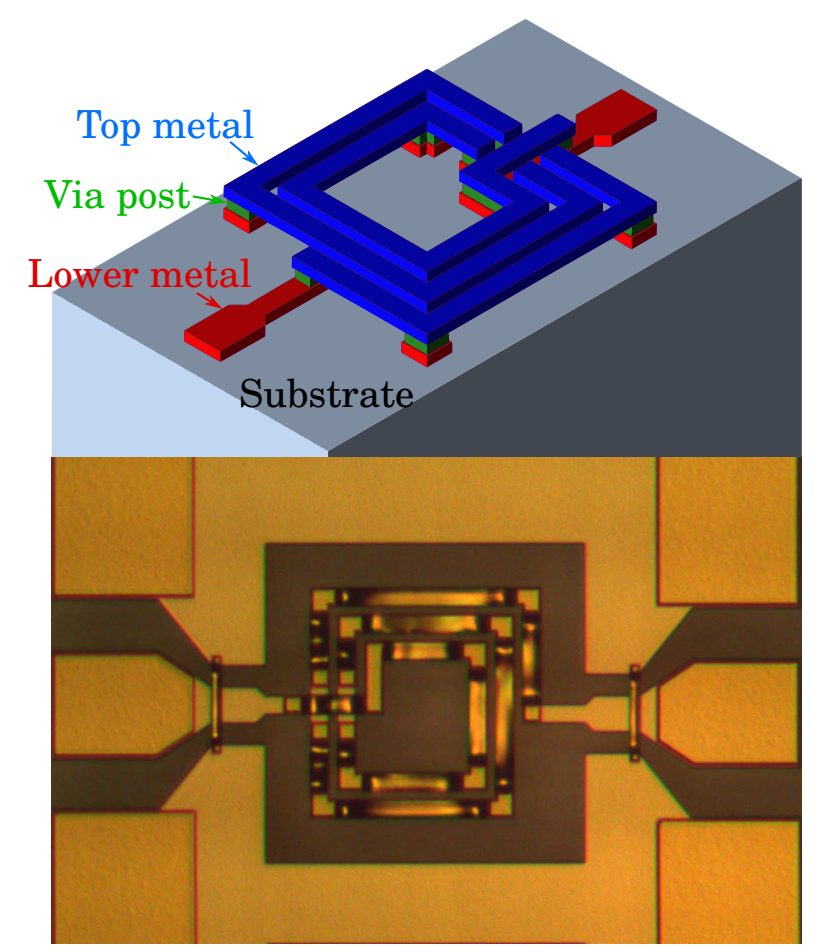

Figure 4.1: Illustration and microphotograph of a $1 \mathrm{nH}$ suspended inductor.

the quality factor of a $1 \mu \mathrm{m}$ suspended inductor improved by $18 \%$ and the self-resonance frequency increased by $4 \%$. Electromagnetic simulation indicates that greater improvement is achievable using processes with airbridges higher than $1 \mu \mathrm{m}$.

These inductors will be used in the design of an X-band phase shifter in Chapter 5, and a K-band phase shifter in Chapter 6.

The remainder of this chapter is organized as follows. In Section 4.1, the accurate model used to analyze the inductors presented here is discussed. Then, in Section 4.2, the suspended inductor is analyzed with the aid of 
full-wave electromagnetic simulation and measured inductors.

\subsection{Inductor modeling}

An accurate inductor model is needed to capture the behaviour of the inductor and to verify the parameters responsible for a change in performance. The model shown in Figure 4.2 is used to represent the inductor. It resembles inductor models commonly used at RF and microwave frequencies [137]. However, while most of the model parameters are frequencyindependent, a frequency-dependent series impedance represents skin effect, which is very important. Some models ignore the frequency dependence of the resistance, while others approximate skin effect using ladders of frequency-independent inductors and resistors [138]-[141]. This approach yields acceptable results in most cases: inductance is predicted very well and quality factor is predicted adequately. However, the equivalent series resistance usually deviates from full-wave EM simulation predictions, particularly between the peak $\mathrm{Q}$ frequency and the self-resonance frequency. The additional model complexity also adds extra parameters which must be calculated and/or fitted.

Since skin effect resistance for smooth metallization is known to be proportional to $\sqrt{f}$ [142], this relationship is included directly in the model. 


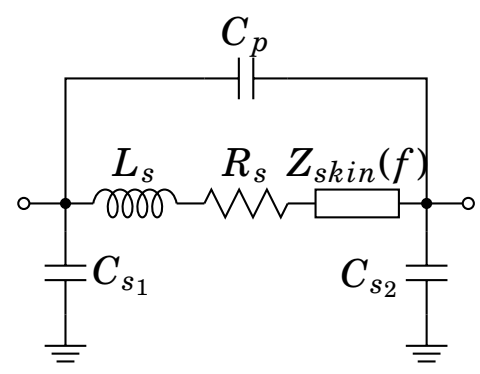

Figure 4.2: Schematic of the linear inductor model used in this work. The frequency-dependent series resistance accurately captures skin effect.

Therefore, in this work, skin effect is represented by

$$
Z_{\text {skin }}(f)=(1+j) R_{\text {skin }_{0}} \sqrt{\frac{f}{f_{0}}}
$$

which includes skin effect's resistive and inductive components. The inductive component is required, otherwise the skin effect model will not be causal, as verified by the Hilbert transform [142]. $R_{s k i n_{0}}$ can be estimated as the difference between actual resistance and DC resistance from a plot of the series resistance at a frequency $f_{0}$ (which should be far below the self-resonance frequency of the inductor), and the square-root variation with frequency is consistent with the frequency behaviour of skin effect. The resistance could also be calculated from geometric and material parameters: $R_{\text {skin }_{0}}=1 /(\sigma \delta)$ where $\sigma$ is material conductivity, $\delta$ is skin depth and $f_{0}$ is set to unity. Implementation of the frequency-dependent impedance as a linear circuit component is straightforward in a modern circuit simulator. Agilent's Advanced Design System was used in this work.

To demonstrate the accuracy of this modeling approach, a $1 \mathrm{nH}$ inductor 
was simulated using Momentum, and the model was fitted to its output. A comparison is shown in Figure 4.3. As seen in the figure, the model fits

very well, even beyond self-resonance. At DC, the skin effect resistance and inductance contributions are zero, so $\operatorname{Re}\{Z\}=R_{d c}=R_{s}$ and $L=L_{d c}=L_{s}$. At very high frequencies there is some deviation, although these are likely due to distributed effects which are not modeled.

\subsection{Suspended inductor}

The suspended inductor shown in Figure 4.1 was simulated for different distances between substrate and inductor metal. The inductor model was then fitted to the electromagnetic simulation results. The model parameters were found to be constant, with the exception of the substrate capacitances $C_{s_{1}}$ and $C_{s_{2}}$. The model parameters are shown in Figure 4.5.

The effect of placing most of the inductor metal in the air is striking, particularly as the airbridge height is increased. The peak $\mathrm{Q}$ and selfresonance frequency are plotted in Figure 4.6. Even in the GaN process used in this work, where the airbridge height is $1 \mu \mathrm{m}$, peak $\mathrm{Q}$ is projected to increase by $21.2 \%$ and the self-resonance frequency is expected to increase by $27.2 \%$. Both of these numbers are relative to the on-substrate inductor. In other processes, where airbridges can be $3-6 \mu \mathrm{m}$ above the substrate or even higher, the improvement is even greater. 


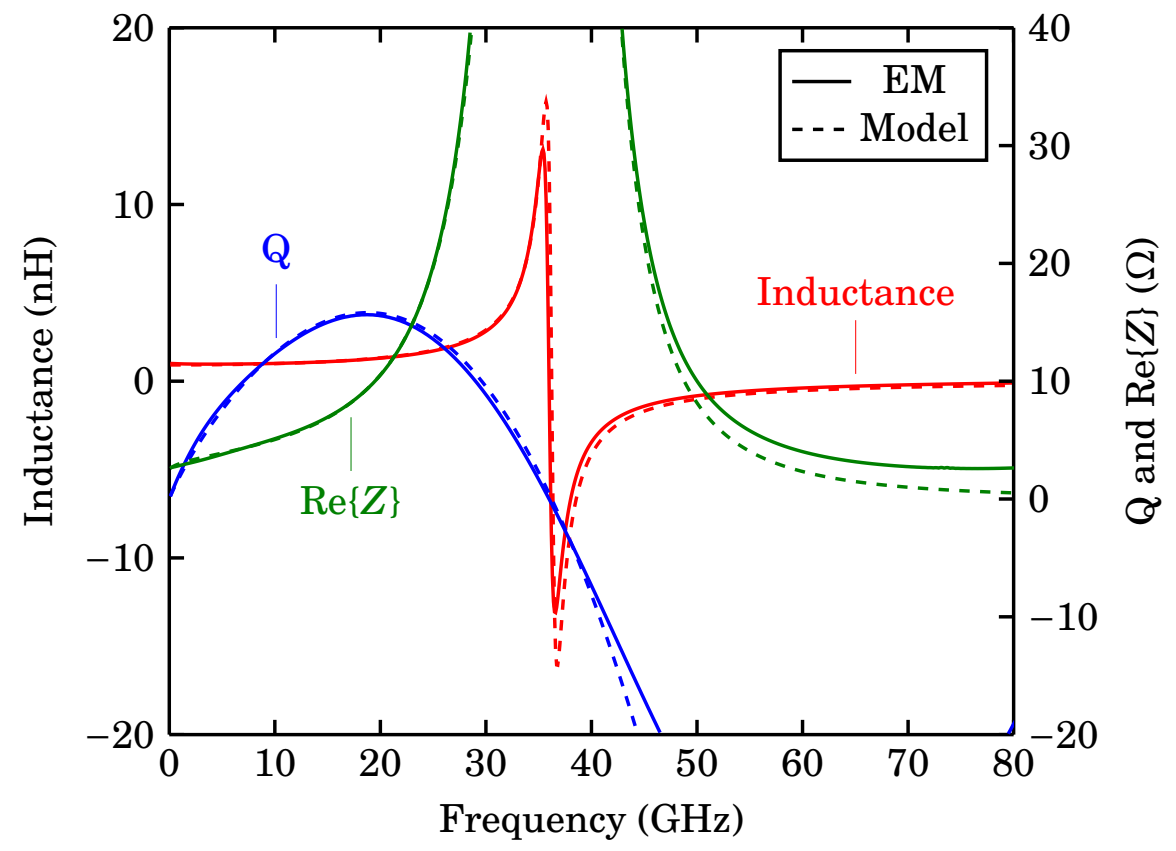

Figure 4.3: Comparison of the model in Figure 4.2 with electromagnetic simulation for a $1 \mathrm{nH}$ inductor directly on the substrate. The definition of quality factor used is $Q=\operatorname{Im}\{Z\} / \operatorname{Re}\{Z\}$.

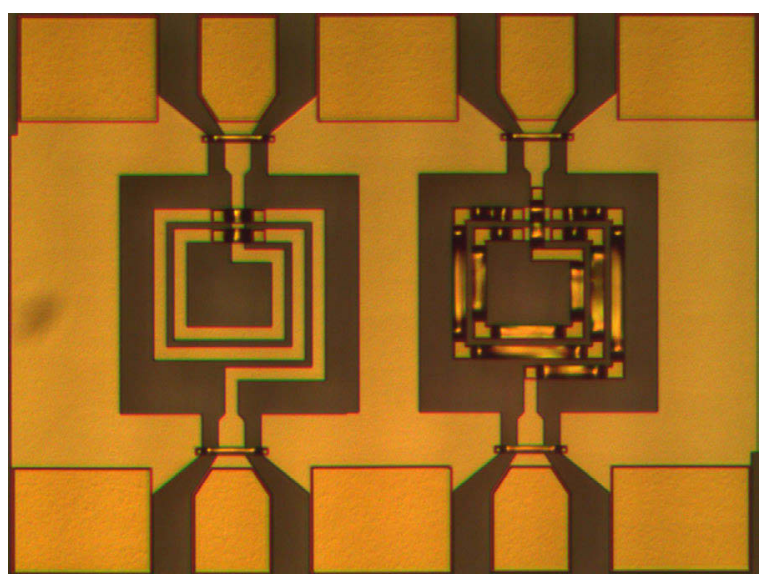

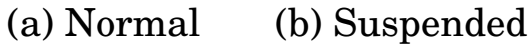

Figure 4.4: Microphotographs of $1 \mathrm{nH}$ inductors (a) laying directly on the substrate, and (b) using an airbridge to lift most of the inductor off of the substrate. 


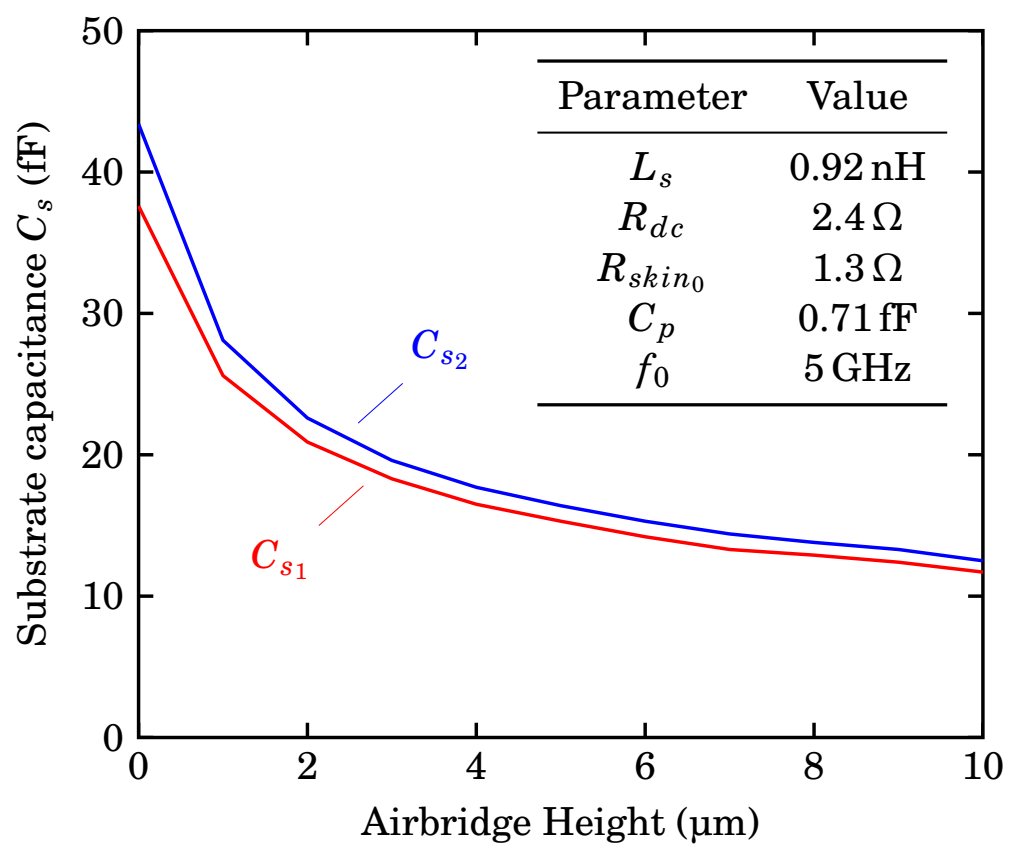

Figure 4.5: Substrate capacitance as a function of the distance between substrate and inductor metal. The parameters shown in the inset table have negligible variation with airbridge height.

The inductors in Figure 4.1 were designed to have the same $1 \mathrm{nH}$ inductance and are laid out identically except for the use of airbridges to raise the inductor $1 \mu \mathrm{m}$ off the substrate. To prevent airbridge collapse and respect process design rules, the corners of the inductor touch down. $669 \mu \mathrm{m}$ of the total coil $(952 \mu \mathrm{m})$, or $70 \%$ of the inductor is raised off the substrate. Figure 4.7 shows how closely the two measured inductors' S-parameters resemble each other. Nearly identical S-parameters are expected for inductors with largely the same inductance, although the extracted resistance and quality factor differ. 


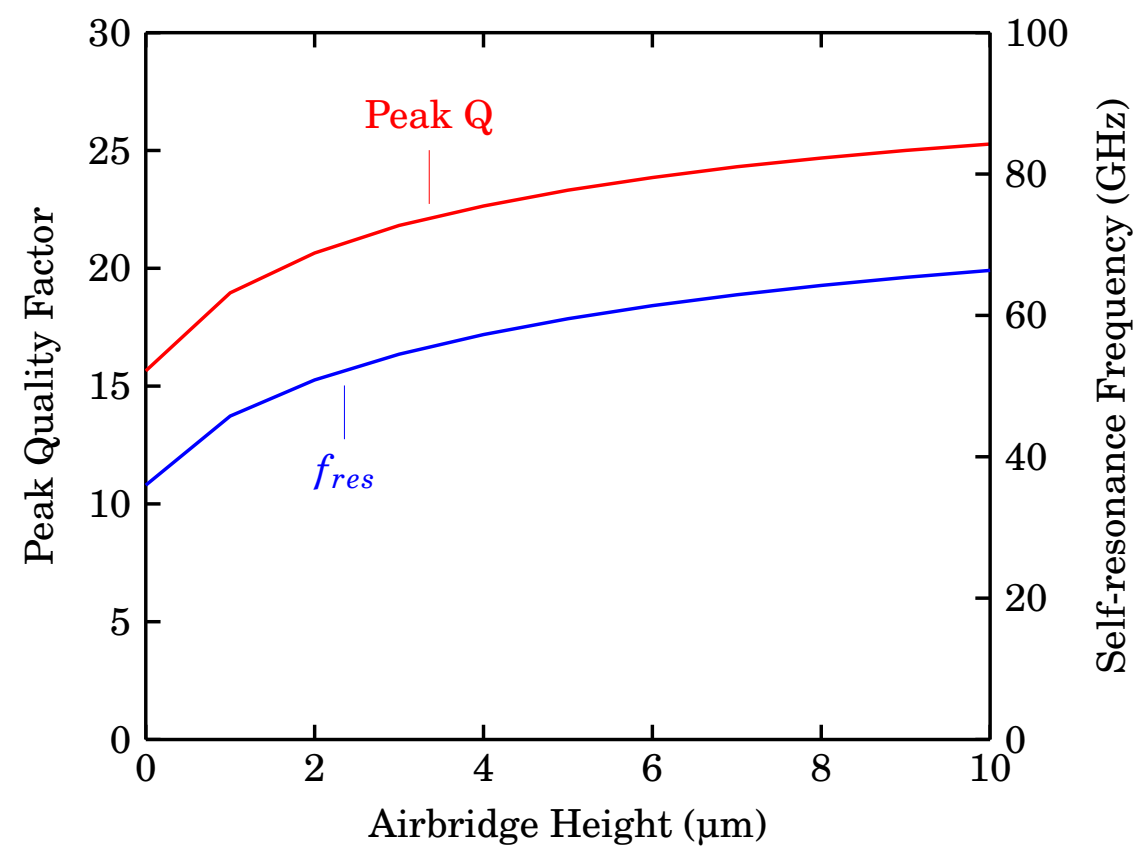

Figure 4.6: Inductor quality factor and self-resonance frequency for different airbridge heights.

Because the measured inductance and quality factor become more difficult to determine at high frequencies, the model presented earlier is fitted to measured data particularly at low frequencies where there is less uncertainty in the measurement. This enables the extraction of the self-resonance frequencies of the inductors. The measured inductance is shown in Figure 4.8, while Figure 4.9 shows the measured inductance and equivalent series resistance. The two figures demonstrate that the model follows the measurements well.

The variation at high frequencies is due to the inductor presenting an almost completely reactive impedance. It is therefore quite susceptible to 


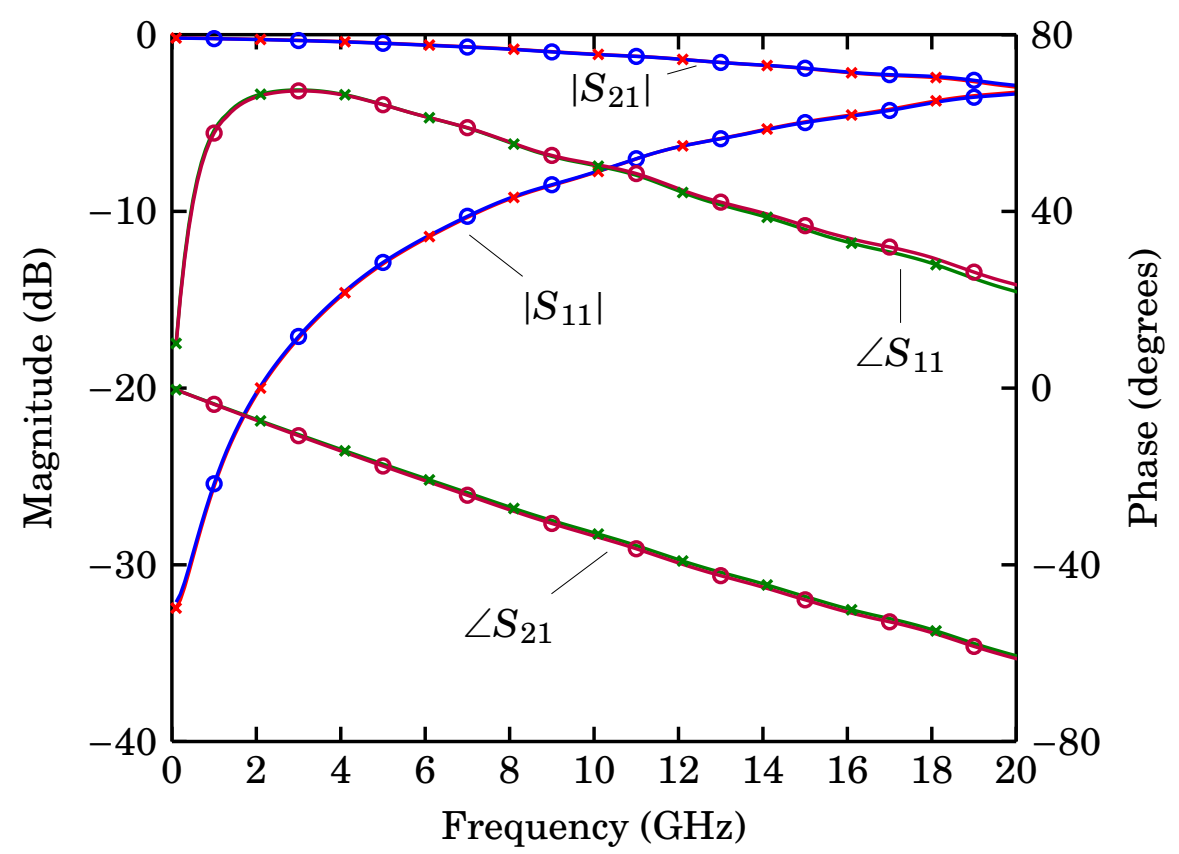

Figure 4.7: Measured S-parameters of the on-substrate $(\mathrm{x})$ and suspended (o) inductors.

calibration imperfections at microwave frequencies [143], [144]. Improving the situation is quite difficult. Standalone, commercially-available calibration substrates have well-defined, consistent and accurately characterized standards, but the calibration substrate and the $\mathrm{SiC} / \mathrm{GaN}$ substrate are not identical and errors creep in. However, calibration standards included on a fabricated circuit are not nearly as well characterized or consistent, and this also causes errors: the measurements might appear to be better-behaved, but they're still wrong.

As shown, there is an improvement of approximately $18 \%$ in the quality factor and $4 \%$ in self-resonance frequency when using a $1 \mu \mathrm{m}$ suspended 


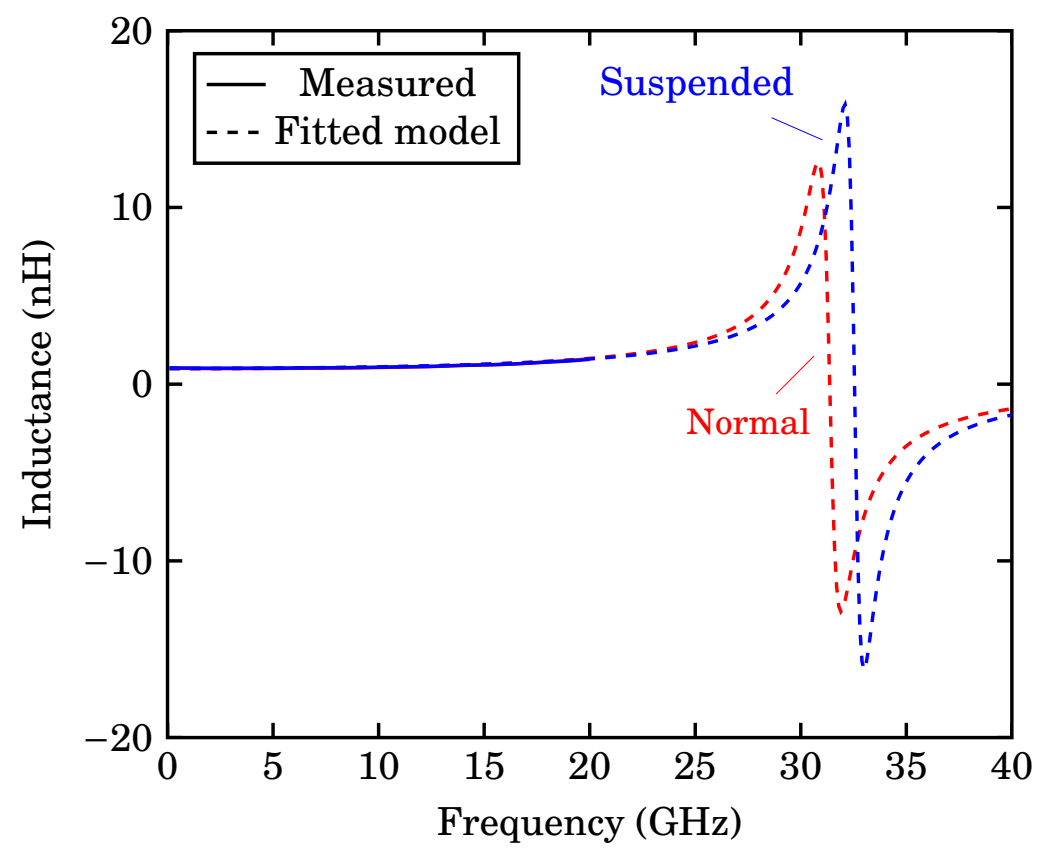

Figure 4.8: Measured inductance. The model in Figure 4.2 is also fitted to low-frequency measurements to enable accurate interpolation and extrapolation.

inductor. While the improvement in quality factor is close to what was simulated, the improvement in self-resonance frequency falls short of the prediction. It is suspected that the airbridge may not maintain its height for its entire span, particularly for the longer inductors.

\subsection{Summary}

This chapter discussed suspended inductors. Suspended inductors are useful in MMIC designs in technologies incorporating airbridges, as they have the potential to greatly improve inductor performance. 


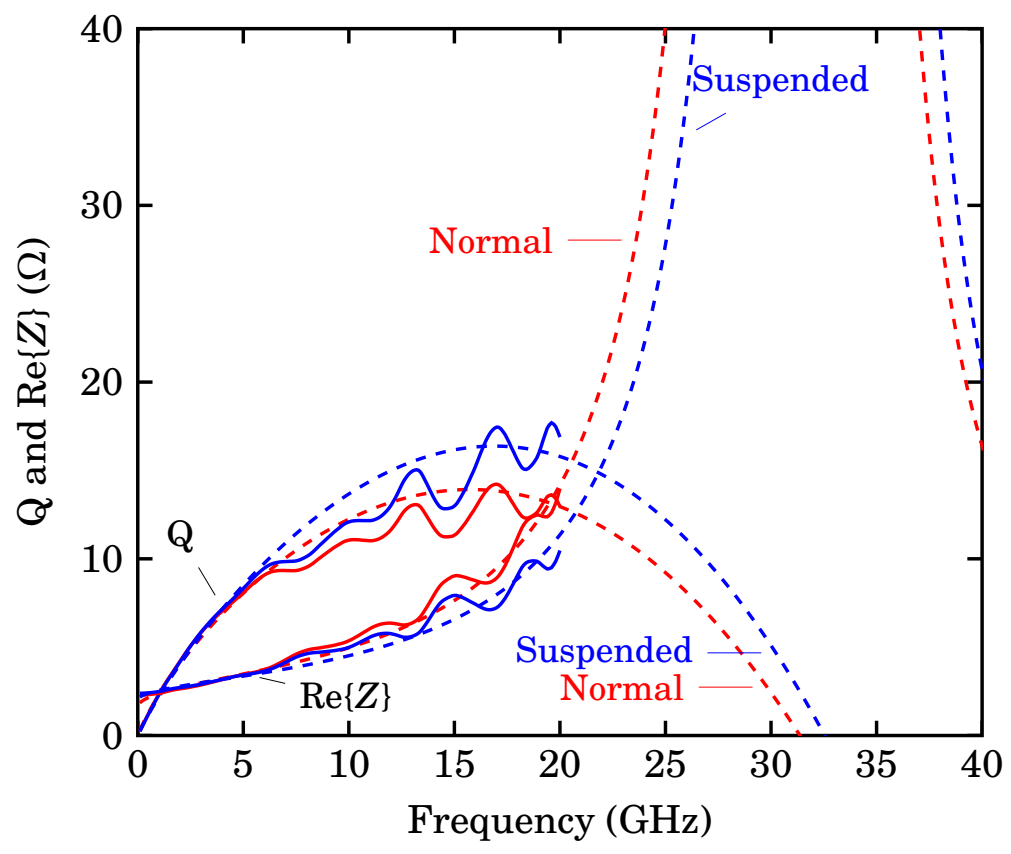

Figure 4.9: Measured quality factor (Q) and equivalent series resistance for the standard and suspended inductors.

To analyze the inductors, a compact inductor model is used, which is capable of very accurately representing the performance of planar inductors. The model is accurate, even beyond self-resonance. The model accurately incorporates skin effect, which has a significant influence at frequencies of several gigahertz and above. While many models attempt to include skin effect as one or more resistor-inductor branches, skin effect is included analytically. This simultaneously improves accuracy, reduces the number of model parameters, allows for direct extraction of parameters from measured/simulated data, but is still physical (linear/causal).

This model is used to analyze planar inductors using airbridges of differ- 
ent heights. It was determined that the only significant physical parameter responsible for change in inductor performance is the shunt substrate capacitance. The reduction in this capacitance as airbridge height increases results in increased self-resonance frequency and improved quality factor. As a result, this type of inductor has been used in some of the later phase shifters to obtain better performance. 


\section{Chapter 5}

\section{LC Resonator GaN Phase}

\section{Shifter}

An investigation of gallium nitride phase shifters resulted in a novel lumped phase shifter topology. This circuit is based on a distributed switched-resonator design. This phase shifter offers wide bandwidth, although its power handling capability is not quite as high. Figure 5.1 shows the topology of the phase shifter, while Figure 5.2 shows a photograph of the fabricated MMIC. 


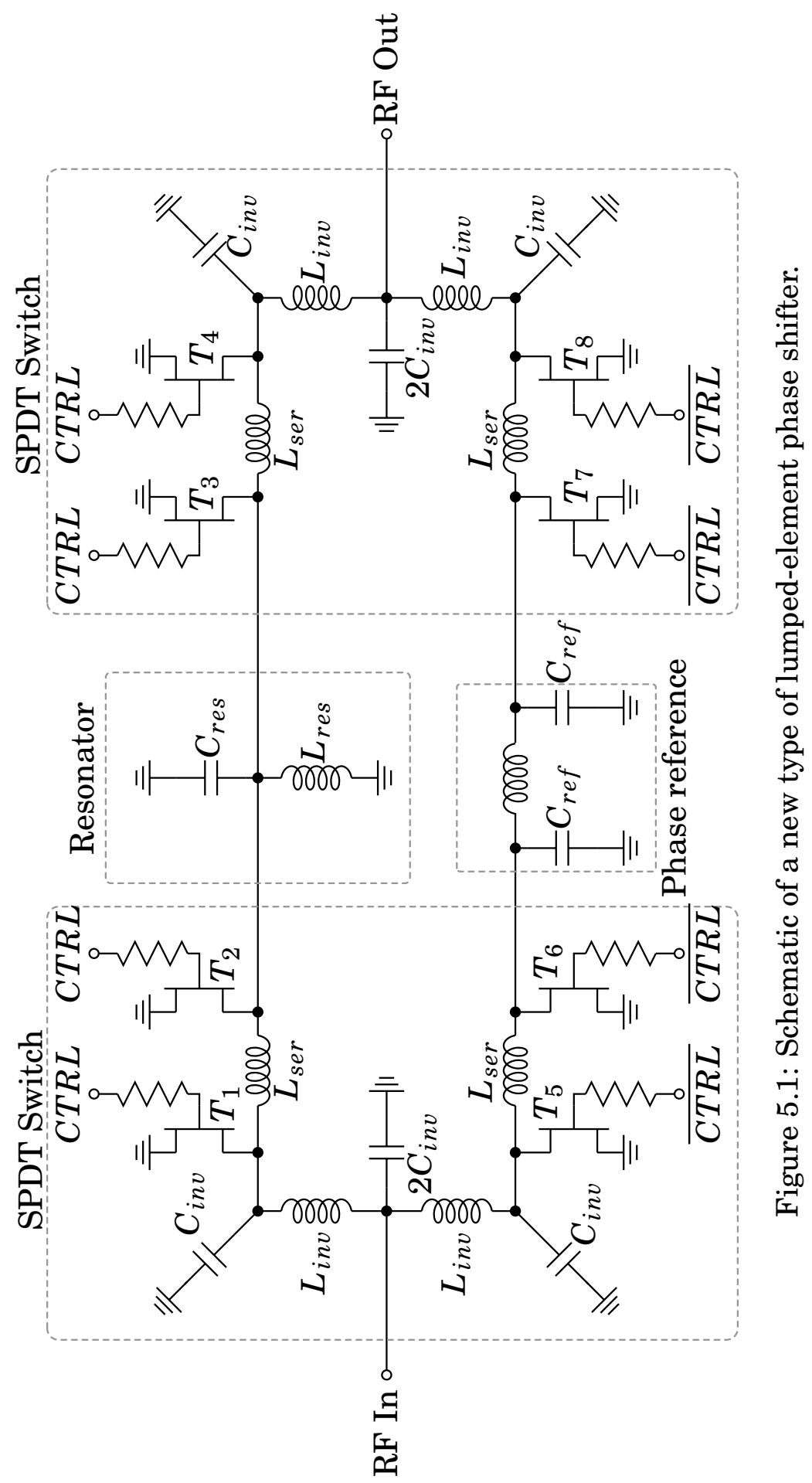




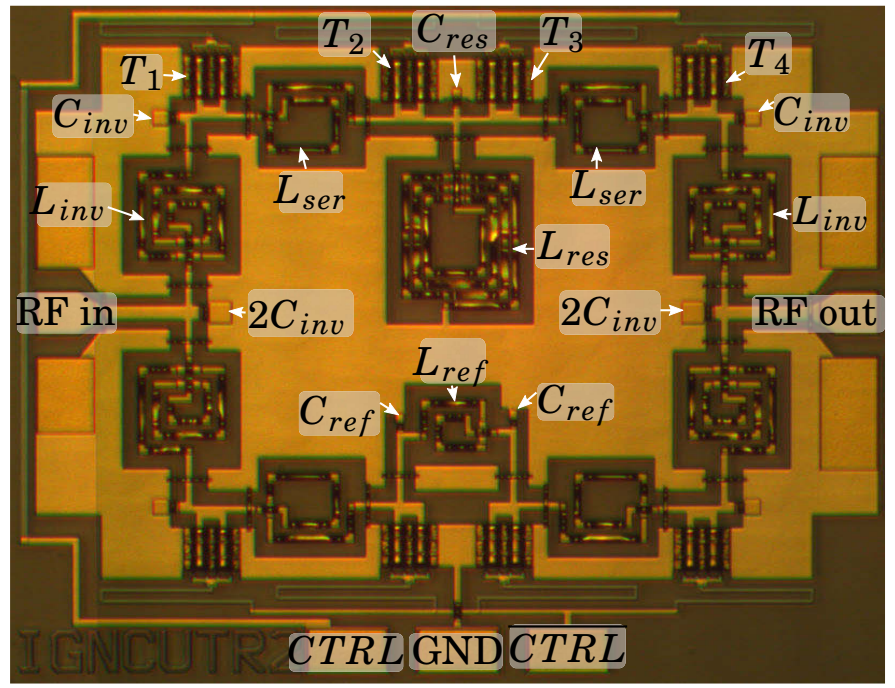

Figure 5.2: Microphotograph of the second $0 \% 22.5^{\circ}$ broadband GaN phase shifter. Circuit dimensions are $1169 \mu \mathrm{m} \times 900 \mu \mathrm{m}$ (Area: $1.05 \mathrm{~mm}^{2}$ ).

\subsection{Phase shifter design}

The phase shift is achieved using a shunt LC resonator. Its parameters are derived from analyzing two parallel $\lambda / 8$, open-end and short-end stub resonators. A schematic of this type of distributed phase shifter is shown in Figure 5.3.

This type of network bears some similarity to that presented in [76], though there are considerable differences in the analysis and the implementation. For example, the design of that type of circuit for small phase shifts such as $45^{\circ}$ or smaller, is quite difficult, as will be shown.

The admittances of the combination of short and open stubs can be 


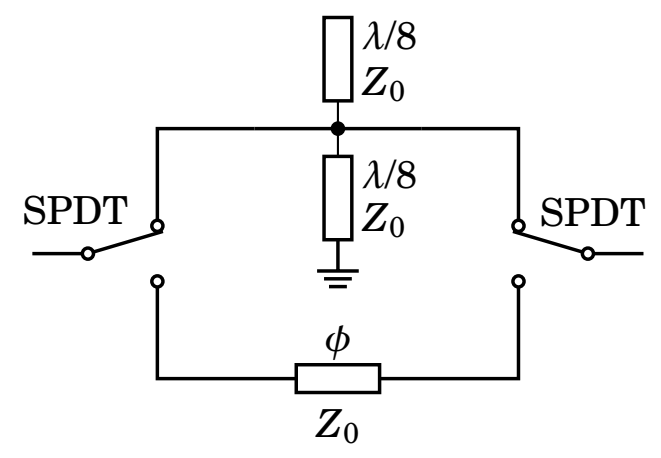

Figure 5.3: Stub-based phase shifter.

found:

$$
\begin{aligned}
Y_{e q} & =j \frac{1}{z_{0}} \tan \theta+\frac{1}{j z_{0} \tan \theta} \\
& =\frac{j\left(\tan ^{2} \theta-1\right)}{z_{0} \tan \theta}
\end{aligned}
$$

This can be simplified using trigonometric identities to yield an equivalent admittance of

$$
Y_{e q}=\frac{2}{j z_{0} \tan 2 \theta}
$$

This shows the equivalence of the two $\lambda / 8$ stubs to a shorted quarterwave stub with the characteristic impedance halved, pictured in Figure 5.4.

The transmission coefficient is found to be

$$
S_{21}=\frac{2}{2+\frac{2}{j z_{0} \tan 2 \theta}} .
$$

Then, the phase shift relative to a phase reference, such as a transmission line is found by determining the insertion phase $\left(\angle S_{21}\right)$ of the network 


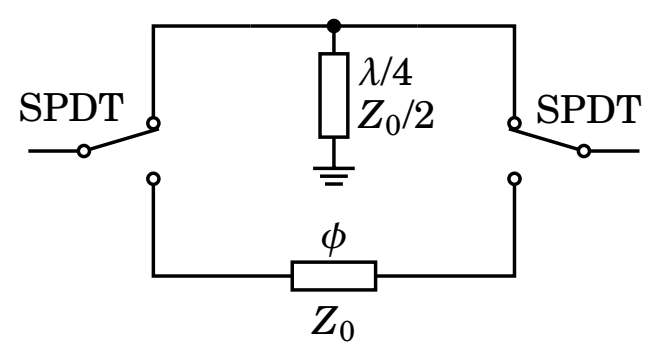

Figure 5.4: Single-stub equivalent of the circuit in Figure 5.3.

and is

$$
\Delta \phi=\phi+\tan ^{-1}\left(\frac{1}{z_{0} \tan 2 \theta}\right) .
$$

Since a flat phase shift over frequency is typically desired, the electrical length $(\theta=\pi \omega / 4)$ of the resonators is substituted to obtain phase shift as a function of frequency

$$
\Delta \phi(\omega)=\phi \omega+\tan ^{-1}\left[\frac{1}{z_{0} \tan \left(\frac{\pi \omega}{2}\right)}\right] .
$$

Then, deriving with respect to frequency (since a flat frequency response is desired):

$$
\frac{d \Delta \phi}{d \omega}=\phi+\frac{\pi z_{0}}{\left(z_{0}^{2}-1\right) \cos \pi \omega-z_{0}^{2}-1} .
$$

Setting this equal to zero, it is possible to calculate the required characteristic impedance for a flat phase shift at the centre frequency $\omega=1$. The following relationship is found:

$$
z_{0}=\frac{\pi}{2 \phi},
$$

where $\phi$ is the desired phase shift. 
Studying this result yields the insight into why this type of phase shifter has, so far, only been used to realize $90^{\circ}$ phase shifts. As shown in Table 5.1, a $90^{\circ}$ phase shift yields a characteristic impedance of $50 \Omega$. Both $180^{\circ}(25 \Omega)$ and $45^{\circ}(100 \Omega)$ phase shifts are also technically feasible (although they are fairly extreme values for line impedance) in microstrip and coplanar waveguide, but beyond this, the values required for the characteristic impedance of the resonators simply cannot be practically implemented.

However, knowing the optimal normalized impedance $z_{0}$ for a desired phase shift, a parallel LC resonator may be synthesized to achieve an optimal response. At higher frequencies, this relationship would also allow for optimal distributed resonator(s) to be designed. The parallel LC resonator will consist of

$$
\begin{aligned}
& L_{\text {res }}=\frac{Z_{0} z_{0}}{\omega}, \\
& C_{\text {res }}=\frac{1}{\omega Z_{0} z_{0}},
\end{aligned}
$$

where $z_{0}$ is the normalized optimal impedance found using (5.8) and $Z_{0}$

Table 5.1: Characteristic impedances required for flat phase shift, from (5.8).

\begin{tabular}{cc}
\hline Phase shift & Resonator impedance \\
\hline $180^{\circ}$ & $25 \Omega\left(0.5 Z_{0}\right)$ \\
$90^{\circ}$ & $50 \Omega\left(Z_{0}\right)$ \\
$45^{\circ}$ & $100 \Omega\left(2 Z_{0}\right)$ \\
$22.5^{\circ}$ & $200 \Omega\left(4 Z_{0}\right)$ \\
$11.25^{\circ}$ & $400 \Omega\left(8 Z_{0}\right)$ \\
\hline
\end{tabular}


is the actual system impedance (e.g., $50 \Omega$ ). The desired phase shift only affects the impedance of the resonator, not its electrical length. In this situation, where a $22.5^{\circ}$ phase shift is desired, $C_{r e s}=80 \mathrm{fF}$ and $L_{r e s}=$ $3.2 \mathrm{nH}$.

It must also be noted that for small phase shifts, the characteristic impedance needed for a distributed structure can be quite high. For example, a $22.5^{\circ}$ phase shift would require $z_{0}=4$, which requires transmission lines with an impedance of $200 \Omega$, which are not readily implemented using microstrip or coplanar waveguide. However, a lumped implementation of its equivalent is not particularly challenging at X-band.

The phase reference can be realized as a simple transmission line, or at lower frequencies, as a lumped-element equivalent. For practical purposes and since lumped elements still work well at X-band, a standard П network is used, as shown in Figure 5.1. A T network would also work, albeit with two inductors, occupying more space and having higher loss. Values for the inductor and capacitors are derived from making the equivalence between the ABCD matrix of the lumped network and a transmission line. Again, for completeness,

$$
\begin{aligned}
L_{r e f} & =\frac{Z_{0} \sin \phi_{r e f}}{\omega} \\
C_{r e f} & =\frac{1-\cos \phi_{r e f}}{\omega Z_{0} \sin \phi_{r e f}} .
\end{aligned}
$$

The inductance of the reference network is $L_{r e f}=305 \mathrm{pH}$ and the capaci- 
tance is $C_{r e f}=63 \mathrm{fF}$.

Since a lumped approach to the implementation of this phase shifter is used, it is also interesting to compare it with the initial idea, with $\lambda / 8$ short and open stub resonators. Figure 5.5 shows this comparison. As shown, the lumped-element version exhibits a similar bandwidth, although its phase shift is not quite as flat at the centre frequency. However, depending on the phase error allowed, it may be even more broadband than the distributed network because the $\lambda / 8$ stubs by their very nature will have a periodic response versus frequency as the stubs resonate when they have an electrical length equal to a multiple of a quarter-wavelength. In theory, a lumped element circuit does not suffer from this periodic behaviour and could in principle extend over multiple harmonics without exhibiting another resonance.

Figure 5.6 shows a microphotograph of the fabricated resonator and $22.5^{\circ}$ reference, while Figure 5.7 shows the measured and simulated Sparameters of the reference state and LC resonator to achieve a $0 \% 22.5^{\circ}$ phase shift. Figure 5.14, discussed later, shows the phase shift and phase error. As shown, the measurements agree quite well with the simulations. The passive circuitry was simulated using Agilent's Momentum solver. Using a standard $5 \%$ definition for phase variation and return loss better than $10 \mathrm{~dB}$, the circuits would operate well from $6.3-16.2 \mathrm{GHz}$ (88\% fractional bandwidth), although the measured phase shift is slightly higher 


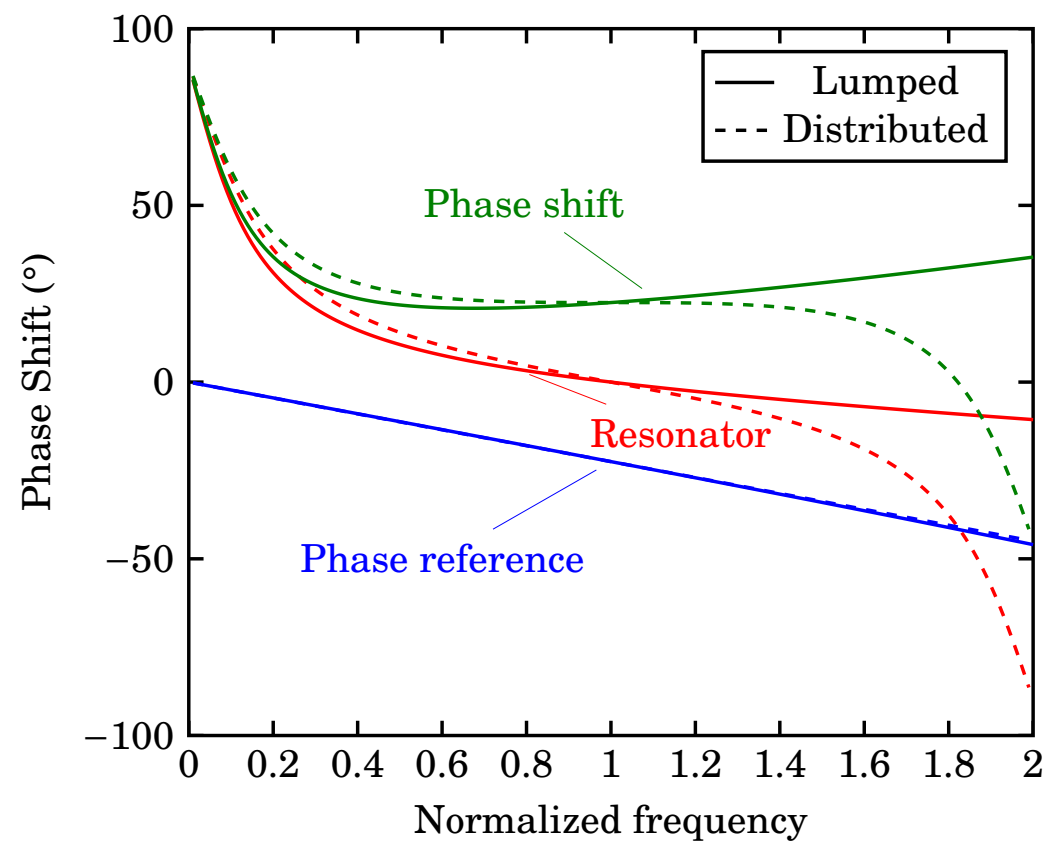

Figure 5.5: Comparison of theoretical phase shift versus frequency for the distributed and lumped circuits.

than expected. In fact, the minimum phase shift is $22.5^{\circ}$. The circuit could be tuned to be centred on this desired phase shift.

As a further example, the design technique was also verified with the design of $0^{\circ} / 45^{\circ}$ phase shift elements. Figure 5.8 shows a photograph of these circuits, while Figure 5.9 shows the measured S-parameters associated with it and Figure 5.14 shows the phase shift and phase error. Due to limited die area, it was not possible to integrate an SPDT switch to alternate between the two phases for this $45^{\circ}$ phase shifter. As shown in the figure, measurements are in good agreement with simulations. The bandwidth of the $0^{\circ} / 45^{\circ}$ differential circuit, bounded by the range where 


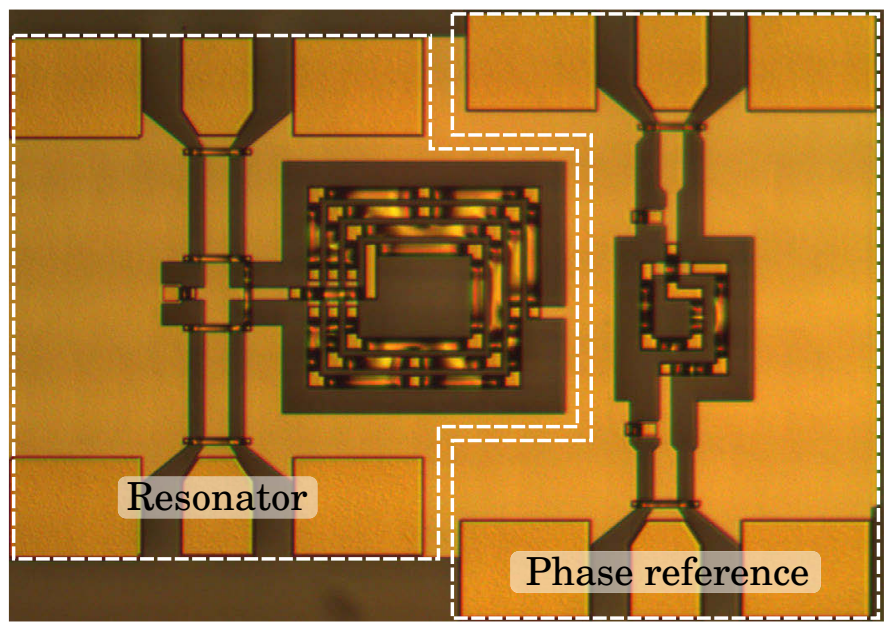

Figure 5.6: Photograph of the resonator and $22.5^{\circ}$ phase reference. Dimensions: $436 \mu \mathrm{m} \times 693 \mu \mathrm{m}$.

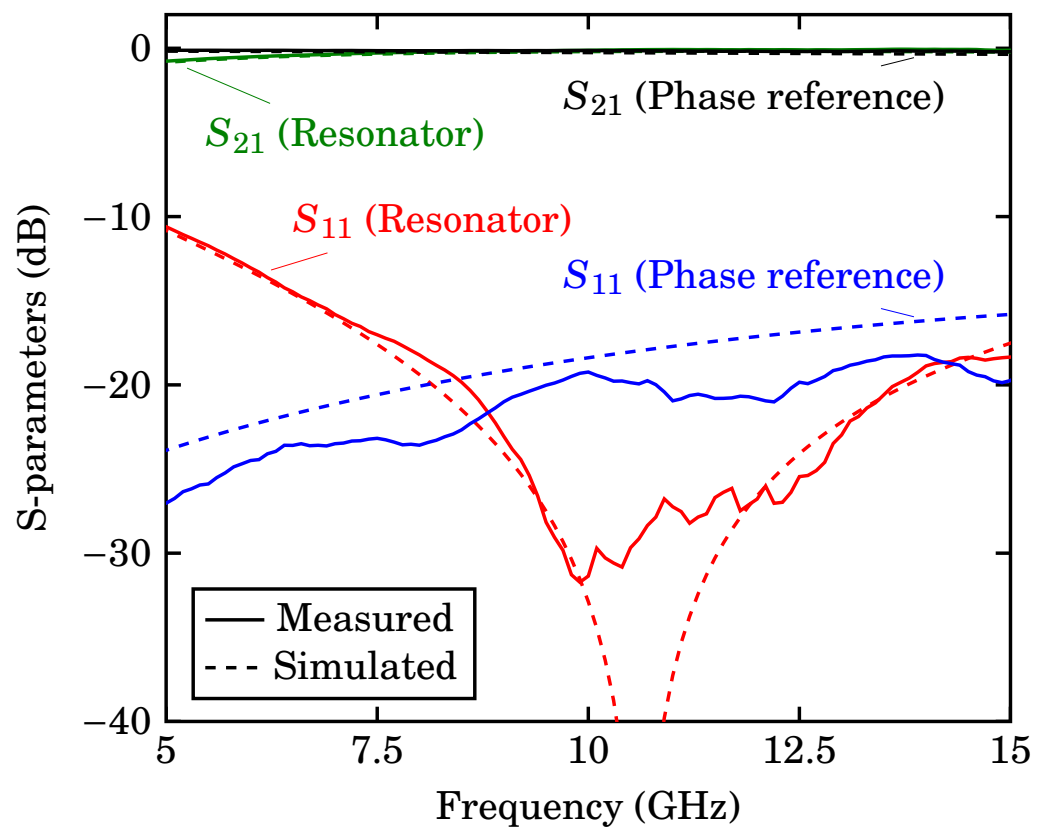

Figure 5.7: Measured and simulated S-parameters for the resonator and $22.5^{\circ}$ phase reference. 
there is less than $5 \%$ phase variation and return loss better than $10 \mathrm{~dB}$, is from $6.4-13.2 \mathrm{GHz}$ (69\% fractional bandwidth).

\subsection{GaN SPDT switch design}

Since the desired phase shift is achieved by switching between the resonator and the phase reference, switches are also required. Two wideband GaN switches have been reported in the literature, based on a travelling-wave structure [124], [145]. While they are quite wideband (lower frequency limit is DC), insertion loss is usually a monotonically increasing function of frequency, which is problematic as the loss is never actually flat. To maintain low amplitude imbalance, the switch should actually have bandwidth beyond the desired upper limit (about 1.5 times the upper limit of

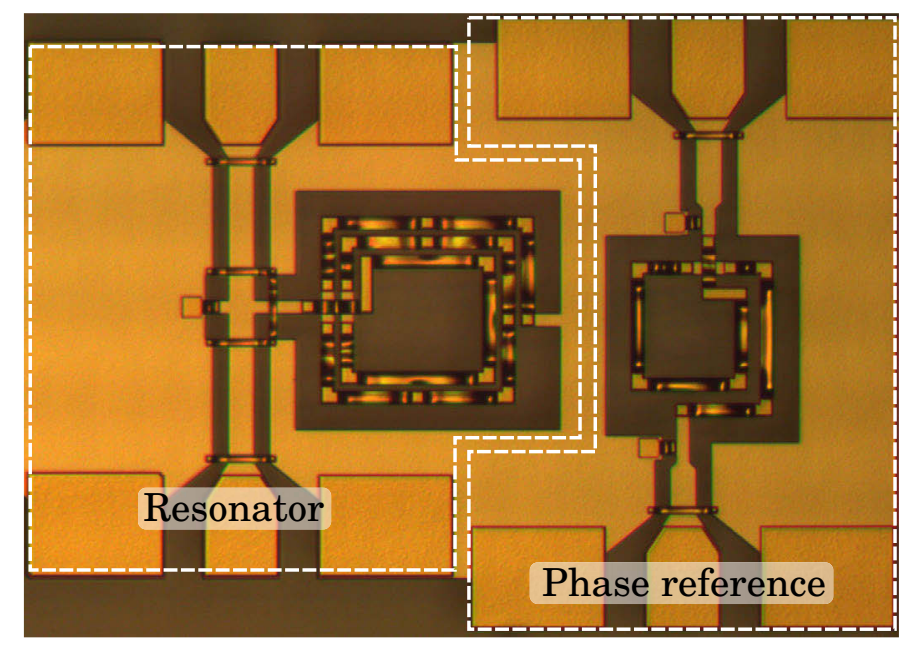

Figure 5.8: Photograph of resonator and $45^{\circ}$ phase reference. Dimensions: $434 \mu \mathrm{m} \times 691 \mu \mathrm{m}$. 


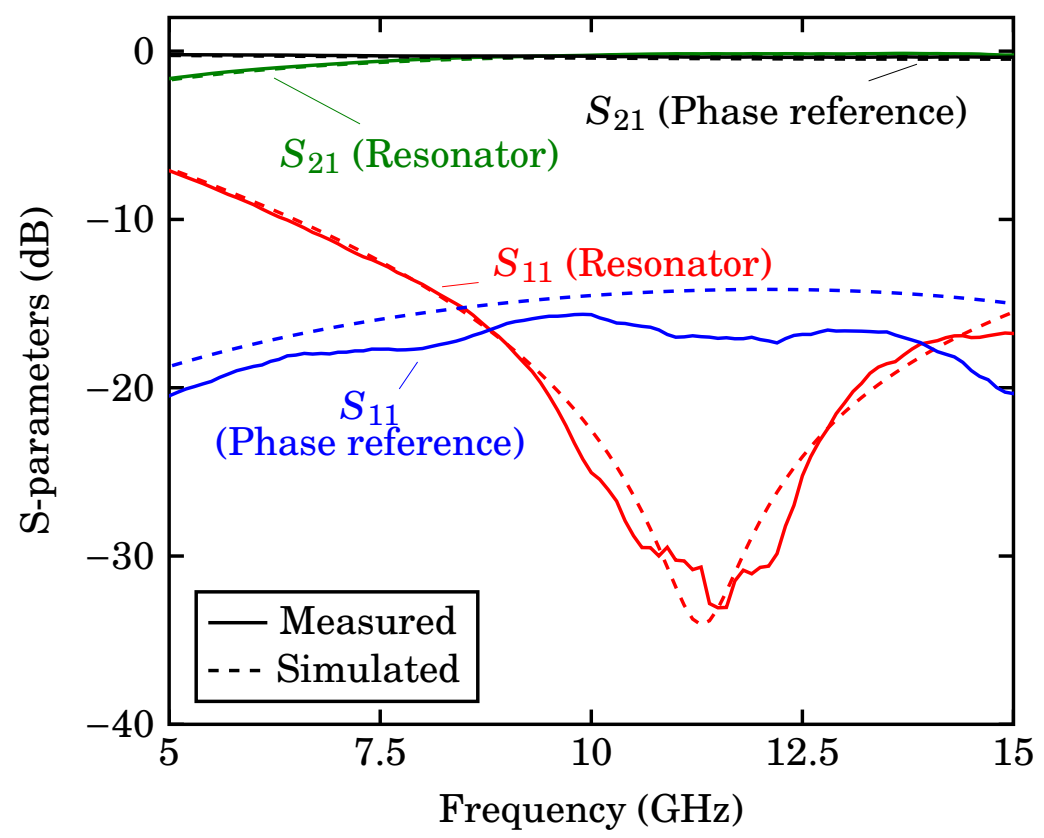

Figure 5.9: Measured and simulated S-parameters for the resonator and $45^{\circ}$ phase reference.

the phase shifter design). For example, an X-band phase shifter might need a traveling-wave switch operating up to $18 \mathrm{GHz}$, which will be rather big.

To avoid this problem, a band-limited, lumped SPDT switch is also presented here which can offer a flat loss characteristic over a given band. Like the actual phase shift, the switch was inspired by distributed design techniques. Its schematic is shown in Fig. 5.10 (also shown in the full phase shifter in Figure 5.1), and a photograph of the SPDT switch is shown in Figure 5.11.

Two shunt transistors, each $240 \mu \mathrm{m}$ wide (four fingers), are used in 


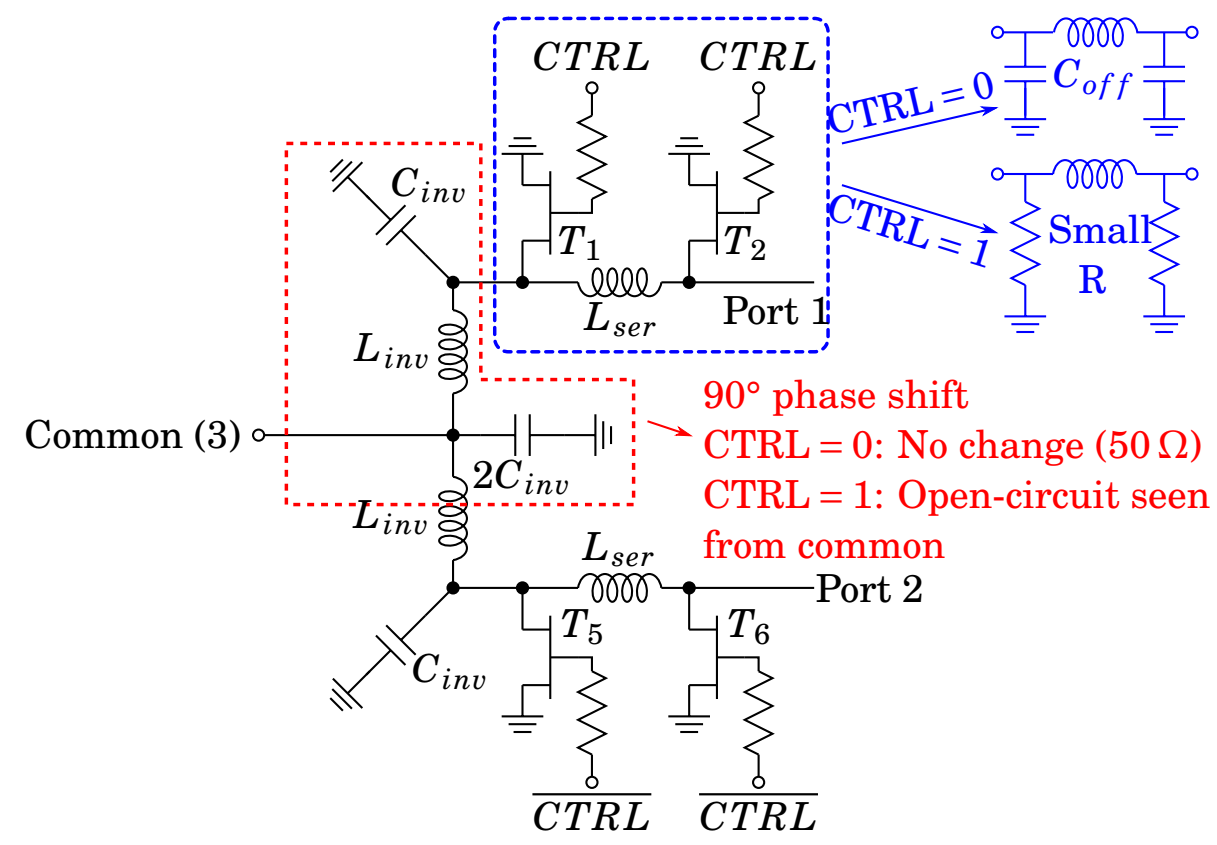

Figure 5.10: Schematic of the SPDT switch showing its operation.

each arm of the SPDT switch. Their off-capacitances (75 fF each, as calculated from the scalable model in Figure 3.1) are absorbed into an artificial transmission line using $L_{s e r}$. Real transmission lines have been used in switch designs in the past, as parasitic capacitances are absorbed into the network with limited effect on bandwidth and loss [122], [146], [147]. In this lumped-element circuit, $L_{\text {ser }}$ is sized to provide an impedance of $50 \Omega$ to the network, using the usual relationship, $Z_{0}=\sqrt{L / C}$. Therefore, $L_{\text {ser }}$ is found to be $188 \mathrm{pH}$. The off-capacitance of each device is proportional to its size, and a capacitance (and transistor) which is too large will limit the bandwidth of the switch because the pole of the network will move to a lower frequency. However, a transistor which is too small (which 


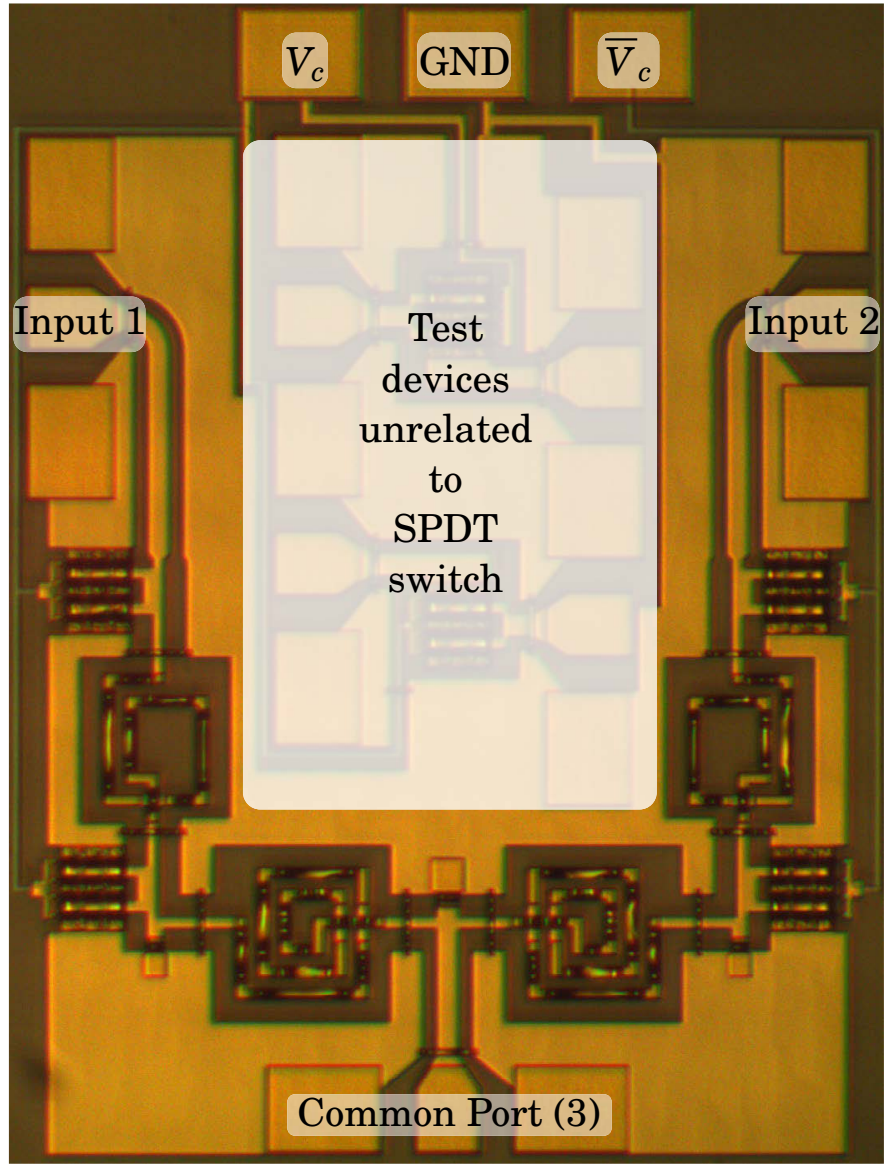

Figure 5.11: Photograph of the SPDT switch. Some test structures, unrelated to the SPDT switch, are in the centre. Dimensions (including pads and access lines): $1038 \mu \mathrm{m} \times 787 \mu \mathrm{m}$. 
might otherwise be good for achieving a wide bandwidth due to its smaller off-capacitance) will have a higher on-resistance, limiting the isolation of the switch. In this case, the transistors were sized to accommodate the bandwidth of the circuit and no smaller (as mentioned above, the devices used have 4 fingers, each $60 \mu \mathrm{m}$ wide). This ensures a good compromise between bandwidth and isolation. In this circuit as well, gate resistors of at least $5 \mathrm{k} \Omega$ were used.

Since these two shunt transistors will provide a short-circuit, a lumped impedance inverter is used to rotate the impedance $180^{\circ}$ around the Smith chart, so that an open-circuit is seen at the RF input and output. This impedance inverter is realized in the same manner as the reference line for the phase shifter, where $Z_{0}=50 \Omega$ and $\phi=\pi / 2$ in (5.11) and (5.12). The inverter is represented in Figure 5.1 by $L_{i n v}$ and $C_{i n v}$. Here $L_{i n v}$ is calculated to be $798 \mathrm{pH}$ and $C_{i n v}$ is $318 \mathrm{fF}$.

The SPDT switch's isolation, insertion loss and return loss are shown in Figure 5.12. As shown, all three parameters are in good agreement with simulations, with insertion loss better than $2.9 \mathrm{~dB}$ ( $0.5 \mathrm{~dB}$ below its peak), return loss better than $10 \mathrm{~dB}$ and isolation better than $22 \mathrm{~dB}$ over a frequency range from $6.6-13.6 \mathrm{GHz}$.

The SPDT's isolation, while better than $22 \mathrm{~dB}$, is limited by the transistors' off-capacitances. It was noted in Section 3.2 that the switching figure of merit is not particularly good in this GaN process (see Table 3.1 on 
page 43), and a compromise between insertion loss and isolation must be made. If $22 \mathrm{~dB}$ is insufficient, insertion loss could be worsened to improve it, or a better-performing GaN process could be used.

In this case, the SPDT switch (specifically its return loss) will be the limiting factor in the bandwidth of the phase shifter, but it does allow for $\mathrm{X}$-band to be comfortably covered.

\subsection{Phase shifter results}

A $0^{\circ} / 22.5^{\circ}$ phase shifter incorporating all elements, including the SPDT switch, was fabricated using the same $0.5 \mu \mathrm{m} \mathrm{AlGaN/GaN} \mathrm{HEMT} \mathrm{process}$ as described earlier. The phase shift elements (phase reference and resonator) and the SPDT switch were also fabricated separately for verification purposes, which were presented earlier. This completely integrated phase shifter is pictured in Figure 5.2.

With all components combined, the complete phase shift circuit was measured. The insertion loss, return loss and the phase shift achieved by the complete circuit are shown in Figure 5.13. Again, there is very good agreement between measurement and simulation. The $5 \%$-variation phase shift bandwidth is $7.5-14.5 \mathrm{GHz}$, although it is not perfectly aligned with the return loss (better than $10 \mathrm{~dB}$ from $5.6-13 \mathrm{GHz}$ ) and insertion loss. The slight error in phase shift $\left(3^{\circ}\right)$ could be corrected in a future iteration of the 


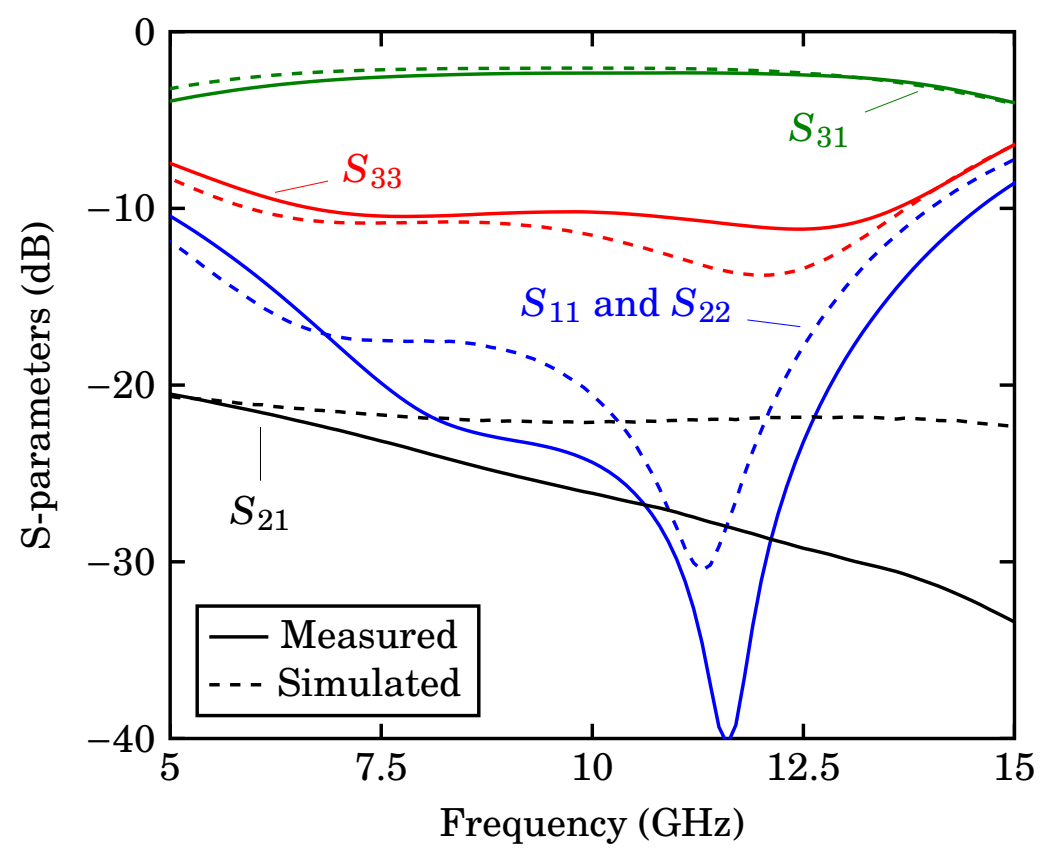

Figure 5.12: Measured and simulated isolation, insertion loss and return loss for the proposed SPDT switch.

design to achieve exactly $22.5^{\circ}$ of phase shift.

Over X-band, the phase shifter offers return loss better than $11 \mathrm{~dB}$, insertion loss better than $5 \mathrm{~dB}$, and phase variation of $1^{\circ}$ across the band. Because the circuit is nearly symmetrical, these parameters have negligible variation when switched between the reference state and the phase-shift state.

The power handling analysis discussed earlier was also performed for this circuit. The limiting transistor is $T_{1}$ when $C T R L=0$ (or $T_{5}$ when $C T R L=1$ ). This analysis, with data shown in Figure 5.15 indicates the 


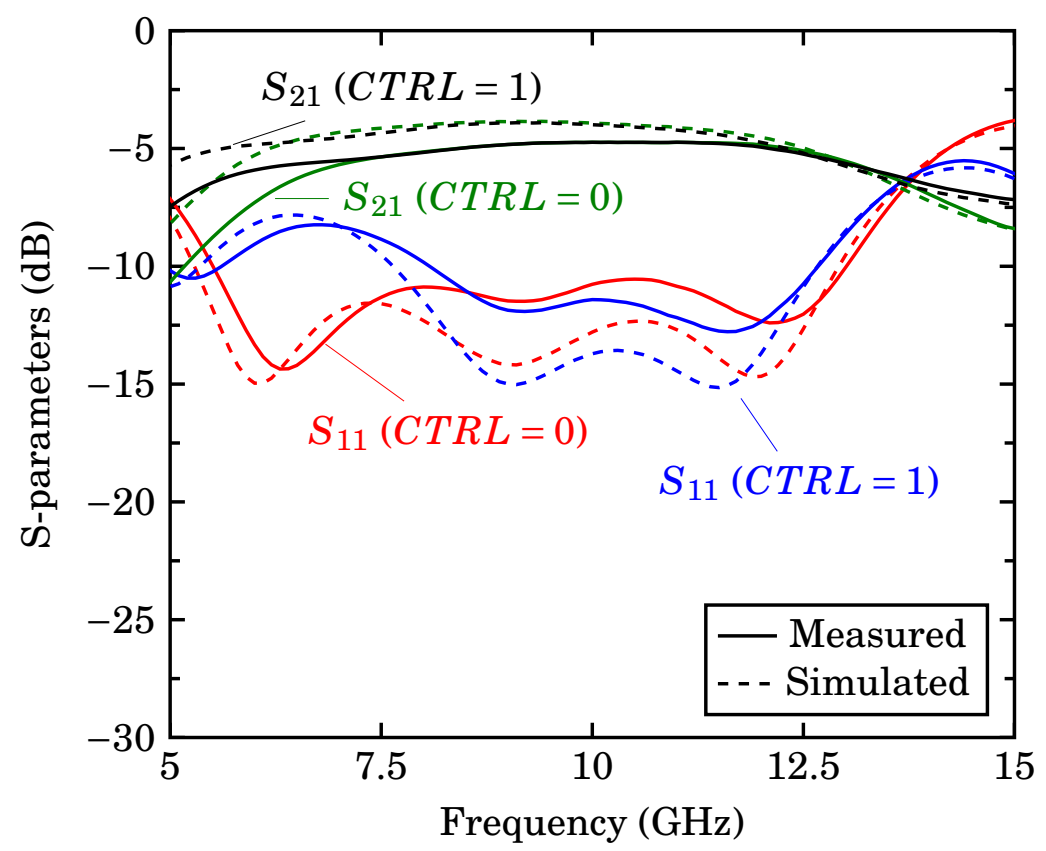

Figure 5.13: Insertion loss, return loss and phase shift for the complete $0 \% 22.5^{\circ}$ phase shifter shown in Figure 5.2.

phase shifter should handle about $30 \mathrm{dBm}$, with the maximum current of the transistor not being a factor. The measured results, shown in Figure 5.16 confirm this prediction, with an input-referred $P_{1 \mathrm{~dB}}$ of $30.1 \mathrm{dBm}$ and $\mathrm{IIP}_{3}$ of $46.3 \mathrm{dBm}$. The separate SPDT switch shows similar performance, with $P_{1 \mathrm{~dB}}$ of approximately $31 \mathrm{dBm}$ and IIP $_{3}$ of $47 \mathrm{dBm}$ when measured, which is expected, as the power handling of the phase shifter is dominated by the power handling of the switch at the input of the phase shifter. 


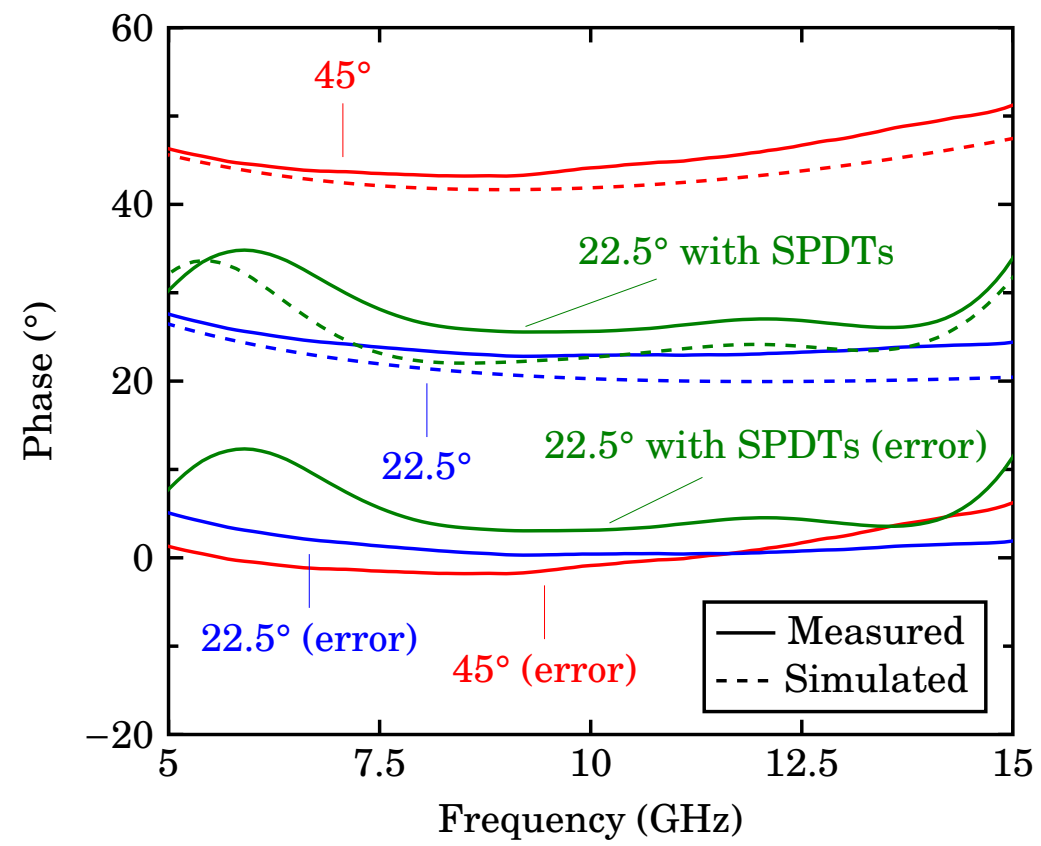

Figure 5.14: Phase shift and phase error for the separate $22.5^{\circ}$ and $45^{\circ}$ phase shifters, as well as for the complete $22.5^{\circ}$ phase shifter with SPDT.

\subsection{Summary}

In this chapter, the design of a novel lumped-element, broadband phase shifter was presented. The design is based on a double- $\lambda / 8$ resonator phase shift circuit previously presented [76]. This earlier work did not present a theoretical analysis of the structure. As part of the design process, this was done here. The earlier design also suffered from two major problems which limited its practical application: its size at lower microwave frequencies, and the requirement of extreme values of characteristic impedances for the stub resonators. As a result, only $90^{\circ}$ phase shifters can be found in the scientific literature and these were implemented on printed circuit board 


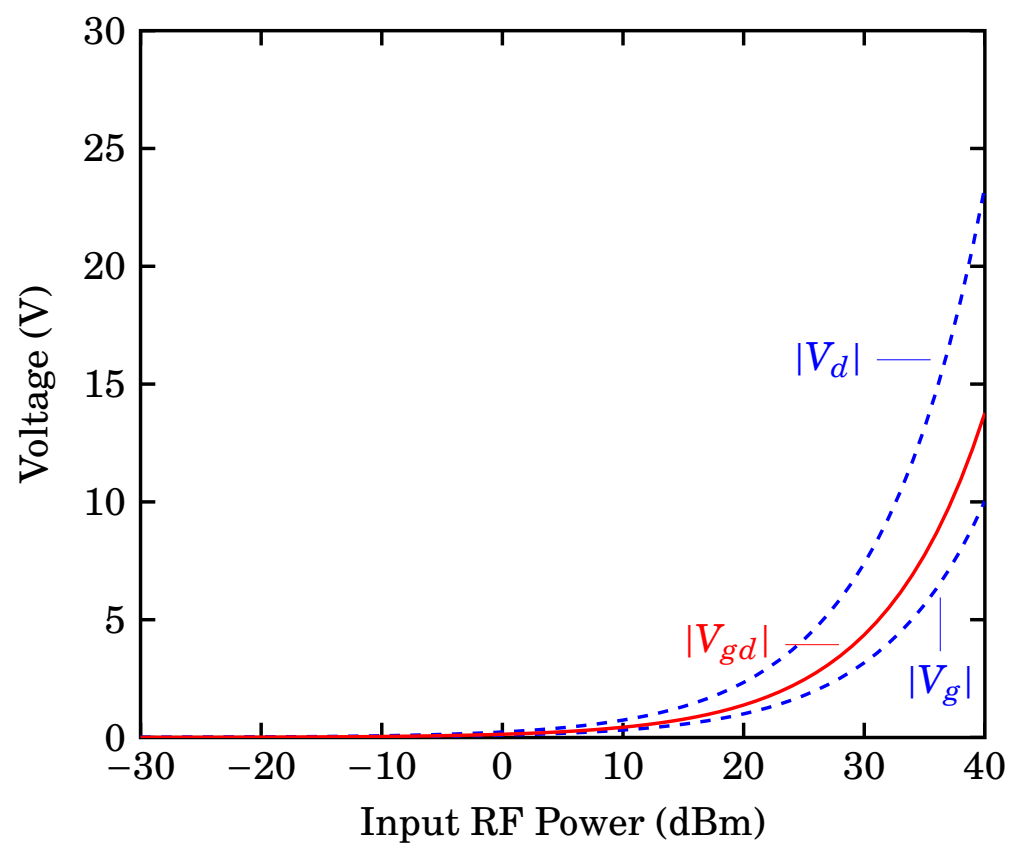

Figure 5.15: Simulated voltages on the terminals of the worst-case transistor, $T_{1}$, with $C T R L=0$. The source of this transistor is grounded, so $V_{s}$ is not shown.

(and without switching elements) due to their large size. In this thesis, a method has been proposed and implemented to overcome these difficulties.

In this work, a lumped-element phase shifter was created using an LC resonator which maintains, or even improves, the wideband performance of the stub-based circuit. Meanwhile, it overcomes the limitations of the original circuit, and can be implemented for phase shift values which would be impractical for the transmission line network.

The circuit was fabricated in the same $0.5 \mu \mathrm{m}$ GaN HEMT process. Measurements are in good agreement with simulated performance. Individual 


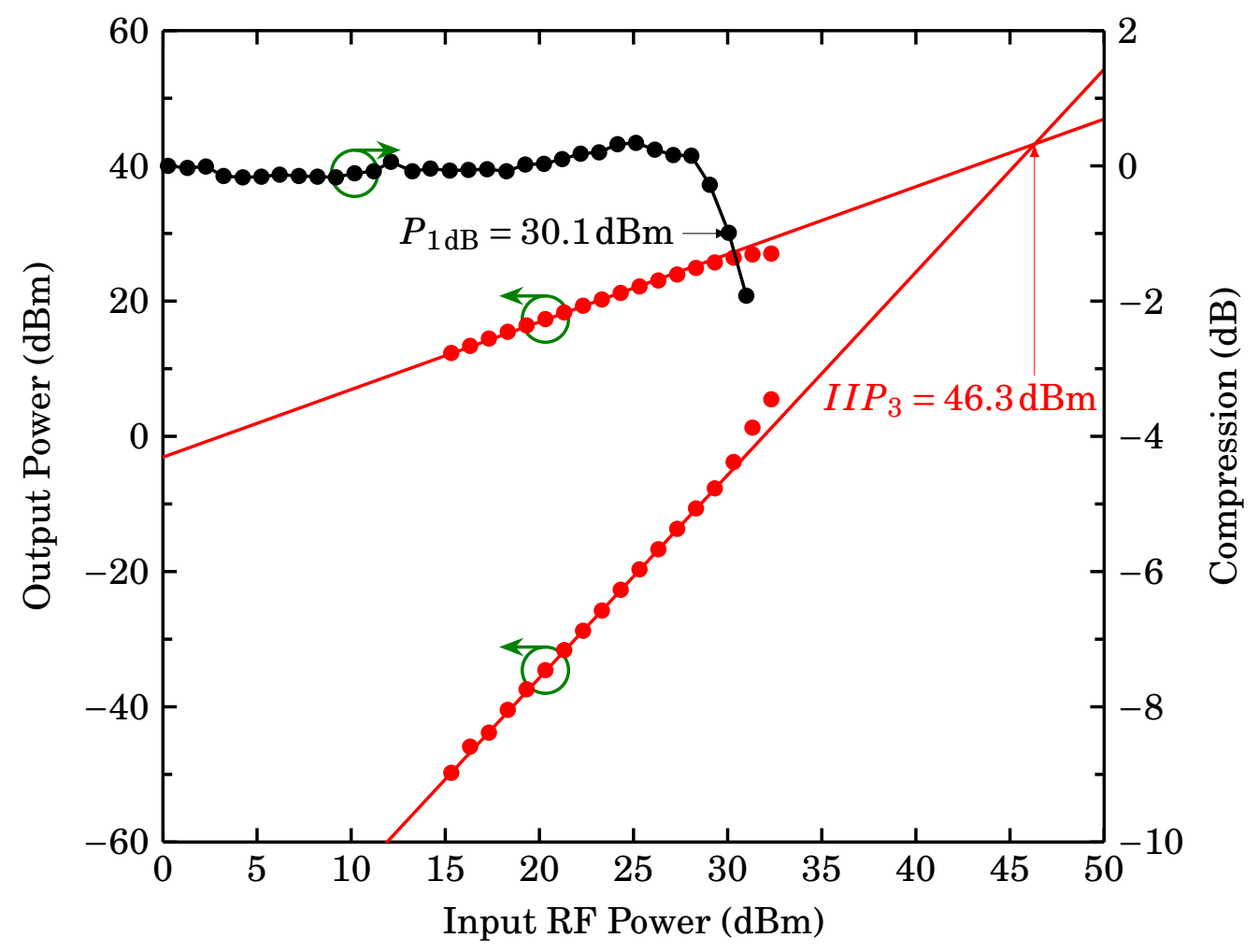

Figure 5.16: Measured power handling (IIP ${ }_{3}$ and compression) of the complete $0^{\circ} / 22.5^{\circ}$ phase shifter. The power handling is the same for both states.

phase shift elements (no switching component) were fabricated $\left(22.5^{\circ}\right.$ and $45^{\circ}$ phase shifts) to verify functionality and to compare with other works. A $22.5^{\circ}$ phase shifter integrating a new type of SPDT switch was also realized, again with good performance and agreement with predictions. Further phase shifts could be realized, but due to constraints on GaN chip area available, this was not possible. 


\section{Chapter 6}

\section{Switched-filter GaN}

\section{Phase Shifters}

This chapter discusses the design of two switched-filter GaN phase shifters. These types of phase shifters are very compact, as the switching element is an integral part of the design.

However, because the switch is integrated in the circuit, having a highly accurate model of the active device is essential. The model must have an accurate phase and magnitude response, characteristics which the model described in Chapter 3 possesses. Using this model, circuits at two frequencies are designed: one operating at X-band (and a little above), and another at K/Ka-band. 


\subsection{X-band switched-filter phase shifter}

Switched-filter phase shifters have found use when compact circuits are desired [68], [69]. This topology requires less chip area than other phase shifter circuit topologies, such as switched high-pass/low-pass, switchedline, and distributed (i.e., Schiffman) phase shifters, although bandwidth is typically reduced. An advantage is that the phase performance of the circuit is independent of the loss and phase variations introduced by lossy transmission lines and routing schemes.

The switched-filter phase shifter switches between a filter (typically lowpass, although a high-pass filter could also be used), offering the desired phase shift, and a bypass state (i.e., an all-pass network), with ideally zero insertion phase. The circuit schematic, using GaN HEMTs as switches, is shown in Figure 6.1.

It should be noted that in Figure 6.1, a low-pass $\Pi$ topology is adopted. This configuration is advantageous since only one inductor is needed. Since inductors typically have higher loss and occupy much more substrate area than capacitors, this topology should be more compact and less lossy than the low-pass $\mathrm{T}$ network, with two inductors. The low-pass $\Pi$ network also requires smaller (in both value and circuit area) inductors than the high-pass T network (also with one inductor).

This circuit may be analyzed using ABCD parameters, as has been 

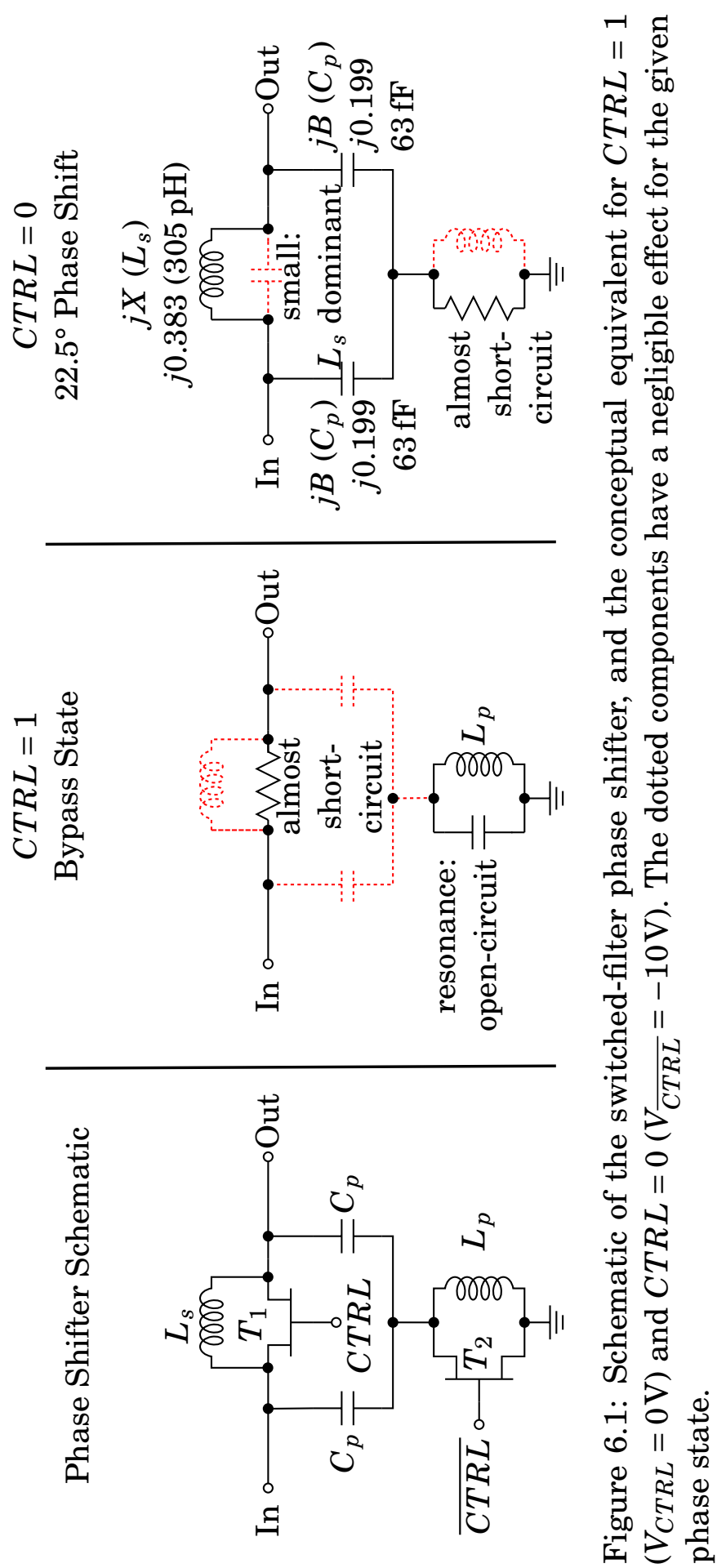
done previously in this thesis. The circuit may be represented as

$$
\begin{aligned}
\mathbf{A B C D} & =\left(\begin{array}{cc}
1 & 0 \\
j B & 1
\end{array}\right) \cdot\left(\begin{array}{cc}
1 & j X \\
0 & 1
\end{array}\right) \cdot\left(\begin{array}{cc}
1 & 0 \\
j B & 1
\end{array}\right) \\
& =\left(\begin{array}{cc}
1-B X & j X \\
j B(2-B X) & 1-B X
\end{array}\right) .
\end{aligned}
$$

The transmission coefficient $S_{21}$ will be

$$
\begin{aligned}
S_{21} & =\frac{2}{A+B+C+D} \\
& =\frac{2}{2-2 B X+j[X+B(2-B X)]} .
\end{aligned}
$$

The insertion phase will then be

$$
\phi=\tan ^{-1}\left[\frac{X+B(2-B X)}{2 B X-2}\right]
$$

If the circuit is matched, then it is possible to find a relationship between $B$ and $X$ :

$$
\begin{aligned}
\left|S_{11}\right|=0 & =\sqrt{1-\left|S_{21}\right|^{2}} \\
1 & =\frac{4}{B^{4} X^{2}+2 B^{2} X^{2}+X^{2}-4 B^{3} X-4 B X+4 B^{2}+4} \\
0 & =B^{4} X^{2}+2 B^{2} X^{2}+X^{2}-4 B^{3} X-4 B X+4 B^{2} \\
0 & =\left(B^{2} X+X-2 B\right)^{2} \\
X & =\frac{2 B}{B^{2}+1}
\end{aligned}
$$


This relationship can be substituted into (6.5), to obtain

$$
\phi=\tan ^{-1}\left(\frac{2 B}{B^{2}-1}\right)
$$

Finally, this equation can be solved for $B$, and then substituted into (6.10) to find $X$. Then the actual values of capacitance and inductance can be found:

$$
B=\tan \frac{\phi}{2} \Rightarrow C=\frac{\tan \frac{\phi}{2}}{\omega_{0} Z_{0}}
$$

and

$$
X=\sin \phi \quad \Rightarrow \quad L=\frac{Z_{0} \sin \phi}{\omega_{0}}
$$

To realize the phase shifter, the values of $B$ and $X$ for a $22.5^{\circ}$ phase shifter were found using (6.12) and (6.13) and they are shown in Figure 6.1. The corresponding values of $C$ and $L$ were then calculated for a $50 \Omega$ system. The circuit was designed for the flattest phase response over a frequency range of 8-12 GHz, a bandwidth of $40 \%$. The circuit was also designed to achieve a return loss better than $10 \mathrm{~dB}$ across this frequency range.

Transistor $T_{1}$ has a total gate width of $80 \mu \mathrm{m}$ (two fingers), while $T_{2}$ has a total gate width of $400 \mu \mathrm{m}$ (four fingers). The gate bias resistors were selected to be at least $5 \mathrm{k} \Omega$, although circuit performance is not sensitive to the precise value. A smaller resistor would allow for a faster switching speed, at the expense of RF performance. 
The phase shifter circuit was fabricated in the GaN MMIC process developed at National Research Council Canada, which was described earlier. Figure 6.2 shows a photograph of the manufactured circuit. The circuit was simulated in Agilent's Advanced Design System (ADS) and Momentum was used to model the passive circuitry. The circuit was designed to provide $0^{\circ} / 22.5^{\circ}$ of phase shift over a frequency range of $8-12 \mathrm{GHz}$.

Figure 6.3 shows the insertion loss of the phase shifter in both phase states (bypass, i.e., no phase shift, and in the phase shift state), with good agreement between simulations and measurements. Switching is accomplished by biasing the gates of the two transistors. $C T R L=0$ is

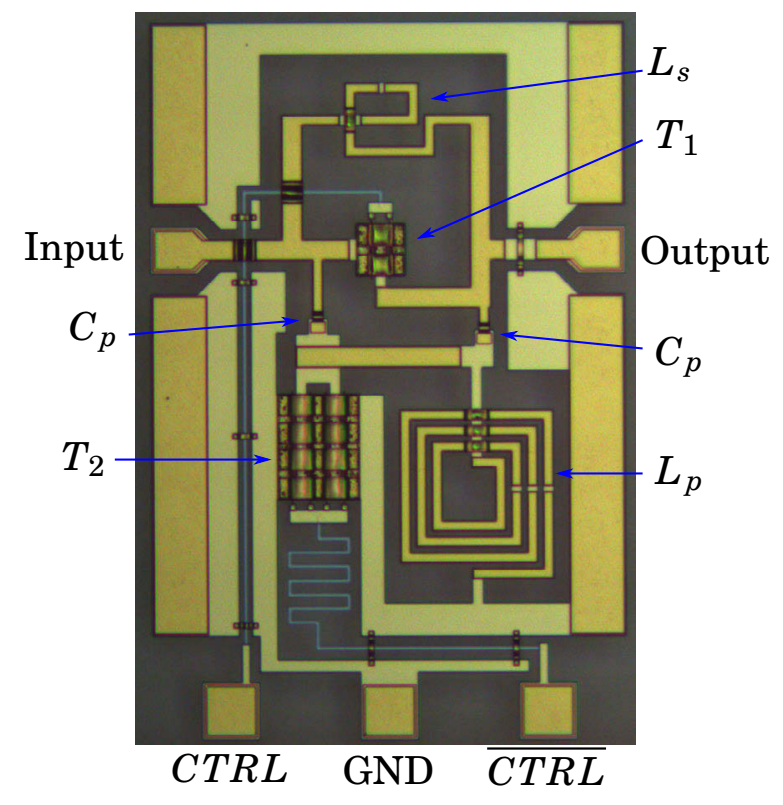

Figure 6.2: Microphotograph of the $0^{\circ} / 22.5^{\circ} \mathrm{GaN}$ switched-filter phase shifter. Circuit dimensions are $448 \mu \mathrm{m} \times 678 \mu \mathrm{m}$ (Area: $0.304 \mathrm{~mm}^{2}$ ). 
achieved by applying a voltage of $-10 \mathrm{~V}$. CTRL $=1$ corresponds to an applied gate voltage of $0 \mathrm{~V}$. Power handling could likely be improved by applying a voltage lower than $-10 \mathrm{~V}$, but there were concerns about transistor breakdown, which the foundry reported was a problem at lower than expected voltages. The foundry has reportedly identified the source of this problem and should be corrected in the future.

As Figure 6.3 shows, the measured insertion loss is better than $2 \mathrm{~dB}$ across $\mathrm{X}$-band, and is better than $3 \mathrm{~dB}$ across a wider range of $8-16 \mathrm{GHz}$. The amplitude imbalance between the two states is worst at $8 \mathrm{GHz}$, and is therefore better than $1.03 \mathrm{~dB}$ over the extended band from 8-16 GHz.

The return loss for both phase shift states can seen in Figure 6.4. Again, the simulation results and measurements are in good agreement. The measured return loss is better than $11.15 \mathrm{~dB}$ across $\mathrm{X}$-band, and is better than $10.2 \mathrm{~dB}$ from 8-16 GHz. Therefore, an effective compromise between bandwidth, return loss and insertion loss can be found for this traditionally narrowband (but compact) circuit configuration.

Figure 6.5 presents the phase shift obtained from the circuit. Although the measured phase shift is slightly less than simulations predict, the measured phase shift is flat over a large bandwidth. The measured phase response is also flatter than than simulations predicted. Since the device model shown in Figure 3.1 was scaled from the original gate width of $160 \mu \mathrm{m}$ to the actual transistor sizes used in the design (400 $\mu \mathrm{m}$ and $80 \mu \mathrm{m})$, 


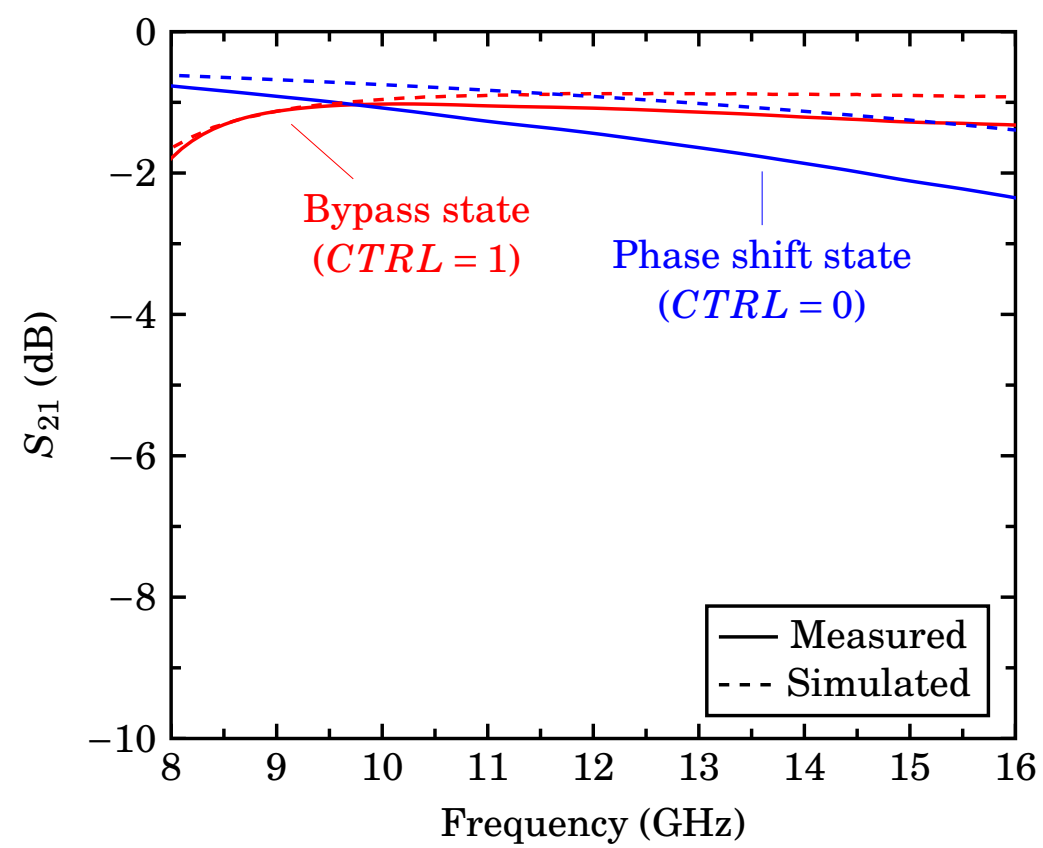

Figure 6.3: Measured and simulated insertion loss of the $0^{\circ} / 22.5^{\circ}$ phase shifter.

it is possible the model used in simulation and the final manufactured device are not in perfect agreement. In particular, the parasitic inductances generally do not scale linearly with geometry [120], while in this model, they do. The coupling between gate and drain is also geometry-dependent, while in this model, it is fixed.

The phase response is also sensitive to the value of $C_{p}$. A variation of about $20 \%$ in this capacitance leads to a $5^{\circ}$ decrease in phase shift in simulation. Since these capacitors are quite small $(14 \mu \mathrm{m} \times 10 \mu \mathrm{m})$, a variation of $2 \mu \mathrm{m}$ in each dimension or a variation in the dielectric thickness could be responsible for the observed phase error. Some small error between 


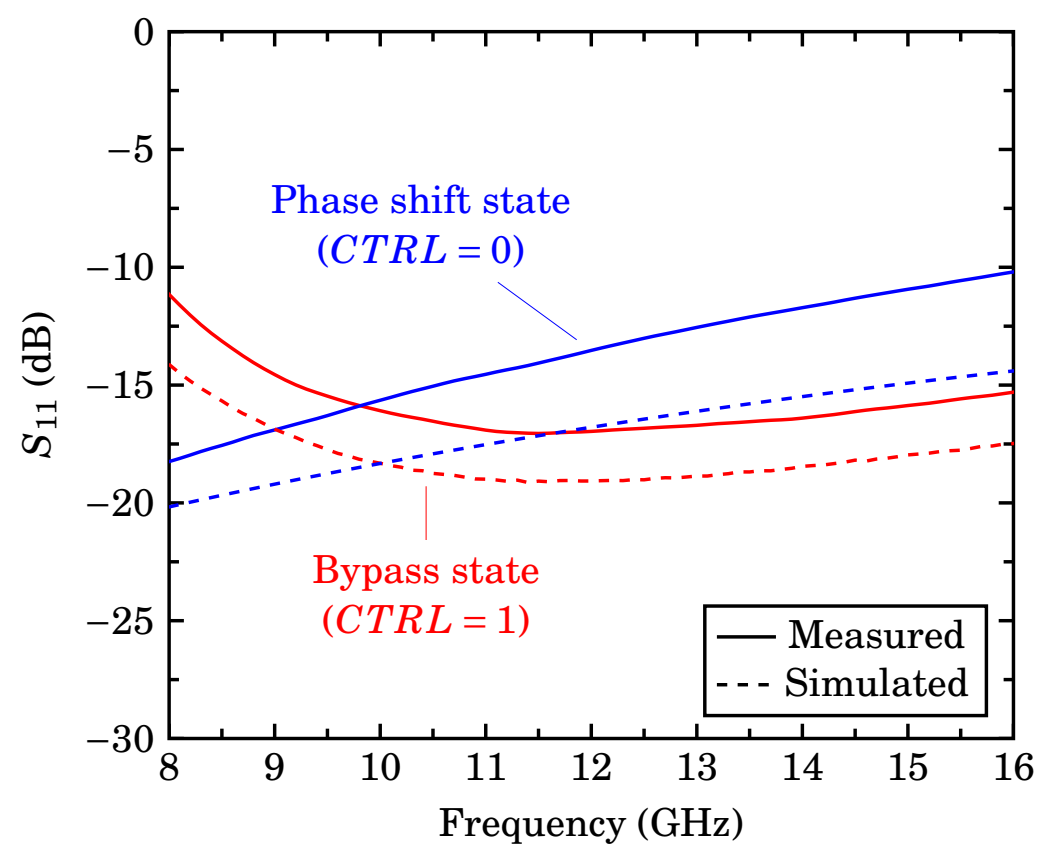

Figure 6.4: Measured and simulated return loss for the phase shifter circuit.

the electromagnetic simulation and the realized passives is also expected (particularly inductors). This is likely responsible for the flatter and offset phase response, especially coupled with manufacturing tolerances which are expected with a new fabrication process under active development. The difference between the measured phase and design target (approximately $5^{\circ}$ ) could be corrected in a future iteration.

For this circuit, the $5 \%$ phase variation bandwidth is found to be $46 \%$ (centred around $17^{\circ}$ ), wide enough to cover X-band. A $10 \%$ phase variation definition yields $64 \%$ bandwidth, covering $8-16 \mathrm{GHz}$. 


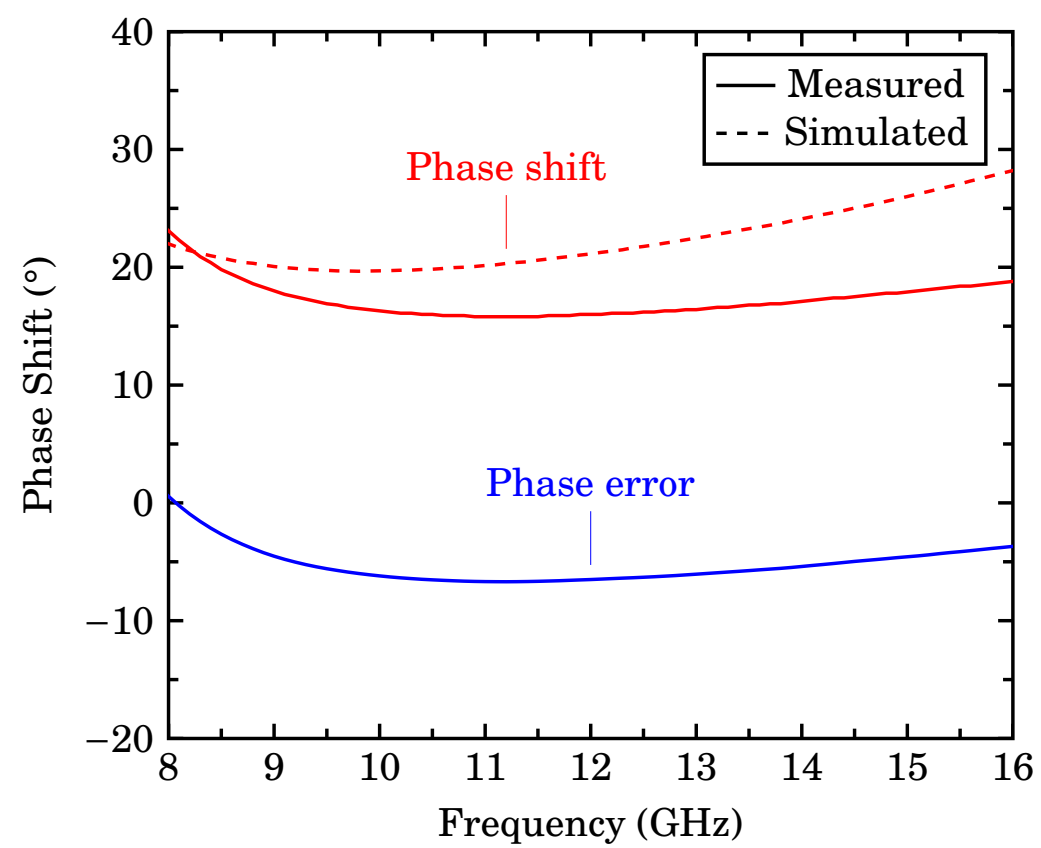

Figure 6.5: Measured and simulated phase shift for the $0^{\circ} / 22.5^{\circ}$ phase shifter.

Finally, the linearity and power handling capability of the circuit were studied. To get an idea of the type of input the circuit can handle, the method described in Section 3.2 was used to calculate voltage swing across the terminals of each transistor, in both the phase-shift and filter bypass states. The voltages as a function of input power is shown in Figure 6.6 for the transistor exhibiting the largest swing, which is $T_{2}$ in the phase-shift state (i.e., when $T_{2}$ is off). As shown, the input power level can rise to about $32 \mathrm{dBm}$ before the transistor starts to turn on. The current at this power is below the maximum level the transistor can support.

The measurements results of this study are shown in Figure 6.7. Due 


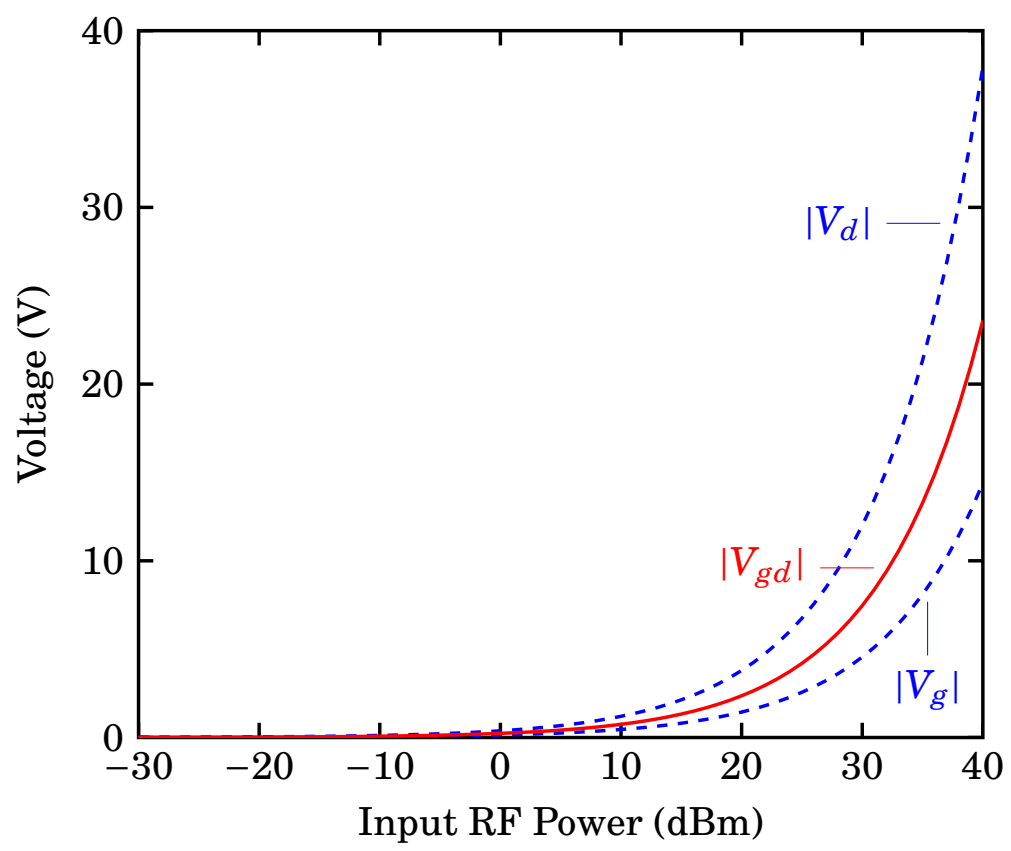

Figure 6.6: Simulated voltages on the terminals of the worst-case transistor, $T_{2}$, in the phase-shift state. The source of this transistor is grounded, so $V_{s}$ is not shown.

to the limitations of the laboratory equipment available, these tests were performed at $8 \mathrm{GHz}$ with a $10 \mathrm{~W}$ power amplifier. For the purposes of determining the third-order intercept point, a second signal at an offset of $1 \mathrm{MHz}$ was used.

The power handling capability indicated is better than the linear simulation showed. This could be due in part to the nonlinearities of the transistor providing an advantage. Of course, variations between the model and the fabricated devices could also play a role, since the foundry was actively developing their process at the time. Due to space constraints, 


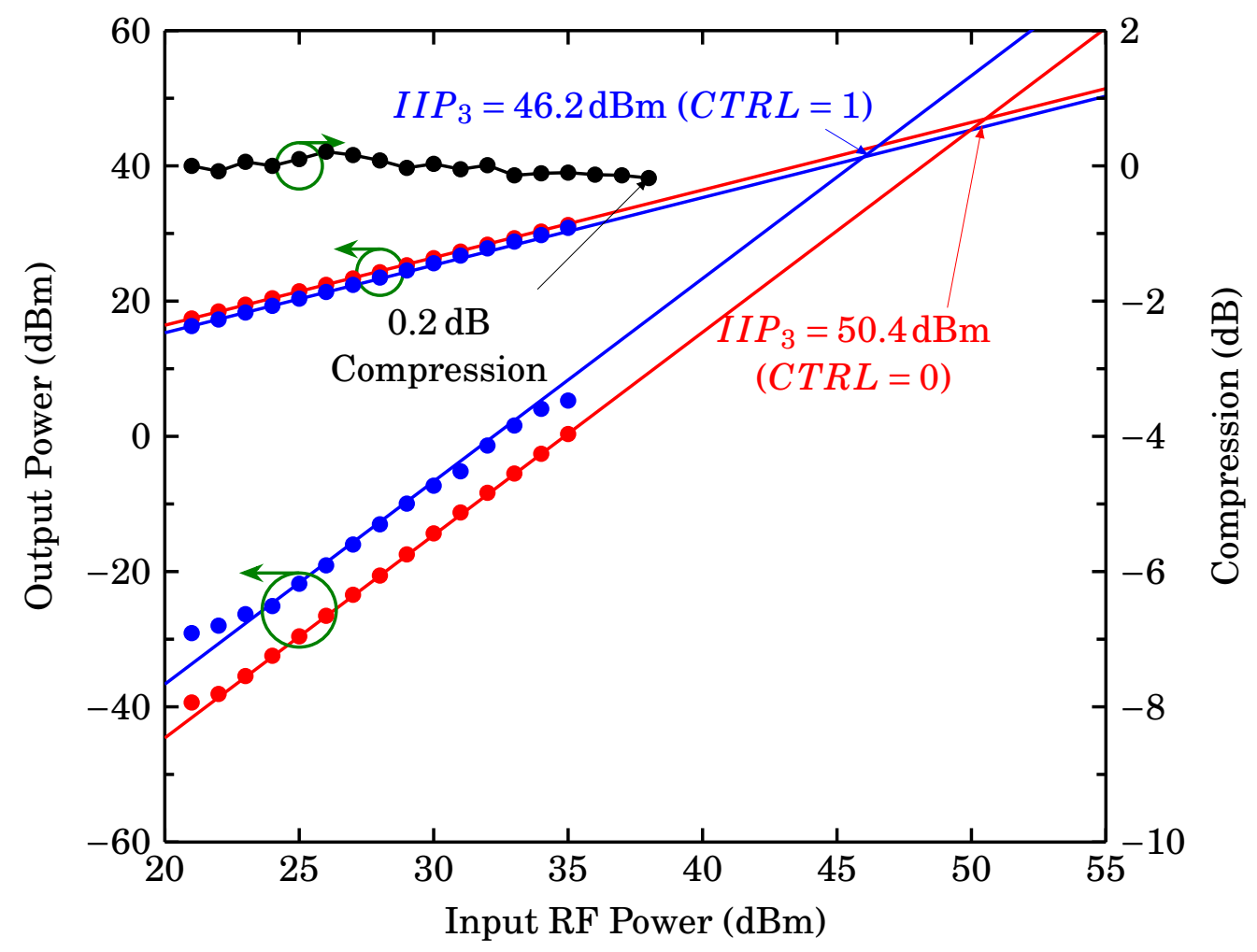

Figure 6.7: Linearity measurement (gain compression and third-order intermodulation) results for the phase shifting circuit.

it was not possible to include extra transistors (for modeling purposes) with this design.

The third-order intercept test was performed for both phase states $\left(0^{\circ}\right.$ and $22.5^{\circ}$ ), as shown. With the $0^{\circ}$ (bypass) state, the measured $\operatorname{IIP}_{3}$ was 46.2 $\mathrm{dBm}$ (determined by extrapolating the $1 \mathrm{~dB} / \mathrm{dB}$ and $3 \mathrm{~dB} / \mathrm{dB}$ curves found from measurements). The $22.5^{\circ}$ phase shift state had a higher $\operatorname{IIP}_{3}$ of $50.4 \mathrm{dBm}$. 
An attempt to determine the $1 \mathrm{~dB}$ compression point was made. With the equipment available in the laboratory, it was not possible to observe $1 \mathrm{~dB}$ compression, as shown with $C T R L=1$ in Figure 6.7 (similar compression behaviour was observed for $C T R L=0$ ). At $38 \mathrm{dBm}$ of input $\mathrm{RF}$ power, only $0.18 \mathrm{~dB}$ of gain compression was observed, relative to a reference input power of $24 \mathrm{dBm}$. It is likely that the $1 \mathrm{~dB}$ compression point is a little over $40 \mathrm{dBm}$.

\subsection{K-band phase shifter using suspended inductors}

To demonstrate that the higher-performance inductors presented earlier can be practically used in a circuit at high frequencies, a $0 \% 45^{\circ}$ switchedfilter phase shifter was designed at K-band. A schematic of this type of phase shifter, which switches between a filter (phase shift) state and a bypass (reference state) is shown in the previous section (see Figure 6.1), while the fabricated circuit is shown in Figure 6.8.

Since the GaN transistors in use have a peak transit frequency of $27 \mathrm{GHz}$, a design at $25 \mathrm{GHz}$ pushes the limits of the technology, as parasitics of the device have a significant impact. Extracting the best performance out of passive components, such as the inductors, is therefore quite important. In this design, symmetrical inductors were used, but the same technique of 


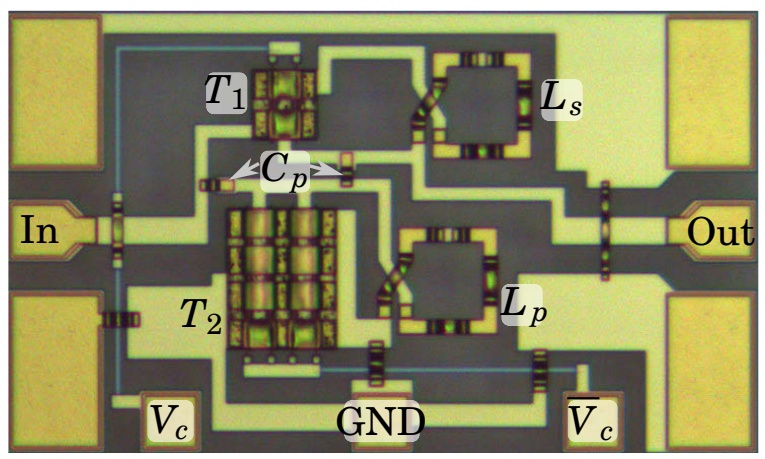

Figure 6.8: Microphotograph of the $0 \% / 45^{\circ} \mathrm{GaN}$ phase shift circuit. Chip dimensions: $532 \mu \mathrm{m} \times 311 \mu \mathrm{m}$ (area: $0.165 \mathrm{~mm}^{2}$ ).

suspending them in the air was applied.

To design the phase shifter, $B$ and $X$ (with corresponding $C$ and $L$ for a $50 \Omega$ design) for a $45^{\circ}$ phase shifter were found using (6.12) and (6.13). The circuit was designed for the flat phase response around $25 \mathrm{GHz}$. The circuit was also designed to achieve return loss better than $10 \mathrm{~dB}$ across this frequency range. Fig. 6.9 shows the simulated S-parameters of the phase shifter.

Figure 6.10 shows the measured insertion loss, return loss and phase shift of the phase shift circuit in both phase states (bypass, i.e., no phase shift, and in the phase shift state). Agreement between measured and simulated results is resonable, although there is a shift upwards in frequency of approximately $10 \%$. While a return loss of $10 \mathrm{~dB}$ was targeted, that level is not quite attained at the higher frequencies but remains below $7 \mathrm{~dB}$ from 20-40 GHz. The insertion loss in the bypass state is higher than expected 


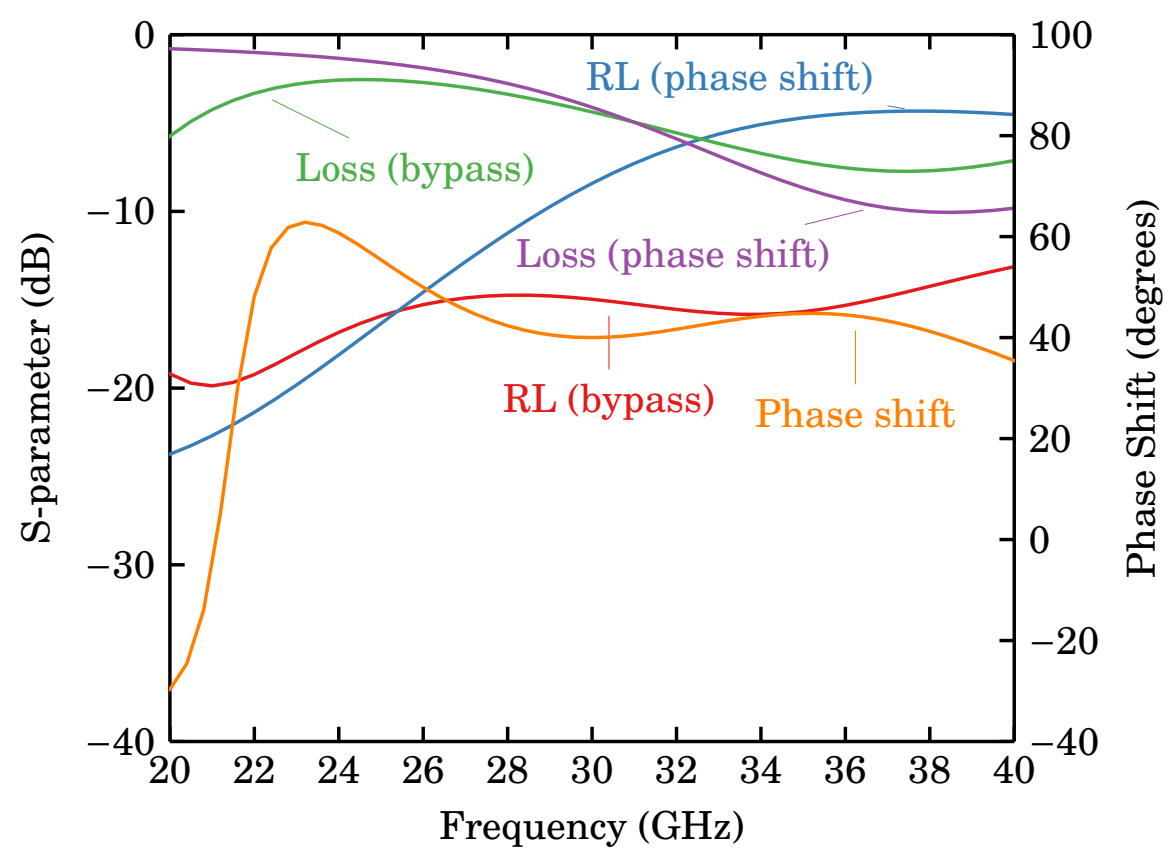

Figure 6.9: Simulated S-parameters of the K-band $0 \% 45^{\circ}$ phase shifter.

at low frequencies, but the circuit offers better than $5 \mathrm{~dB}$ over $23-32 \mathrm{GHz}$ in both states. Switching states is again accomplished by biasing the gates of the two transistors. As in the previous designs, $C T R L=0$ (and $\overline{C T R L}=1$ ) is achieved by applying a voltage of $-10 \mathrm{~V} . C T R L=1$ (and $\overline{C T R L}=0$ ) corresponds to an applied gate voltage of $0 \mathrm{~V}$. Power handling could likely be improved by applying a voltage higher than $-10 \mathrm{~V}$, but as with the other circuits, there were concerns about transistor breakdown.

Although the measured phase shift is about $4^{\circ}$ less than the desired $45^{\circ}$, the measured phase shift is flat over a large bandwidth $(24.6-38.3 \mathrm{GHz}$, or $43.6 \%$ ), assuming $5 \%$ phase variation. The error in phase is likely due to 


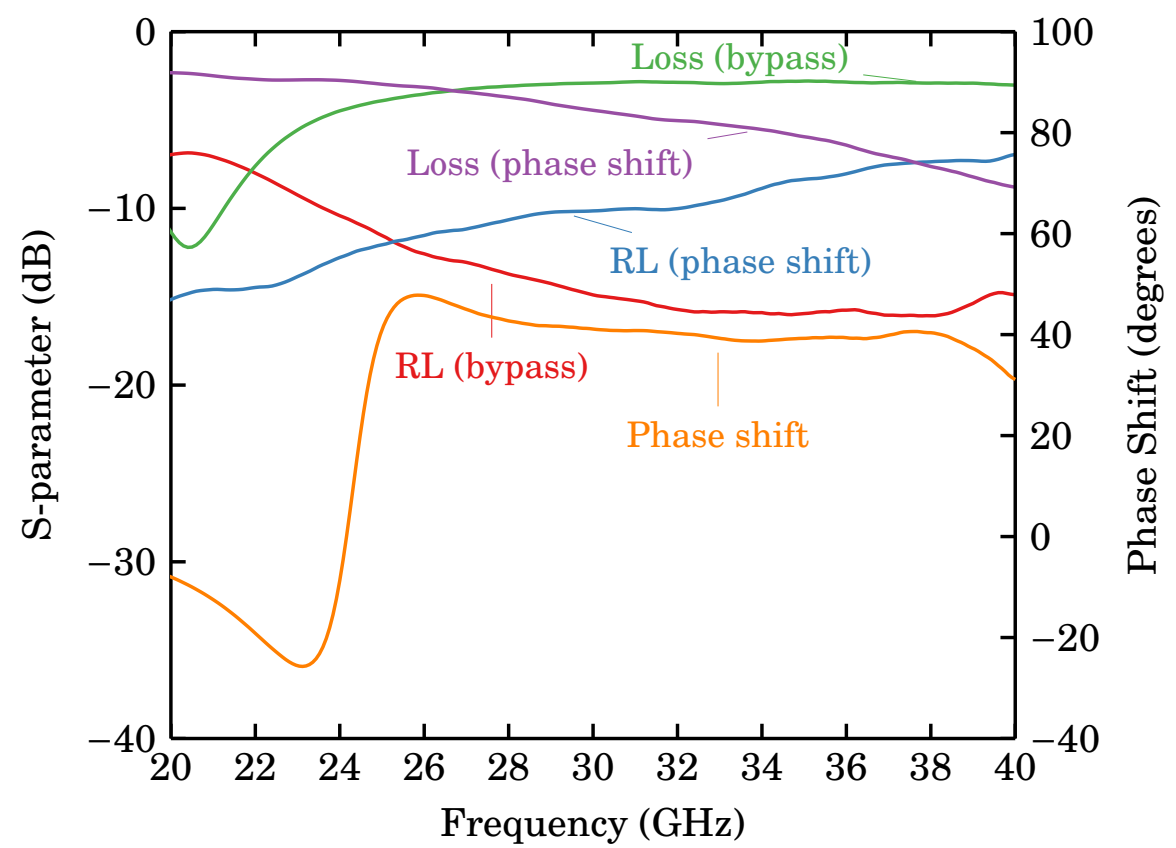

Figure 6.10: Measured behaviour of the $0^{\circ} / 45^{\circ}$ phase shifter.

differences between the modeled and fabricated device, due to manufacturing tolerance. The $4^{\circ}$ difference in phase could be corrected in a future iteration along with an optimization of the insertion and return losses.

Finally, the linearity of the circuit was studied. It was not possible to see $1 \mathrm{~dB}$ compression at these frequencies with the equipment available in the laboratory, but a third-order intercept test was performed at $25 \mathrm{GHz}$ with two signals separated by $1 \mathrm{MHz}$. The results are shown in Figure 6.11. The $\mathrm{IIP}_{3}$ was found to be $19.5 \mathrm{dBm}$. 


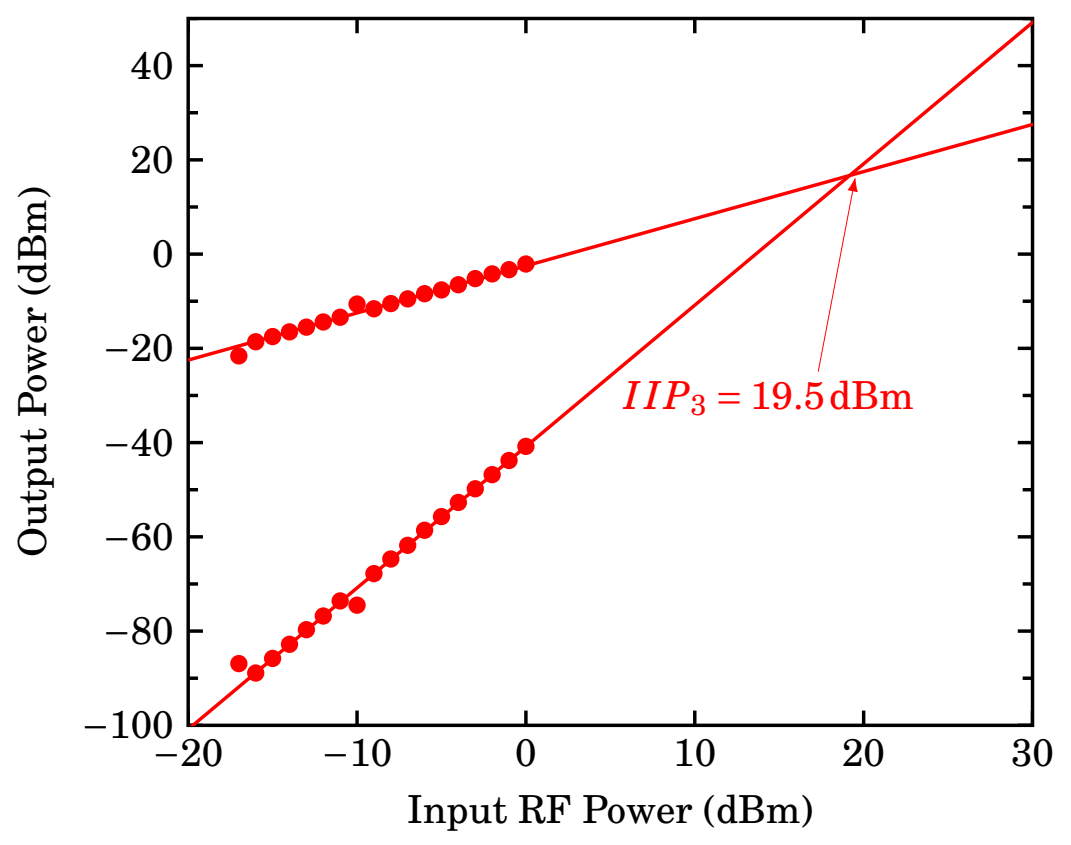

Figure 6.11: Third order intermodulation for the $0 \% / 45^{\circ}$ phase shifter.

\subsection{Summary}

In this chapter, the design of switched-filter phase shifters was discussed. This type of circuit is more compact since switching elements are integrated in the circuit and separate SPDT switches are not required. However, since a resonance inductor is used, in the shunt branch of the circuit, it tends to be more narrowband.

A $0^{\circ} / 22.5^{\circ}$ switched-filter phase shifter was designed for X-band. Agreement was strong between measurements and simulation. Furthermore, of particular interest, the measured $1 \mathrm{~dB}$ compression point was above what was measurable in the laboratory; it is estimated to be over $40 \mathrm{dBm}(10 \mathrm{~W})$ 
$\mathrm{RF}$ input power. $\mathrm{IIP}_{3}$ was found to be $46.2 \mathrm{dBm}$.

There is a compromise to be made between linearity, bandwidth and insertion loss in the design of this type of phase shifter. Larger transistors will allow for better power handling, but will also increase the off-capacitance of the transistors. For the series device, a larger capacitance will lead to an inconvenient resonance with the series inductor. For the shunt device, the open-circuit to ground will be imperfect, which will worsen the insertion loss.

A $0 \% 45^{\circ}$ phase shift circuit was also designed for K-band. Power handling is reduced, which is expected at higher frequencies, but a $20 \mathrm{dBm}$ $\mathrm{IIP}_{3}$ was obtained. The performance of the K-band phase shifter is not as good, with relative high loss, increasing with frequency. However, when operating above the peak $f_{t}$ of the GaN process, transistor parasitics have a strong effect on circuit performance. The circuit does nevertheless demonstrate that flat phase shift can be obtained above conventional frequency limits. Nevertheless, the K-band phase shifter could probably be improved by using more die area, which would enable better grounding; the size of the fabricated circuit was limited due to very tight external constraints. 


\section{Chapter 7}

\section{Conclusions}

In this thesis, two types of broadband, compact, high power phase shifters were presented. One phase shifter is based on a switched-filter topology, while the other novel lumped-element design is based on a resonator and phase reference. Designs were implemented in a $0.5 \mu \mathrm{m} \mathrm{AlGaN/GaN}$ process.

The design of both types of phase shifters has been described, and simulation results agree with measurements, with the LC resonator design offering good return loss (11 dB), decent insertion loss (5 dB) and very low phase variation $\left(1^{\circ}\right)$ across X-band. The switched-filter design had insertion loss below $2 \mathrm{~dB}$, return loss better than $11.5 \mathrm{~dB}$ and amplitude imbalance less than $1.03 \mathrm{~dB}$ across X-band. 
Table 7.1: Comparison with some other phase shifters

\begin{tabular}{|c|c|c|c|c|c|c|c|}
\hline Ref. & Type & $\begin{array}{l}\text { Bandwidth } \\
(\mathrm{GHz} / \%)\end{array}$ & $\begin{array}{c}\text { Phase error } \\
\left(^{\circ}\right)\end{array}$ & $\begin{array}{l}\text { Insertion } \\
\text { Loss (dB) }\end{array}$ & $\begin{array}{l}\text { Return } \\
\text { Loss (dB) }\end{array}$ & $\begin{array}{c}\text { Size } \\
\left(\mathrm{mm}^{2}\right)\end{array}$ & $\begin{array}{c}\text { Power } \\
\text { handling } \\
(\mathrm{dBm})\end{array}$ \\
\hline$[66]$ & $\begin{array}{c}45^{\circ} \text { high-pass/low- } \\
\text { pass }\end{array}$ & $8-12(40 \%)$ & 10 & 2.5 & 10 & 4 & $P_{1 \mathrm{~dB}}: 38$ \\
\hline [67] & $\begin{array}{c}\text { 2-bit high- } \\
\text { pass/low-pass }\end{array}$ & $2-8(120 \%)$ & $\approx 30$ & 6 & 10 & 8.16 & $P_{1 \mathrm{~dB}}: 30$ \\
\hline$[70]$ & $\begin{array}{c}\text { 4-bit high- } \\
\text { pass/low-pass and } \\
\text { switched-filter } \\
\text { hybrid }\end{array}$ & $1.4-2.4(53 \%)$ & 3 & 3.5 & 10 & 2.6 & $\begin{array}{r}P_{1 \mathrm{~dB}}: 30 \\
\operatorname{IIP}_{3}: 32\end{array}$ \\
\hline$[76]$ & $\begin{array}{c}45^{\circ} \text { loaded } \\
\text { transmission line }\end{array}$ & $2-6(100 \%)$ & 6 & 2.1 & 10 & - & - \\
\hline [78] & $\begin{array}{c}90^{\circ} \text { loaded } \\
\text { transmission line }\end{array}$ & $2.4-5.6(82 \%)$ & 6.4 & 0.6 & 10 & - & - \\
\hline [79] & $\begin{array}{l}90^{\circ} \text { broadside } \\
\text { coupling }\end{array}$ & $3-7(82 \%)$ & 4 & 2.7 & 12.5 & $\approx 165$ & - \\
\hline$[80]$ & $\begin{array}{l}30^{\circ} / 45^{\circ} \text { broadside } \\
\text { coupling }\end{array}$ & $\begin{array}{l}3.1-10.6 \\
(109 \%)\end{array}$ & $2.5 / 2.3$ & 1 & 10 & 500 & - \\
\hline [84] & 5-bit MEMS & $8-12(40 \%)$ & 10 & 4.5 & 10 & 9.2 & - \\
\hline$[85]$ & 4-bit MEMS & $12-18(40 \%)$ & 7 & 1.7 & 15 & - & - \\
\hline This work & $\begin{array}{c}22.5^{\circ} \\
\text { switched-filter }\end{array}$ & $8-16(67 \%)$ & 5.2 & 2 & 11.15 & 0.304 & $\begin{array}{r}P_{1 \mathrm{~dB}}: \approx 40 \\
\mathrm{IIP}_{3}: 46.2\end{array}$ \\
\hline \multirow[t]{3}{*}{ This work } & \multirow[t]{2}{*}{$\begin{array}{l}22.5^{\circ} \mathrm{LC} \\
\text { resonator }\end{array}$} & $7.5-13(54 \%)$ & 5.63 & 5 & 11 & 1.05 & $\begin{array}{r}P_{1 \mathrm{~dB}}: 30.1 \\
\mathrm{IIP}_{3}: 46.3\end{array}$ \\
\hline & & $\begin{array}{l}\text { No SPDT: } \\
6.3-16.2 \\
(88 \%)\end{array}$ & 2.83 & 0.45 & 13.9 & & \\
\hline & $45^{\circ} \mathrm{LC}$ resonator & $\begin{array}{l}\text { No SPDT: } \\
6.4-13.2 \\
(69 \%)\end{array}$ & 2.86 & 0.9 & 10 & & \\
\hline
\end{tabular}


Both designs offer good performance over a wider band, with the LC resonator phase shifter operating well over $7.5-13 \mathrm{GHz}$ and the switchedfilter design offering good performance over $8-16 \mathrm{GHz}$. The LC resonator phase shifter's bandwidth is limited by the SPDT switch; the differential phase shifter alone (excluding the effect of the switch) works over 6.3$16.2 \mathrm{GHz}$.

We have only presented $0^{\circ} / 22.5^{\circ}$ and $0^{\circ} / 45^{\circ}$ phase shifters in order to demonstrate the design concept and its feasibility. However, the design procedure presented here could be used to design circuits with an arbitrary phase shift and can be cascaded to obtain full $360^{\circ}$ coverage.

Also of particular interest, the power handling capability of the circuits was shown to be very high. The LC resonator phase shifter using SPDT switches has a somewhat lower power handling capability, with a thirdorder intercept point of $46.3 \mathrm{dBm}$ and $P_{1 \mathrm{~dB}}$ of $30.1 \mathrm{dBm}$. The switched-filter circuit has what is estimated to be a $P_{1 \mathrm{~dB}}$ of over $10 \mathrm{~W}(40 \mathrm{dBm})$, and the third-order intercept point was determined to be near $50 \mathrm{dBm}$ at X-band. The K-band circuit's power handling cannot be measured due to signal generators not being able to produce sufficient power, and a high power amplifier is not available at these frequencies.

A comparison of the X-band phase shifters with some others found in the literature is shown in Table 7.1. When reading this table, one should be aware that some authors use different definitions for bandwidth. The 
table shows the bandwidth as given in the respective papers. In addition, many studies have not included a way to switch between the reference and phase shift states (such as SPDT switches). For the switched-filter phase shifter presented, the switch is an integral part and cannot be removed, but for the LC resonator phase shifter, the bandwidth without the SPDT switches is included to facilitate more equal comparisons.

\subsection{Scientific contributions}

A number of contributions to the field of microwave integrated circuit design have been made during the course of my studies. These include seven articles published in peer-reviewed periodicals, one book chapter and 14 refereed conference presentations. Some of these include second-author publications where I have made significant contributions, although I am principal author on eight of these scientific contributions. Two are invited papers on transistor modeling. Other publications are not directly related to this thesis and are not listed here. The published works discussing topics related to this thesis include:

- Significant work on GaN phase shifter design and switches [148][154]. This includes the work presented in Chapters 5 and 6, and the designs presented therein. In fact, at the time of writing, the papers listed are the only published studies on gallium nitride phase 
shifters.

- GaN switch transistor modeling and power predictions from linear models, as well as the nonlinear modeling of microwave power transistors [148], [150], [155]-[157]. Some of this modeling work has won prizes in student competitions at the IEEE International Microwave Symposium in Montréal (2012), Seattle, WA (2013) and Tampa, FL (2014) [158]-[160].

- Suspended inductors and their use in the design of a K-band phase shifter [149].

\subsection{Future work}

There are several areas related to this thesis which are ripe for study. First, if the required (expensive) equipment became available, large-signal GaN device modeling, particularly for switching applications is an area which should be developed. As it stands, the only research into GaN device modeling originates from large universities and corporations with the necessary resources.

Next, the phase shifters presented here are limited in a couple of respects. First, they are implemented in a technology which has a limited capability in frequency. The K-band phase shifter in particular (which is 
actually operating above the maximum $f_{t}$ of the technology) stands to gain, as it is currently limited by the high frequency parasitics of the transistors.

Third, larger transistors could be used and higher power phase shifters designed. Currently, the fabrication process is a bit limiting: it cannot support microstrip (coplanar waveguide is not ideal for dissipating large amounts of heat), its substrate is quite thick complicating heat dissipation, the metallization is quite thin and the active devices suffer from low breakdown voltage. If this is improved or if a different process is used, it could be quite interesting-in principle, there is no reason why at least $100 \mathrm{~W}$ could not be handled at X-band, as GaN transistors with breakdown voltages well over $100 \mathrm{~V}$ at the frequencies discussed do exist. Acquiring the equipment to produce that amount of power (for test purposes) might also be problematic for monetary reasons, however. 


\section{List of References}

[1] T. S. Ralston and G. L. Charvat, "Real-time through-wall imaging using an ultrawideband multiple-input multiple-output (MIMO) phased array radar system", in Proceedings of the IEEE International Symposium on Phased Array Systems and Technology, Waltham, MA, Oct. 2010, pp. 551-558.

[2] C. T. Rodenbeck, S.-G. Kim, W.-H. Tu, M. R. Coutant, S. Hong, M. Li and K. Chang, "Ultra-wideband low-cost phased-array radars", IEEE Transactions on Microwave Theory and Techniques, vol. 53, no. 12 , Dec. 2005 , pp. $3697-3706$.

[3] K. Chen, "MIMO beamforming and its impact on testing TD-LTE", Microwave Journal, vol. 55, no. 2, Feb. 2012, pp. 96-102.

[4] F. Rusek, D. Persson, B. K. Lau, E. G. Larsson, T. L. Marzetta, O. Edfors and F. Tufvesson, "Scaling up MIMO: opportunities and challenges with very large arrays", IEEE Signal Processing Magazine, vol. 30, no. 1, Jan. 2013, pp. 40-60. 
[5] A. Bleicher, "The 5G phone future", IEEE Spectrum, vol. 50, no. 7, Jul. 2013, pp. 15-16.

[6] W. Roh, J.-Y. Seol, J.-H. Park, B. Lee, J. Lee, Y. Kim, J. Cho, K. Cheun and F. Aryanfar, "Millimeter-wave beamforming as an enabling technology for $5 \mathrm{G}$ cellular communications: theoretical feasibility and prototype results", IEEE Communications Magazine, vol. 52, no. 2, Feb. 2014, pp. 106-113.

[7] E. Dahlman, G. Mildh, S. Parkvall, J. Peisa, J. Sachs and Y. Selén, “5G radio access", Ericsson Review, vol. 91, Jun. 2014, pp. 42-47.

[8] R. J. Mailloux, Phased Array Antenna Handbook, 2nd ed. Norwood, MA: Artech House, 2005.

[9] D. Brizzolara, "79 GHz high resolution short range automotive radar evolution", Microwave Journal, vol. 56, no. 7, Sep. 2013, pp. 78-86.

[10] T. S. Rappaport, S. Sun, R. Mayzus, H. Zhao, Y. Azar, K. Wang, G. N. Wong, J. K. Schulz, M. Samimi and F. Gutierrez, "Millimeter wave mobile communications for 5G cellular: it will work!", IEEE Access, vol. 1, May 2013, pp. 335-349.

[11] G. B. Norris, D. C. Boire, G. St. Onge, C. Wutke, C. Barratt, W. Coughlin and J. Chickanosky, "A fully monolithic $4-18 \mathrm{GHz}$ digital vector modulator", in IEEE MTT-S International Microwave Symposium Digest, Dallas, TX, May 1990, pp. 789-792. 
[12] J. Grajal, J. Gismero, M. Mahfoudi and F. A. Petz, “A 1.4-2.7-GHz analog MMIC vector modulator for a crossbar beamforming network", IEEE Transactions on Microwave Theory and Techniques, vol. 45 , no. 10 , Oct. 1997 , pp. $1705-1714$.

[13] D. Antolovic, Radiolocation in Ubiquitous Wireless Communication. New York, NY: Springer, 2010.

[14] J. S. Jaffe and R. C. Mackey, "Microwave frequency translator", IEEE Transactions on Microwave Theory and Techniques, vol. 13, no. 3, May 1965, pp. 371-378.

[15] S. Lucyszyn, I. D. Robertson and H. Aghvami, "24 GHz serrodyne frequency translator using a $360^{\circ}$ analog CPW MMIC phase shifter”, IEEE Microwave and Guided Wave Letters, vol. 4, no. 3, Mar. 1994, pp. $71-73$.

[16] N. Arabäck and P. Hallbjörner, "Serrodyne RF frequency translators for Doppler shift in multipath propagation simulators", in Proceedings of the European Conference on Antennas and Propagation, Göteborg, Sweden, Apr. 2013, pp. 985-987.

[17] M. I. Skolnik, Radar Handbook, 3rd ed. New York, NY: McGrawHill, 2008.

[18] M. S. Gast, 802.11ac: A Survival Guide. Sebastopol, CA: O’Reilly, 2013. 
[19] W. Saito, Y. Takada, M. Kuraguchi, K. Tsdua, I. Omura and T. Ogura, "600 V AlGaN/GaN power-HEMT: design, fabrication and demonstration on high voltage DC-DC converter", in IEEE International Electron Devices Meeting Technical Digest, Washington, DC, Dec. 2003, pp. 23.7.1-23.7.4.

[20] W. Saito, M. Kuraguchi, Y. Takada, K. Tsuda, I. Omura and T. Ogura, "High breakdown undoped AlGaN-GaN power HEMT on sapphire substrate and its demonstration for DC-DC converter application”, IEEE Transactions on Electron Devices, vol. 51, no. 11, Nov. 2004, pp. 1913-1917.

[21] S. Inoue and H. Akagi, "A bi-directional isolated DC/DC converter as a core circuit of the next-generation medium-voltage power conversion system", in Proceedings of the IEEE Power Electronics Specialists Conference, Jeju, South Korea, Jun. 2006.

[22] T. Morita, S. Tamura, Y. Anda, M. Ishida, Y. Uemoto, T. Ueda, T. Tanaka and D. Ueda, "99.3\% efficiency of three-phase inverter for motor drive using GaN-based gate injection transistors", in Proceedings of the IEEE Applied Power Electronics Conference and Exposition, Fort Worth, TX, Mar. 2011, pp. 481-484.

[23] J. Das, J. Everts, J. van den Keybus, M. van Hove, D. Visalli, P. Srivastava, D. Marcon, K. Cheng, M. Leys, S. Decoutere, J. Driesen and G. Borghs, "A $96 \%$ efficient high-frequency DC-DC converter 
using E-mode GaN DHFETs on Si", IEEE Electron Device Letters, vol. 32 , no. 10, Oct. 2011, pp. 1370-1372.

[24] J. Delaine, P.-O. Jeannin, D. Frey and K. Guepratte, "High frequency DC-DC converter using GaN device", in Proceedings of the IEEE Applied Power Electronics Conference and Exposition, Orlando, FL, Feb. 2012, pp. 1754-1761.

[25] H. Morkoç, S. Strite, G. B. Gao, M. E. Lin, B. Sverdlov and M. Burns, "Large-band-gap SiC, III-V nitride, and II-VI ZnSe-based semiconductor device technologies", Journal of Applied Physics, vol. 76, no. 3, Aug. 1994, pp. 1363-1398.

[26] S. Nakamura, M. Senoh, S. Nagahama, N. Iwasa, T. Yamada, T. Matsushita, H. Kiyoku, Y. Sugimoto, T. Kozaki, H. Umemoto, M. Sano and K. Chocho, "Continuous-wave operation of InGaN/GaN/AlGaNbased laser diodes grown on GaN substrates", Applied Physics Letters, vol. 72, no. 16, Apr. 1998, pp. 2014-2016.

[27] SG25 process specifications, Rev. 2.5, IHP Microelectronics, Mar. 2012.

[28] Discrete GaAs pHEMT, TGF2018, Rev. D, TriQuint Semiconductor, Nov. 2013.

[29] Discrete power GaN on SiC HEMT, TGF2023-2-01, Rev. C, TriQuint Semiconductor, Sep. 2013. 
[30] J. L. B. Walker, Ed., Handbook of RF and Microwave Power Amplifiers. Cambridge, UK: Cambridge University Press, 2012.

[31] W. Saito, Y. Takada, M. Kuraguchi, K. Tsuda, I. Omura, T. Ogura and $\mathrm{H}$. Ohashi, "High breakdown voltage AlGaN-GaN powerHEMT design and high current density switching behavior", IEEE Transactions on Electron Devices, vol. 50, no. 12, Dec. 2003, pp. $2528-2531$.

[32] A. Chini, R. Coffie, G. Meneghesso, E. Zanoni, D. Buttari, S. Heikman, S. Keller and U. K. Mishra, " $2.1 \mathrm{~A} / \mathrm{mm}$ current density AlGaN/GaN HEMT", Electronics Letters, vol. 39, no. 7, Apr. 2003, pp. 625-626.

[33] T. Zimmermann, D. Deen, Y. Cao, J. Simon, P. Fay, D. Jena and H. G. Xing, "AlN/GaN insulated-gate HEMTs with $2.3 \mathrm{~A} / \mathrm{mm}$ output current and $480 \mathrm{mS} / \mathrm{mm}$ transconductance", IEEE Electron Device Letters, vol. 29, no. 7, Jul. 2008, pp. 661-664.

[34] Y.-F. Wu, M. Moore, A. Saxler, T. Wisleder and P. Parikh, "40-W/mm double field-plated GaN HEMTs", in Proceedings of the Device Research Conference, State College, PA, Jun. 2006, pp. 151-152.

[35] J. W. Chung, W. E. Hoke, E. M. Chumbes and T. Palacios, "AlGaN/GaN HEMT with 300-GHz $f_{\text {max }}$ ", IEEE Electron Device Letters, vol. 31, no. 3, Mar. 2010, pp. 195-197. 
[36] M. L. Schuette, A. Ketterson, B. Song, E. Beam, T.-M. Chou, M. Pilla, H.-Q. Tserng, X. Gao, S. Guo, P. J. Fay, H. G. Xing and P. Saunier, "Gate-recessed integrated E/D GaN HEMT technology with $f_{t} / f_{\max }>300 \mathrm{GHz}$, IEEE Electron Device Letters, vol. 34, no. 7, Jun. 2013, pp. 741-743.

[37] V. Palankovski and S. Selberherr, "Thermal models for semiconductor device simulation", in Proceedings of the European Conference on High Temperature Electronics, Berlin, Germany, Jul. 1999, pp. 2528.

[38] R. Quay, Gallium Nitride Electronics. Berlin, Germany: Springer, 2008.

[39] S. Krukowski, A. Witek, J. Adamczyk, J. Jun, M. Bockowski, I. Grzegory, B. Lucznik, G. Nowak, M. Wróblewski, A. Presz, S. Gierlotka, S. Stelmach, B. Palosz, S. Porowski and P. Zinn, "Thermal properties of indium nitride", Journal of Physics and Chemistry of Solids, vol. 59, no. 3, Mar. 1998, pp. 289-295.

[40] E. A. Burgemeister, W. von Muench and E. Pettenpaul, "Thermal conductivity and electrical properties of $6 \mathrm{H}$ silicon carbide", Journal of Applied Physics, vol. 50, no. 9, Sep. 1979, pp. 5790-5794.

[41] S. T. Sheppard, K. Doverspike, W. L. Pribble, S. T. Allen, J. W. Palmour, L. T. Kehias and T. J. Jenkins, "High-power microwave 
GaN/AlGaN HEMT's on semi-insulating silicon carbide substrates", IEEE Electron Device Letters, vol. 20, no. 4, Apr. 1999, pp. 161-163.

[42] Y.-F. Wu, B. P. Keller, S. Keller, D. Kapolnek, P. Kozodoy, S. P. Denbaars and U. K. Mishra, "High power AlGaN/GaN HEMTs for microwave applications", Solid-State Electronics, vol. 41, no. 10, Oct. 1997, pp. 1569-1574.

[43] M. Seelmann-Eggebert, P. Meisen, F. Schaudel, P. Koidl, A. Vescan and H. Leier, "Heat-spreading diamond films for GaN-based highpower transistor devices", Diamond Related Materials, vol. 10, no. 3-7, Mar.-Jul. 2001, pp. 744-749.

[44] A. Prejs, S. Wood, R. Pengelly and W. Pribble, "Thermal analysis and its application to high power GaN HEMT amplifiers", in IEEE MTT-S International Microwave Symposium Digest, Boston, MA, Jun. 2009, pp. 917-920.

[45] R. Sandhu, V. Gambin, B. Poust, I. Smorchkova, G. Lewis, R. Elmadjian, D. Li, C. Geiger, B. Heying, M. Wojtowicz, A. Oki, T. Feygelson, K. Hobart, B. Pate, J. Tabeling, E. Bozorg-Grayeli and K. Goodson, "GaN HEMT near junction heat removal", in Procedings of the International Conference on Compound Semiconductor Manufacturing Technology, New Orleans, LA, May 2013, pp. 175-178.

[46] $40 \mathrm{~W}, 6.0 \mathrm{GHz}$, GaN HEMT die, CGHV60040D, Cree, Inc., Sep. 2014. 
[47] J. D. Brown, R. Borges, E. Piner, A. Vescan, S. Singhal and R. Therrien, "AlGaN/GaN HFETs fabricated on 100-mm GaN on silicon (111) substrates", Solid-State Electronics, vol. 46, no. 10, Oct. 2002, pp. $1535-1539$.

[48] T. Beechem, A. Christensen, D. S. Green and S. Graham, "Assessment of stress contributions in GaN high electron mobility transistors of different substrates using Raman spectroscopy", Journal of Applied Physics, vol. 106, no. 11, Dec. 2009, pp. 114509-1-114509-9.

[49] D. Babic, F. Ejeckam, D. Francis, F. Faili, F. Lowe, J. Wilman, T. Mollart, J. Dodson, D. Twitchen and B. Bolliger, "GaN-on-diamond: the next GaN", Microwave Journal, vol. 57, no. 5, May 2014, pp. 124130.

[50] T. Paskova, D. A. Hanser and K. R. Evans, "GaN substrates for IIInitride devices", Proceedings of the IEEE, vol. 98, no. 7, Jul. 2010, pp. $1324-1338$.

[51] K. Gurnett and T. Adams, "Native substrates for GaN: the plot thickens", III-V Review, vol. 19, no. 9, Dec. 2006, pp. 39-41.

[52] R. Dwiliński, R. Doradziński, J. Garczyński, L. P. Sierzputowski, A. Puchalski, Y. Kanbara, K. Yagi, H. Minakuchi and H. Hayashi, "Bulk ammonothermal GaN", Journal of Crystal Growth, vol. 311, no. 10, May 2009, pp. 3015-3018. 
[53] T. Hashimoto, E. Letts, M. Ikari and Y. Nojima, "Improvement of crystal quality in ammonothermal growth of bulk GaN", Journal of Crystal Growth, vol. 312, no. 18, Sep. 2010, pp. 2503-2506.

[54] B. Łucznik, B. Pastuszka, I. Grzegory, M. Boćkowski, G. Kamler, E. Litwin-Staszewska and S. Porowski, "Deposition of thick GaN layers by HVPE on the pressure grown GaN substrates", Journal of Crystal Growth, vol. 281, no. 1, Jul. 2005, pp. 38-46.

[55] A. D. Hanser, L. Liu, E. A. Preble, D. Tsvetkov, M. Tutor, N. M. Williams, K. Evans, Y. Zhou, D. Wang, C. Ahyi, C.-C. Tin, J. Williams, M. Park, D. F. Storm, D. S. Katzer, S. C. Binari, J. A. Roussos and J. A. Mittereder, “An overview of gallium nitride substrate materials developments for optoelectronic and microelectronic applications", in Proceedings of the International Conference on Compound Semiconductor Manufacturing Technology, Vancouver, Canada, Apr. 2006, pp. 67-69.

[56] K. K. Chu, P. C. Chao, M. T. Pizzella, R. Actis, D. E. Meharry, K. B. Nichols, R. P. Vaudo, X. Xu, J. S. Flynn, J. Dion and G. R. Brandes, “9.4-W/mm power density AlGaN-GaN HEMTs on free-standing GaN substrates", IEEE Electron Device Letters, vol. 25, no. 9, Sep. 2004, pp. 596-598.

[57] N. Billström, J. Nilsson, A. Tengs and N. Rorsman, "High performance GaN front-end MMICs", in Proceedings of the European 
Microwave Integrated Circuits Conference, Manchester, UK, Oct. 2011, pp. 348-351.

[58] K. Krishnamurthy, J. Martin, B. Landberg, R. Vetury and M. J. Poulton, "Wideband $400 \mathrm{~W}$ pulsed power GaN HEMT amplifiers", in IEEE MTT-S International Microwave Symposium Digest, Atlanta, GA, Jun. 2008, pp. 303-306.

[59] C. D. Nordquist, C. W. Dyck, G. M. Kraus, I. C. Reines, C. L. Goldsmith, W. D. Cowan, T. A. Plut, F. Austin IV, P. S. Finnegan, M. H. Ballance and C. T. Sullivan, "A DC to 10-GHz 6-b RF MEMS time delay circuit", IEEE Microwave and Wireless Components Letters, vol. 16, no. 5, May 2006, pp. 305-307.

[60] D. Parker and D. C. Zimmermann, "Phased arrays—part I: theory and architecture", IEEE Transactions on Microwave Theory and Techniques, vol. 50, no. 3, Mar. 2002, pp. 678-687.

[61] B. A. Kopp, M. Borkowski and G. Jerinic, "Transmit/receive modules", IEEE Transactions on Microwave Theory and Techniques, vol. 50, no. 3, Mar. 2002, pp. 827-834.

[62] K.-J. Koh, J. W. May and G. M. Rebeiz, "A millimeter-wave (40$45 \mathrm{GHz}$ ) 16-element phased-array transmitter in 0.18- $\mu \mathrm{m}$ SiGe BiCMOS technology", IEEE Journal of Solid-State Circuits, vol. 44, no. 5, May 2009, pp. 1498-1509. 
[63] J. F. White, "High power, p-i-n diode controlled, microwave transmission phase shifters", IEEE Transactions on Microwave Theory and Techniques, vol. 13, no. 2, Mar. 1965, pp. 233-242.

[64] R. V. Garver, "Broad-band diode phase shifters", IEEE Transactions on Microwave Theory and Techniques, vol. MTT-20, no. 5, May 1972, pp. 314-323.

[65] C. Moye, G. Sakamoto and M. Brand, "A compact broadband, sixbit MMIC phasor with integrated digital drivers", in IEEE MTT-S International Microwave Symposium Digest, Dallas, TX, May 1990, pp. $457-460$.

[66] K. Hettak, T. Ross, D. Gratton and J. Wight, "A new type of GaN HEMT based high power high-pass/low-pass phase shifter at $\mathrm{X}$ band", in IEEE MTT-S International Microwave Symposium Digest, Montréal, Canada, Jun. 2012.

[67] Y. Ayasli, S. W. Miller, R. Mozzi and L. K. Hanes, "Wide-band monolithic phase shifter", IEEE Transactions on Electron Devices, vol. ED-31, no. 12, Dec. 1984, pp. 1943-1947.

[68] C. F. Campbell and S. A. Brown, "A compact 5-bit phase-shifter MMIC for $K$-band satellite communication systems", IEEE Transactions on Microwave Theory and Techniques, vol. 48, no. 12, Dec. 2000, pp. 2652-2656. 
[69] B.-W. Min and G. M. Rebeiz, "Single-ended and differential Ka-band BiCMOS phased array front-ends", IEEE Journal of Solid-State Circuits, vol. 43, no. 10, Oct. 2008, pp. 2239-2250.

[70] I. J. Bahl and D. Conway, "L- and S-band compact octave bandwidth 4-bit MMIC phase shifters", IEEE Transactions on Microwave Theory and Techniques, vol. 56, no. 2, Feb. 2008, pp. 293-299.

[71] B. M. Schiffman, "A new class of broad-band microwave 90-degree phase shifters", IRE Transactions on Microwave Theory and Techniques, vol. MTT-6, no. 2, Apr. 1958, pp. 232-237.

[72] B. M. Schiffman, "Multisection microwave phase-shift network", IEEE Transactions on Microwave Theory and Techniques, vol. 14, no. 4, Apr. 1966, p. 209.

[73] E. M. T. Jones and J. T. Bolljahn, "Coupled-strip-transmission-line filters and directional couplers", IRE Transactions on Microwave Theory and Techniques, vol. 4, no. 2, Apr. 1956, pp. 75-81.

[74] J. L. R. Quirarte and J. P. Starski, "Synthesis of Schiffman phase shifters", IEEE Transactions on Microwave Theory and Techniques, vol. 39 , no. 11, Nov. 1991, pp. 1885-1889.

[75] Y.-X. Guo, Z.-Y. Zhang and L. C. Ong, "Improved wide-band Schiffman phase shifter", IEEE Transactions on Microwave Theory and Techniques, vol. 54, no. 3, Mar. 2006, pp. 1196-1200. 
[76] S. Y. Zheng, S. H. Yeung, W. S. Chan, K. F. Man and S. H. Leung, "Improved broadband dumb-bell-shaped phase shifter using multisection stubs”, Electronics Letters, vol. 44, no. 7, Mar. 2008, pp. 478480.

[77] X. Tang and K. Mouthaan, "Phase-shifter design using phase-slope alignment with grounded shunt $\lambda / 4$ stubs", IEEE Transactions on Microwave Theory and Techniques, vol. 58, no. 6, Jun. 2010, pp. $1573-1583$.

[78] S. Y. Zheng, W. S. Chan and K. F. Man, "Broadband phase shifter using loaded transmission line", IEEE Microwave and Wireless Components Letters, vol. 20, no. 9, Sep. 2010, pp. 498-500.

[79] M. Sorn, R. Lech and J. Mazur, "Simulation and experiment of a compact wideband $90^{\circ}$ differential phase shifter", IEEE Transactions on Microwave Theory and Techniques, vol. 60, no. 3, Mar. 2012, pp. $494-501$.

[80] A. M. Abbosh, "Ultra-wideband phase shifters", IEEE Transactions on Microwave Theory and Techniques, vol. 55, no. 9, Sep. 2007, pp. 1935-1941.

[81] A. Stehle, G. Georgiev, V. Ziegler, B. Schoenlinner, U. Prechtel, H. Seidel and U. Schmid, "RF-MEMS switch and phase shifter optimized for W-band", in Proceedings of the European Microwave Conference, Amsterdam, The Netherlands, Oct. 2008, pp. 104-107. 
[82] J. S. Hayden and G. M. Rebeiz, "Very low-loss distributed $X$-band and $\mathrm{Ka}$-band MEMS phase shifters using metal-air-metal capacitors", IEEE Transactions on Microwave Theory and Techniques, vol. 51, no. 1, Jan. 2003, pp. 309-314.

[83] J. Lampen, S. Majumder, C. Ji and J. Maciel, "Low-loss, MEMS based, broadband phase shifters", in Proceedings of the International Symposium on Phased Array Systems and Technology, Waltham, MA, Oct. 2010, pp. 219-224.

[84] M. A. Morton and J. Papapolymerou, "A packaged MEMS-based 5-bit $X$-band high-pass/low-pass phase shifter", IEEE Transactions on Microwave Theory and Techniques, vol. 56, no. 9, Sep. 2008, pp. $2025-2031$.

[85] B. Pillans, L. Coryell, A. Malczewski, C. Moody, F. Morris and A. Brown, "Advances in RF MEMS phase shifters from $15 \mathrm{GHz}$ to $35 \mathrm{GHz}$, in IEEE MTT-S International Microwave Symposium Digest, Montréal, Canada, Jun. 2012.

[86] M. Unlu, S. Demir and T. Akin, "A 15-40-GHz frequency reconfigurable RF MEMS phase shifter", IEEE Transactions on Microwave Theory and Techniques, vol. 61, no. 8, Aug. 2013, pp. 2865-2877.

[87] J. Maciel, S. Majumder, J. Lampen and C. Guthy, "Rugged and reliable ohmic MEMS switches", in IEEE MTT-S International Microwave Symposium Digest, Montréal, Canada, Jun. 2012. 
[88] A. L. Hartzell, M. G. da Silva and H. R. Shea, MEMS Reliability. New York, NY: Springer, 2011.

[89] C. Tsironis and P. Harrop, "Dual gate GaAs M.E.S.F.E.T. phase shifter with gain at $12 \mathrm{GHz}$, Electronics Letters, vol. 16, no. 14, Jul. 1980, pp. 553-554.

[90] M. Kumar, R. J. Menna and H.-C. Huang, "Broad-band active phase shifter using dual-gate MESFET", IEEE Transactions on Microwave Theory and Techniques, vol. MTT-29, no. 10, Oct. 1981, pp. 10981099.

[91] A. Kozyrev, V. Osadchy, A. Pavlov and L. Sengupta, "Application of ferroelectrics in phase shifter design", in IEEE MTT-S International Microwave Symposium Digest, Boston, MA, Jun. 2000, pp. 13551358.

[92] Y. Liu, A. S. Nagra, E. G. Erker, P. Periaswamy, T. R. Taylor, J. Speck and R. A. York, "BaSrTiO 3 interdigitated capacitors for distributed phase shifter applications", IEEE Microwave and Guided Wave Letters, vol. 10, no. 11, Nov. 2000, pp. 448-450.

[93] D. Kim, Y. Choi, M. G. Allen, J. S. Kenney and D. Kiesling, "A wideband reflection-type phase shifter at S-band using BST coated substrate", IEEE Transactions on Microwave Theory and Techniques, vol. 50, no. 12, Dec. 2002, pp. 2903-2909. 
[94] M. A. Antoniades and G. V. Eleftheriades, "Compact linear lead/lag metamaterial phase shifters for broadband applications", IEEE Antennas and Wireless Propagation Letters, vol. 2, no. 1, 2003, pp. 103-106.

[95] J. Bardwell, T. Lester, H. Tang, B. Surridge, A. Harrison and A. Lau, "AlGaN/GaN transistors and circuits", Electrochemical Society Transactions, vol. 16, no. 7, Oct. 2008, pp. 193-198.

[96] M. Golio, Ed., The RF and Microwave Handbook. Boca Raton, FL: CRC Press, 2001.

[97] Atlas user's manual, Silvaco, Inc., Santa Clara, CA, Sep. 2014.

[98] A. H. Zaabab, Q.-J. Zhang and M. Nakhla, "A neural network modeling approach to circuit optimization and statistical design”, IEEE Transactions on Microwave Theory and Techniques, vol. 43, no. 6, Jun. 1995, pp. 1349-1358.

[99] Q.-J. Zhang, K. C. Gupta and V. K. Devabhaktuni, “Artificial neural networks for RF and microwave design-from theory to practice”, IEEE Transactions on Microwave Theory and Techniques, vol. 51, no. 4, Apr. 2003, pp. 1339-1350.

[100] D. E. Root, J. Xu, J. Horn, M. Iwamoto and G. Simpson, "Device modeling with NVNAs and X-parameters", in Proceedings of the Workshop on Integrated Nonlinear Microwave and Millimeter-Wave Circuits, Göteborg, Sweden, Apr. 2010, pp. 12-15. 
[101] F. Lin and G. Kompa, "FET model parameter extraction based on optimization with multiplane data-fitting and bidirectional search-a new concept", IEEE Transactions on Microwave Theory and Techniques, vol. 42, no. 7, Jul. 1994, pp. 1114-1121.

[102] C. van Niekerk and P. Meyer, "Performance and limitations of decomposition-based parameter-extraction procedures for FET small-signal models", IEEE Transactions on Microwave Theory and Techniques, vol. 46, no. 11, Nov. 1998, pp. 1620-1627.

[103] I. Angelov, H. Zirath and N. Rorsman, "A new empirical nonlinear model for HEMT and MESFET devices", IEEE Transactions on Microwave Theory and Techniques, vol. 40, no. 12, Dec. 1992, pp. $2258-2266$.

[104] I. Angelov, L. Bengtsson and M. Garcia, "Extensions of the Chalmers nonlinear HEMT and MESFET model", IEEE Transactions on Microwave Theory and Techniques, vol. 44, no. 10, Oct. 1994, pp. 16641674.

[105] I. Angelov, N. Rorsman, J. Stenarson, M. Garcia and H. Zirath, "An empirical table-based FET model", IEEE Transactions on Microwave Theory and Techniques, vol. 47, no. 12, Dec. 1999, pp. 23502357.

[106] I. Angelov, V. Desmaris, K. Dynefors, P. Å. Nilsson, N. Rorsman and H. Zirath, "On the large-signal modelling of AlGaN/GaN HEMTs 
and SiC MESFETs", in Proceedings of the European Gallium Arsenide and Other Semiconductor Applications Symposium, Paris, France, Oct. 2005, pp. 309-312.

[107] I. Angelov, K. Andersson, D. Schreuers, N. Rorsman, V. Desmaris, M. Sudow and H. Zirath, "Large-signal modelling and comparison of AlGaN/GaN HEMTs and SiC MESFETs", in Proceedings of the Asia-Pacific Microwave Conference, Yokohama, Japan, Dec. 2006, pp. 279-282.

[108] W. R. Curtice, "Nonlinear modeling of compound semiconductor HEMTs state of the art”, in IEEE MTT-S International Microwave Symposium Digest, Anaheim, CA, May 2010, pp. 1194-1197.

[109] L. Dunleavy, C. Baylis, W. Curtice and R. Connick, "Modeling GaN: powerful but challenging”, IEEE Microwave Magazine, vol. 11, no. 6, Oct. 2010 , pp. $82-96$.

[110] S. Vitanov, V. Palankovski, S. Maroldt, R. Quay, S. Murad, T. Rödle and S. Selberherr, "Physics-based modeling of GaN HEMTs", IEEE Transactions on Electron Devices, vol. 59, no. 3, Mar. 2012, pp. 685693.

[111] S. Khandelwal, N. Goyal and T. A. Fjeldly, "A physics-based analytical model for 2DEG charge density in AlGaN/GaN HEMT devices”, IEEE Transactions on Electron Devices, vol. 58, no. 10, Oct. 2011, pp. $3622-3625$. 
[112] J. Zhang, B. Syamal, X. Zhou, S. Arulkumaran and G. I. Ng, "A compact model for generic MIS-HEMTs based on the unified 2DEG density expression", IEEE Transactions on Electron Devices, vol. 61, no. 2, Feb. 2014, pp. 314-323.

[113] G. Callet, J. Faraj, O. Jardel, C. Charbonniaud, J.-C. Jacquet, T. Reveyrand, E. Morvan, S. Piotrowicz, J.-P. Teyssier and R. Quéré, "A new nonlinear HEMT model for AlGaN/GaN switch applications", International Journal of Microwave and Wireless Technologies, vol. 2, no. 3-4, Aug. 2010, pp. 283-291.

[114] A. Prasad, C. Fager, M. Thorsell, C. M. Andersson and K. Yhland, "Symmetrical large-signal modeling of microwave switch FETs", IEEE Transactions on Microwave Theory and Techniques, vol. 62, no. 8, Aug. 2014, pp. 1590-1598.

[115] S. C. Binari, K. Ikossi, J. A. Roussos, W. Kruppa, D. Park, H. B. Dietrich, D. D. Koleske, A. E. Wickenden and R. L. Henry, "Trapping effects and microwave power performance in AlGaN/GaN HEMTs", IEEE Transactions on Electron Devices, vol. 48, no. 3, Mar. 2001, pp. $465-471$.

[116] O. Jardel, F. De Groote, T. Reveyrand, J.-C. Jacquet, C. Charbonniaud, J.-P. Teyssier, D. Floriot and R. Quéré, “An electrothermal model for AlGaN/GaN power HEMTs including trapping effects to improve large-signal simulation results on high VSWR", IEEE 
Transactions on Microwave Theory and Techniques, vol. 55, no. 12, Dec. 2007, pp. 2660-2669.

[117] G. Dambrine, A. Cappy, F. Heliodore and E. Playez, "A new method for determining the FET small-signal equivalent circuit", IEEE Transactions on Microwave Theory and Techniques, vol. 36, no. 7, Jul. 1988, pp. 1151-1159.

[118] M. Berroth and R. Bosch, "Broad-band determination of the FET small-signal equivalent circuit”, IEEE Transactions on Microwave Theory and Techniques, vol. 38, no. 7, Jul. 1990, pp. 891-895.

[119] R. Tayrani, J. E. Gerber, T. Daniel, R. S. Pengelly and U. L. Rohde, "A new and reliable direct parasitic extraction method for MESFETs and HEMTs", in Proceedings of the European Microwave Conference, Madrid, Spain, Sep. 1993, pp. 451-453.

[120] P. H. Aaen, J. A. Plá and J. Wood, Modeling and Characterization of RF and Microwave Power FETs. Cambridge, UK: Cambridge University Press, 2007.

[121] M. D. Yore, C. A. Nevers and P. Cortese, "High-isolation low-loss SP7T pHEMT switch suitable for antenna switch modules", in Proceedings of the European Microwave Integrated Circuits Conference, Paris, France, Sep. 2010, pp. 69-72. 
[122] A. Tomkins, P. Garcia and S. P. Voinigescu, "A 94GHz SPST switch in 65nm bulk CMOS”, in Proceedings of the Compound Semiconductor Integrated Circuits Symposium, Monterey, CA, Oct. 2008.

[123] A. Botula, A. Joseph, J. Slinkman, R. Wolf, Z.-X. He, D. Ioannou, L. Wagner, M. Gordon, M. Abou-Khalil, R. Phelps, M. Gautsch, W. Abadeer, D. Harmon, M. Levy, J. Benoit and J. Dunn, “A thin-film SOI 180nm CMOS RF switch technology", in Proceedings of the IEEE Topical Meeting on Silicon Monolithic Integrated Circuits in RF Systems, San Diego, CA, Jan. 2009.

[124] C. F. Campbell and D. C. Dumka, "Wideband high power GaN on SiC SPDT switch MMICs", in IEEE MTT-S International Microwave Symposium Digest, Anaheim, CA, May 2010, pp. 145-148.

[125] S. Hara, T. Tokumitsu, T. Tanaka and M. Aikawa, "Broad-band monolithic microwave active inductor and its application to miniaturized wide-band amplifiers", IEEE Transactions on Microwave Theory and Techniques, vol. 36, no. 12, Dec. 1988, pp. 1920-1924.

[126] S. Lucyszyn and I. D. Robertson, "Monolithic narrow-band filter using ultrahigh-Q tunable active inductors", IEEE Transactions on Microwave Theory and Techniques, vol. 42, no. 12, Dec. 1994, pp. $2617-2622$.

[127] Y.-H. Cho, S.-C. Hong and Y.-S. Kwon, "A novel active inductor and its application to inductance-controlled oscillator", IEEE Transac- 
tions on Microwave Theory and Techniques, vol. 45, no. 8, Aug. 1997, pp. $1208-1213$.

[128] C.-C. Hsiao, C.-W. Kuo, C.-C. Ho and Y.-J. Chan, "Improved qualityfactor of 0.18-um CMOS active inductor by a feedback resistance design", IEEE Microwave and Wireless Components Letters, vol. 12, no. 12 , Dec. 2002 , pp. $467-469$.

[129] W. B. Kuhn, N. K. Yanduru and A. S. Wyszynski, "Q-enhanced $L C$ bandpass filters for integrated wireless applications", IEEE Transactions on Microwave Theory and Techniques, vol. 46, no. 12, Dec. 1998, pp. 2577-2586.

[130] T. Soorapanth and S. S. Wong, "A 0-dB $2140 \pm 30 \mathrm{MHz}$ bandpass filter utilizing $Q$-enhanced spiral inductors in standard CMOS", IEEE Journal of Solid-State Circuits, vol. 37, no. 5, May 2002, pp. 579-586.

[131] D. Pepe and D. Zito, " $50 \mathrm{GHz}$ mm-wave CMOS active inductor", IEEE Microwave and Wireless Components Letters, vol. 24, no. 4, Apr. 2014, pp. 254-256.

[132] J. Wight, J. R. Long, L. R. Carley and T. Riley, "On-die synthesized inductors: boon or bane?", IEEE Microwave Magazine, vol. 11, no. 3, May 2010, pp. 95-104. 
[133] J. Y.-C. Chang, A. A. Abidi and M. Gaitan, "Large suspended inductors on silicon and their use in a 2- $\mu \mathrm{m}$ CMOS RF amplifier", IEEE Electron Device Letters, vol. 14, no. 5, May 1993, pp. 246-248.

[134] C.-Y. Lee, Y.-H. Kao, J.-J. Luo and K.-M. Chang, "The enhanced Q spiral inductors with MEMS technology for RF applications", in Proceedings of the Asia-Pacific Microwave Conference, Sydney, Australia, Dec. 2000, pp. 1326-1329.

[135] L.-H. Lu, P. Bhattacharya, L. P. B. Katehi and G. E. Ponchak, "High$\mathrm{Q} \mathrm{X}$-band and K-band micromachined spiral inductors for use in Sibased ICs", in Topical Meeting on Silicon Monolithic Integrated Circuits in RF Systems Digest, Garmish, Germany, Apr. 2000, pp. 108112.

[136] M. E. Goldfarb and V. K. Tripathi, "The effect of air bridge height on the propagation characteristics of microstrip", IEEE Microwave and Guided Wave Letters, vol. 1, no. 10, Oct. 1991, pp. 273-274.

[137] I. J. Bahl, Lumped Elements for RF and Microwave Circuits. Norwood, MA: Artech House, 2003.

[138] Y. Cao, R. A. Groves, X. Huang, N. D. Zamdmer, J.-O. Plouchart, R. A. Wachnik, T.-J. King and C. Hu, "Frequency-independent equivalentcircuit model for on-chip spiral inductors", IEEE Journal of SolidState Circuits, vol. 38, no. 3, Mar. 2003, pp. 419-426. 
[139] T. O. Dickson, M.-A. LaCroix, S. Boret, D. Gloria, R. Beerkens and S. P. Voinigescu, “30-100 GHz inductors and transformers for millimeter-wave (Bi)CMOS integrated circuits", IEEE Transactions on Microwave Theory and Techniques, vol. 53, no. 1, Jan. 2005, pp. $123-133$.

[140] W. Gao and Z. Yu, "Scalable compact circuit model and synthesis for RF CMOS spiral inductors”, IEEE Transactions on Microwave Theory and Techniques, vol. 54, no. 3, Mar. 2006, pp. 1055-1064.

[141] H. Wang, L. Sun, J. Liu, Z. Huanhuan, Z. Yu and J. Gao, “Transfer function analysis and broadband scalable model for on-chip spiral inductors", IEEE Transactions on Microwave Theory and Techniques, vol. 59, no. 7, Jul. 2011, pp. 1696-1708.

[142] S. H. Hall and H. L. Heck, Advanced Signal Integrity for High-speed Digital Designs. Hoboken, NJ: Wiley, 2009.

[143] Impedance measurement handbook, 4th ed., Agilent Technologies, Santa Clara, CA, Sep. 2013.

[144] W. B. Kuhn and A. P. Boutz, "Measuring and reporting high quality factors of inductors using vector network analyzers", IEEE Transactions on Microwave Theory and Techniques, vol. 58, no. 4, Apr. 2010, pp. $1046-1055$.

[145] A. Bettidi, A. Cetronio, W. Ciccognani, M. de Dominicis, C. Lanzieri, E. Limiti, A. Manna, M. Peroni, C. Proietti and P. Romanini, "High 
power GaN-HEMT SPDT switches for microwave applications", International Journal of RF and Microwave Computer-Aided Engineering, vol. 19, no. 5, Sep. 2009, pp. 598-606.

[146] M.-C. Yeh, Z.-M. Tsai and H. Wang, "A miniature DC-to-50 GHz CMOS SPDT distributed switch", in Proceedings of the European Microwave Conference, Paris, France, Oct. 2005.

[147] H.-Y. Chang and C.-Y. Chan, "A low loss high isolation DC-60 GHz SPDT traveling-wave switch with a body bias technique in $90 \mathrm{~nm}$ CMOS process", IEEE Microwave and Wireless Components Letters, vol. 20, no. 2, Feb. 2010, pp. 82-84.

[148] T. N. Ross, K. Hettak, G. Cormier and J. S. Wight, "Design of X-band GaN phase shifters", IEEE Transactions on Microwave Theory and Techniques, vol. 63, no. 1, Jan. 2015, pp. 244-255.

[149] T. N. Ross, K. Hettak, G. Cormier and J. S. Wight, "Improved inductor $\mathrm{Q}$ using airbridges for GaN phase shifters", Microwave and Optical Technology Letters, vol. 57, no. 6, Jun. 2015, pp. 1455-1459.

[150] T. N. Ross, G. Cormier, K. Hettak and J. S. Wight, "High power X-band GaN switched-filter phase shifter", in IEEE MTT-S International Microwave Symposium Digest, Tampa, FL, Jun. 2014.

[151] K. Hettak, T. N. Ross, G. Cormier and J. S. Wight, "A new type of robust GaN HEMT-based high power high-pass/low-pass $22.5^{\circ}$ 
phase shifter", Microwave and Optical Technology Letters, vol. 56, no. 2, Feb. 2014, pp. 347-349.

[152] K. Hettak, T. N. Ross, G. Cormier and J. S. Wight, "Broadband high power GaN SPDT switch using stacked-shunt FETs and resonance inductors", Microwave and Optical Technology Letters, vol. 55, no. 9, Sep. 2013, pp. 2093-2095.

[153] K. Hettak, T. Ross, N. Irfan, D. Gratton, M. C. E. Yagoub and J. S. Wight, "High-power broadband GaN HEMT SPST/SPDT switches based on resonance inductors and shunt-stacked transistors", in Proceedings of the European Microwave Integrated Circuits Conference, Amsterdam, The Netherlands, Nov. 2012, pp. 215-218.

[154] K. Hettak, T. Ross, D. Gratton and J. S. Wight, "A new type of GaN HEMT based high power high-pass/low-pass phase shifter at X band", in IEEE MTT-S International Microwave Symposium Digest, Montréal, Canada, Jun. 2012.

[155] T. N. Ross, G. Cormier and J. S. Wight, "Extraction of a model for a microwave power pHEMT", IEEE Microwave Magazine, vol. 15, no. 1, Jan. 2014, pp. 102-108, invited paper.

[156] T. N. Ross, G. Cormier and J. S. Wight, "Development of a model for a GaInP/GaAs HBT", IEEE Microwave Magazine, vol. 16, no. 1, Feb. 2015, pp. 104-110, invited paper. 
[157] G. Cormier and T. Ross, "Microwave circuit design", in Swarm Intelligence for Electric and Electronic Engineering, G. Fornarelli and L. Mescia, Eds., pp. 18-39. Hershey, PA: IGI Global, 2013.

[158] T. N. Ross, "LDMOS transistor modeling", in IEEE MTT-S International Microwave Symposium, Montréal, Canada, Jun. 2012.

[159] T. N. Ross, "Microwave transistor modeling", in IEEE MTT-S International Microwave Symposium, Seattle, WA, Jun. 2013.

[160] T. N. Ross, "Modeling a microwave GaInP/GaAs HBT", in IEEE MTT-S International Microwave Symposium, Tampa, FL, Jun. 2014. 